Universidade DE SÃo PaUlo

Instituto DE FísicA

\title{
Deslocalização e superfluidez em condensados atômicos de Bose-Einstein
}

FERNANDA RAQUEL PINHEIRO

Dissertação de mestrado apresentada ao Instituto

de Física para a obtenção do título de Mestre em

Ciências.

ORIENTADOR: PROF. DR. ANTONIO FERNANDO RIBEIRO DE TOLEDO PIZA

Banca Examinadora:

Prof. Dr. Antonio Fernando Ribeiro de Toledo Piza (IF-USP)

Prof. Dr. Emerson José Veloso de Passos (IF-USP)

Prof. Dr. Maria Carolina Nemes (DF-UFMG)

São Paulo

Abril de 2010 
À curiosidade. E para que nunca se ausente. 


\section{Sumário}

1 Introdução $\quad 1$

2 Condensação de Bose Einstein em gases alcalinos $\quad 4$

2.1 A condensação de Bose-Einstein no gás ideal aprisionado . . . . . . . . . . . . 5

2.2 Definição geral da condensação de Bose-Einstein . . . . . . . . . . . . . . 8

3 Superfluidez $\quad 11$

3.1 A superfluidez pelo critério de dois fluidos . . . . . . . . . . . . . . . . 12

3.1.1 Considerações estatísticas sobre o cálculo de $\rho_{s} \ldots \ldots \ldots$. . . . . . 13

3.1.2 Relacionando fração inercial de superfluido com o espectro dos autoestados do sistema com $\omega=0 \ldots \ldots$. . . . . . . . . . 14

4 Apresentação do modelo $\quad 17$

4.1 Considerações gerais sobre Hamiltonianos de sistemas de gases bosônicos . . . 17

4.1.1 Comprimento de espalhamento de onda-s e interação efetiva . . . . . . 19

4.1.2 A física por trás da escolha do potencial periódico . . . . . . . . . 20

4.1.3 Segunda quantização do Hamiltoniano e o modelo de Bose-Hubbard . 25

4.2 Considerações sobre o Hamiltoniano do sistema que efetua rotação . . . . . . 27

4.2.1 Sobre a rotação, os referenciais e os Hamiltonianos . . . . . . . . . . . 28

4.2.2 Adaptação de técnicas de cranking ao Hamiltoniano da primeira banda e obtenção da expressão segundo quantizada . . . . . . . . . . . . . 29

5 Apresentação da resolução numérica e dos resultados 33

5.1 Diagrama de fases do estado fundamental . . . . . . . . . . . . . 36

5.2 A condensação de Bose-Einstein . . . . . . . . . . . . . . . . 38

5.3 A superfluidez . . . . . . . . . . . . . . . . . . 53

6 Conclusões e Perspectivas $\quad 56$

$\begin{array}{ll}\text { A Apêndices } & \mathbf{5 8}\end{array}$

A.1 Resolução do problema de Kronig-Penney com potenciais $\delta$-Dirac . . . . . . . 58

A.1.1 Adaptação de técnicas de cranking ao modelo . . . . . . . . . . . . 60

A.2 A teoria de Landau . . . . . . . . . . . . . . . . . . . . . 62 


\section{Agradecimentos}

Ao meu orientador, o Prof. A. F. R. de Toledo Piza, agradeço pelo imenso aprendizado que me foi proporcionado. Agradeço pelo problema, tão interessante, que foi o objeto deste trabalho e por todas as discussões, desde aquelas relacionadas à Física quanto as outras sobre literatura, música ou sobre 'coisas da vida' em geral. Esta convivência toda teve e terá sempre um influência muito grande e muito positiva sobre mim, e apesar de eu não encontrar um 'muito obrigado' que o valha, devo agradecer, mesmo assim, pela oportunidade e por toda a sua paciência. E também, professor, 'por você ser assim'. Isto só me faz pensar em quanta sorte eu tive.

Aos professores que encontrei no 'meio do caminho', Alinka Lèpine-Szily, Henrique Fleming, Émerson Passos, João Barata, Nestor Caticha, Walter Wrezinski, Mário José de Oliveira, Marcelo Martinelli e Maria Carolina Nemes, quero agradecer. À alguns pelos ensinamentos, outros pelas discussões e a outros, tão especiais, por terem servido, além de tudo, como fonte de inspiração, utilizo este espaço para verbalizar o meu muito obrigado.

Ao Edgar Zanella Alvarega, especificamente no que concerne as realizações deste trabalho, agradeço pela sugestão da linguagem Haskell, por ter me ensinado a programar nela, por ter tirado minhas dúvidas e por ter ajudado no programa. Este trabalho não seria 'em Haskell' se não fosse pela sua ajuda.

Às pessoas que estiveram envolvidas diretamente, seja pelas discussões como Eduardo Toshio, Nelson Yokomizo e Yul Otani ou pela ajuda no processo complicado que é 'escrever uma dissertação', como Renann Lipinski e Rone Petterson, também agradeço. Agradeço ainda, de forma geral, aos meus amigos, por serem meus amigos.

Agradeço à minha família, especialmente à minha avó Vitória e aos meus pais Fátima e Antônio, e à minha irmã Vanessa, por todo o apoio e por me ajudarem a aproveitar as oportunidades que me proporcionaram chegar até aqui.

E por último, mas igualmente importante, agradeço à FAPESP pelo apoio financeiro que proporcionou o desenvolvimento deste trabalho. 


\section{Resumo}

O presente trabalho apresenta o estudo das propriedades da condensação de Bose-Einstein e da superfluidez em um sistema bosônico disposto em um arranjo unidimensional de potenciais periódicos em formato de anel. O Hamiltoniano efetivo usual em termos dos operadores de campo é implementado na representação construída em termos das funções de Bloch da primeira banda e o problema é resolvido por meio da sua diagonalização através de métodos numéricos. No limite de hopping pequeno, este modelo é essencialmente equivalente à representação usual do modelo de Bose-Hubbard, mas incorpora efeitos adicionais através das energias de Bloch de partícula independente e dos elementos da matriz de dois corpos na situação em que o hopping é grande [19]. Através da inclusão de rotação no sistema, as energias de partícula independente são forçadas a depender da velocidade angular. Isto implica, correspondentemente, uma dependência da velocidade angular nas funções de onda de partícula independente e nos resultados de muitos corpos obtidos através da diagonalização do Hamiltoniano. Com o objetivo de estudar a superfluidez, o critério de dois fluidos é empregado e através de resultados numéricos obtêm-se a variação da fração de superfluido com o quadrado da velocidade angular.

Ainda, considera-se aqui uma expressão perturbativa para o parâmetro inercial do sistema expresso em termos das excitações do sistema sem rotação, o que permite relacionar as energias do sistema com rotação com aquelas do sistema sem rotação. Isto é particularmente interessante para obter a fração de superfluido em termos da informação espectral do sistema sem rotação. Resultados semelhantes podem ser encontrados através da definição de superfluido baseada na resposta do sistema a uma variação de fase, imposta através de condições de contorno torcidas [30, 33], mas com a diferença de que os desenvolvimentos aqui não fazem uso da hipótese do modo condensado.

De maneira geral, os resultados numéricos obtidos indicam, que pelo menos para este sistema, as frações de superfluido e condensado são quantidades sem relação direta, sugerindo então que mesmo para sistemas gasosos diluídos a idéia de que a superfluidez é uma consequência da condensação de Bose-Einstein deve ser considerada com mais cuidado. 


\begin{abstract}
In this work we study the properties of Bose-Einstein condensation and superfluidity in a finite bosonic system in a 1-dimensional ring with a periodic potential under rotation. The usual field effective Hamiltonian is implemented in a representation constructed in terms of the first band Bloch functions and the problem is solved by numeric diagonalization. In the limit of small hopping, this model is essentially equivalent to the quasi-momentum representation of the usual Bose-Hubbard model but incorporates additional effects via Bloch single particle energies and two-body matrix elements in the case of large hopping [19]. By including rotation in the system we force the single particle energies to be a function of the angular velocity. This implies a corresponding angular velocity dependence of the single particle wavefunctions and many-body diagonalization results. In order to study superfluidity, we consider the two fluid criterion. Numerical results for the superfluid fraction involving the change of intrinsic ground state energy with the square of the angular velocity are obtained.

We also consider a perturbative expression for the system inertial parameter expressed in terms of the excitation spectrum of the non rotating system, which enables us to relate the energies in the rotating system to the ones in the system without rotation. This is particularly interesting for obtaining superfluid fraction in terms of spectral information of the non rotating system. Similar results can be found by using the definition of superfluid fraction based on the response of the system to a phase variation imposed by means of twisted boundary conditions [30, 33], but with the difference that our developments do not assume the hypothesis of a condensate mode.

Our numerical results indicate that in this system condensate and superfluid fractions are quite unrelated in terms of parameter values, indicating that even for dilute gases the concept that superfluidity is a consequence of Bose-Einstein condensation should be considered more carefully.
\end{abstract}




\section{Capítulo 1}

\section{Introdução}

Qualquer estudante que já se deparou com a teoria Quântica provavelmente conhece (e também concorda com) a célebre afirmação de autoria de Richard Feynman que enuncia: 'I think I can safely say that nobody understands Quantum Mechanics' [1]. Deixando de lado questões que podem porventura envolver o significado atribuído ao ato de 'entender' alguma coisa, esta frase ilustra de maneira muito adequada o caráter totalmente não intuitivo e fora do senso comum do comportamento da natureza em pequenas escalas.

Dentre muitos dos fenômenos quânticos que 'rompem com as linhas clássicas de pensamento' [2], um dos mais dramáticos envolve justamente a descrição dos sistemas de muitos corpos. Nos domínios da Mecânica Quântica, a indistinguibilidade das partículas exerce um papel crucial, dando origem a efeitos de natureza coletiva [3] e cujas características dependem de propriedades intrínsecas das componentes do sistema. Quando as partículas tratadas são de natureza bosônica, um dos fenômenos coletivos que aparecem é o fenômeno conhecido como condensação de Bose-Einstein.

O fenômeno da condensação bosônica foi enunciado pela primeira vez em 1924 por S. Bose, no contexto de um sistema constituído de partículas de luz [4]. Logo em seguida Einstein generalizou a idéia de Bose para um sistema de partículas massivas [5] e enunciou o fenômeno na forma como ele é entendido nos dias de hoje [6]. Entretanto, durante um bom tempo depois do trabalho de Einstein, o fenômeno da condensação permaneceu desacreditado $[7]$.

Um acontecimento que impulsionou consideravelmente o estudo dos sistemas condensados foi a descoberta, em 1938, da superfluidez no Hélio líquido. Allen e Missener, e independentemente, Kapitza, perceberam que abaixo de $\mathrm{T}=2.17 \mathrm{~K}$ o Hélio era capaz de fluir sem fricção mesmo que através de capilares muito estreitos $[8,9]$, e a este fenômeno foi cunhado o nome de superfluidez. Este resultado, em particular, motivou London a enunciar o que hoje se conhece como 'a hipótese de London': de que a superfluidez é uma manifestação da condensação bosônica; e deste então estes sistemas têm sido extensivamente estudados. Entretanto, apesar de toda uma área da Física ter sido construída para caracterizar e entender estes fenômenos, a relação entre a condensação e a superfluidez ainda não é bem estabelecida [3], e a hipótese de London permanece sem uma comprovação teórica geral.

Com relação à compreensão da classe dos fenômenos relacionados com a condensação bosônica, é importante destacar os progressos obtidos nos últimos 15 anos. Impulsionado pela obtenção em laboratório dos condensados de ${ }^{87} \mathrm{Rb}$ [10] e ${ }^{23} \mathrm{Na}$ [11] em 1995, o refinamento das técnicas experimentais permitiu o controle e manipulação de tais sistemas e sua efetiva utilização para a obtenção de resultados significativos [12]. Atualmente as técnicas experimentais atingiram um nível tão apurado, que é possível até mesmo controlar a in- 
tensidade e o caráter repulsivo ou atrativo da interação efetiva entre pares de bósons, bem como realizar o aprisionamento dos condensados em armadilhas múltiplas e promover a sua manipulação por agentes externos [13]. Em posição de especial importância para os assuntos que serão tratados neste trabalho, está a recente realização das redes ópticas [14, 15] e a demonstração de que elas podem ser utilizadas para simular o Hamiltoniano do modelo de Bose-Hubbard [16], possibilitando assim a obtenção de resultados relevantes sobre o regime fortemente correlacionado dos gases bosônicos rarefeitos.

No que concerne a compreensão dos diversos fenômenos ligados à superfluidez, apesar dos progressos existentes e em particular a verificação experimental em 2003 da transição superfluido - isolante de Mott em redes ópticas [15], é adequado manter que uma compreensão mais satisfatória da realidade experimental referente aos condensados diluídos ainda demanda uma análise mais cuidadosa [13].

Além das conveniências relacionadas com a implementação de arranjos experimentais, do ponto de vista teórico, o tratamento de gases rarefeitos proporciona uma grande vantagem em relação ao tratamento do ${ }^{4} \mathrm{He}$, porque permite utilizar técnicas simples de aproximação de forma eficaz, mas que no entanto se mostram inadequadas para o tratamento de sistemas densos. Desta forma, a viabilidade de modelos suficientemente realísticos, eventualmente associada à atual viabilidade de tratamentos numéricos para sistemas com um número relativamente pequeno de bósons, tem permitido elucidar alguns aspectos de sistemas de muitos corpos associadas à superfluidez, como por exemplo as oscilações Josephson [6, 17]. Na realidade, o tratamento de sistemas finitos com número relativamente reduzido de bósons exacerba tais características, residualmente presentes nas situações realizadas em laboratório, contribuindo de forma eficaz para a sua identificação [13].

Motivado pelos argumentos acima, este trabalho descreve os resultados do estudo de propriedades relacionadas aos fenômenos da condensação e superfluidez em um sistema de átomos frios sujeitos a um potencial periódico de $M$ barreiras igualmente espaçadas e dispostas em geometria de anel. Este arranjo compreende uma simplificação dos modelos de redes ópticas, no sentido de que ao invés de consistir nos tradicionais arranjos do tipo cosseno que são utilizados na sua implementação experimental ${ }^{1}$, a estrutura periódica corresponde a barreiras de potencial na forma de degraus. Aqui, a dinâmica do sistema é descrita a partir do Hamiltoniano efetivo usual de muitos corpos, tomado na representação construída em termos das autofunções do problema de um corpo equivalente - que devido à natureza periódica, compreendem as funções de Bloch - com a aproximação de primeira banda (isto justifica a denominação deste, ao longo do trabalho, de Hamiltoniano da primeira banda).

Em particular, para as situações em que as barreiras de potencial da rede são altas (termo de hopping pequeno), a descrição obtida a partir do Hamiltoniano da primeira banda é essencialmente equivalente à descrição obtida em termos do Hamiltoniano usualmente empregado na descrição de sistemas de gases bosônicos rarefeitos (modelo de Bose-Hubbard) [19]. Entretanto, no limite de barreiras baixas (termo de hopping grande), o modelo descrito pelo Hamiltoniano da primeira banda adquire efeitos adicionais por meio das energias de Bloch de partícula independente [19] e inclui efeitos advindos de processos de Umklapp (uma vez que dependendo da altura das barreiras os termos de interação de dois corpos referentes a estes processos diferem dos demais por diferentes ordens de grandezas).

Com o objetivo de construir um modelo mais próximo da realidade experimental especialmente no que concerne as propriedades da superfluidez, considera-se ainda efeitos de rotação do potencial periódico através da adaptação de técnicas de cranking ao Hamiltoniano que modela o sistema de muitos corpos. Todas as resoluções do sistema foram obtidas a partir de um programa, confeccionado na linguagem Haskell, que efetua a diagonalização exata do

\footnotetext{
${ }^{1}$ Veja as referências [3] e [18] para detalhes da teoria e realização experimental das redes ópticas.
} 
Hamiltoniano. Portanto, a menos das aproximações que compreendem o truncamento das autofunções do sistema às funções de Bloch da primeira banda, esta é a solução exata do modelo de muitos corpos.

A dissertação está organizada do seguinte modo: o capítulo 2 apresenta uma breve revisão da teoria da condensação e é seguido pelo capítulo em que discute-se o critério de dois fluidos na caracterização da superfluidez. Aqui este critério será desenvolvido através de um método alternativo ao usualmente utilizado.

No capítulo 4 são realizadas todas as considerações acerca do modelo utilizado: o Hamiltoniano é apresentado a partir de cada um dos seus termos, bem como o processo de obtenção de suas autofunções e autoenergias. Depois explicita-se a inclusão dos efeitos de rotação através das técnicas de cranking e as consequências que estes produzem no sistema.

A exposição dos resultados numéricos é realizada no capítulo 5, em que discutem-se conjuntamente as propriedades da condensação e da superfluidez do sistema que será caracterizado ao longo do trabalho.

Finalmente no capítulo 6 apresentam-se as conclusões e perspectivas deste trabalho. Como forma de complementar o texto, algumas discussões e desenvolvimentos podem ser encontradas na seção de apêndices. 


\section{Capítulo 2}

\section{Condensação de Bose Einstein em gases alcalinos}

Data de 1924 o trabalho seminal em que S. Bose [4] deriva a lei de radiação do corpo negro a partir do tratamento estatístico de um sistema de partículas de luz (objetos sem massa e descritos como constituintes de um sistema sem número fixo de partículas) tomadas como quantizadas e indistinguíveis. Este trabalho inspirou Einstein a extender as considerações de Bose para um sistema de partículas massivas e com número bem definido, e dos resultados obtidos surgiram o conceito de estatística de Bose-Einstein [20] e a idéia do fenômeno conhecido como condensação de Bose-Einstein [21].

Os objetos que satisfazem a estatística de Bose-Einstein são chamados de bósons e para que uma partícula receba o título de bóson, ela deve satisfazer dois requisitos: ser descrita pelas das regras da Mecânica Quântica e ter spin inteiro. Como consequência do tratamento quântico requerido, um conjunto de bósons compreende um sistema de partículas indistinguíveis descritas por uma função de onda; e por obedecerem a estatística de Bose-Einstein, esta função de onda deve ser simétrica em relação à troca de quaisquer duas partículas deste sistema. Apesar de não enunciadas como aqui, estas características são exatamente as mesmas adotadas por Bose no tratamento dos fótons [22].

Einstein propôs então que em um gás de bósons não interagentes e em equilíbrio térmico com um banho à temperatura $T$, a distribuição das partículas sobre os estados disponíveis para ocupação deveria ser dada por

$$
<n_{i}>=\frac{1}{e^{\beta\left(\epsilon_{i}-\mu\right)}-1}
$$

com $i$ o índice do estado com energia dada por $\epsilon_{i}, \beta=\frac{1}{k_{B} T}$ com $k_{B}$ a constante de Boltzmann e $\mu$ o multiplicador de Lagrange responsável pela inclusão do vínculo que fixa o número total das partículas no sistema; e que abaixo de uma certa temperatura, uma fração das partículas passaria a ocupar o estado de partícula independente com o menor valor de energia $\epsilon_{i}$. Quando esta 'decisão coletiva' ganha proporções da ordem do número total das partículas do sistema acontece o fenômeno conhecido como condensação de Bose-Einstein.

Este capítulo é dedicado à caracterização da condensação. Uma vez que a literatura na área é bastante rica ${ }^{1}$ serão enfatizados aqui apenas os conceitos necessários aos desenvolvimentos dos capítulos subsequentes e que foram de fato utilizados na construção da resolução numérica. A próxima seção contém uma breve revisão sobre a idéia da condensação em gases

\footnotetext{
${ }^{1}$ Veja especialmente as referências [3] e [6].
} 
livres e sujeitos a um potencial externo confinante e é seguida pela seção em que é realizada a generalização da definição do fenômeno.

\subsection{A condensação de Bose-Einstein no gás ideal aprisionado}

A maneira tradicional de descrever estatisticamente um gás de bósons consiste no emprego do ensemble Grande Canônico. De forma geral, o ensemble Grande Canônico é utilizado na descrição de sistemas que satisfazem os seguintes vínculos:

- $E=\sum_{i}<n_{i} \epsilon_{i}>$ : que fixa a temperatura $T$;

- $N=\sum_{i}<n_{i}>$ : que fixa o valor do número médio de partículas no sistema,

para os quais o princípio de máxima entropia define - para um sistema descrito pelo Hamiltoniano $H$ à temperatura $T$ - o operador densidade como

$$
\rho=\frac{e^{-\beta(H-\mu N)}}{\operatorname{Tr}\left(e^{-\beta(H-\mu N)}\right)}
$$

em que $\beta=\frac{1}{k_{B} T}$, com $k_{B}$ a constante de Boltzmann. $\mu$ é o multiplicador de Lagrange relacionado com o vínculo sobre o número de partículas do sistema e é obtido a partir da condição subsidiária $\operatorname{Tr}(\rho N)=<N>[6]$.

Uma vez que nos sistemas de gases bosônicos o número de partículas é uma quantidade bem definida (e não sua média), o ensemble Grande Canônico pode não ser, à primeira vista, a escolha mais natural de ensemble estatístico a ser empregado na sua descrição. Entretanto ele é usualmente escolhido por ser facilmente adaptável ao formalismo da segunda quantização e porque evita complicações técnicas que aparecem no tratamento destes sistemas quando os outros ensembles são utilizados. De forma geral, a consistência da descrição a partir do uso do ensemble Grande Canônico é obtida através da equivalência entre os ensembles no limite termodinâmico ${ }^{2}$. É importante atentar, no entanto, que é comum o tratamento de gases bosônicos em condições tais que não é possível definir ou atingir a situação do limite termodinâmico, e nestes casos a descrição do sistema vem acompanhada de peculiaridades que evidenciam os problemas do emprego deste ensemble ${ }^{3}$. Portanto, o que de fato justifica a escolha do ensemble Grande Canônico para descrever este tipo de sistema são principalmente as conveniências técnicas de sua manipulação.

Uma situação em que não é possível tomar o limite termodinâmico, por exemplo, consiste no caso do gás ideal armadilhado em um potencial confinante [6]. Entretanto, apesar de pequenas observações que devem ser feitas em relação às quantidades que porventura exibem traços introduzidos pela inadequação da descrição por meio do ensemble Grande Canônico, como é o caso da flutuação no número das partículas [6], este é um dos poucos casos que podem ser tratados de maneira simples com a aplicação das técnicas de Mecânica Estatística e o formalismo da segunda quantização; e portanto será utilizado aqui para ilustrar a idéia da condensação ${ }^{4}$.

\footnotetext{
${ }^{2}$ Uma discussão sobre o uso do ensemble Canônico vs. ensemble Grande Canônico na descrição destes sistemas pode ser encontrada no capítulo 2 da da referência [3].

${ }^{3}$ Ver a seção 1 da referência [6] para uma exposição mais detalhada.

${ }^{4}$ Esta seção, incluindo todos os desenvolvimentos e expressões, é toda baseada nos desenvolvimentos da seção 1 da referência [6].
} 
Considere a expressão segundo quantizada do Hamiltoniano de um gás de bósons não interagentes disposto em uma armadilha:

$$
H=\sum_{n} \epsilon_{n} a_{n}^{\dagger} a_{n}
$$

em que as energias $\epsilon_{n}$ correspondem aos autovalores da equação de Schrödinger

$$
\left(-\frac{\hbar^{2}}{2 m} \nabla^{2}+V(\vec{r})\right) \phi_{n}(\vec{r})=\epsilon_{n} \phi_{n}(\vec{r})
$$

cujos autoestados são denotados por $\phi_{n}(\vec{r})$ e $m$ representa a massa das partículas constituintes do sistema. Aqui a natureza bosônica destas partículas está implícita nas relações de comutação que são satisfeitas pelos operadores de criação $a_{n}^{\dagger}$ e aniquilação $a_{n}$, dadas por

$$
\left[a_{m}, a_{n}^{\dagger}\right]=\delta_{m n}, \quad\left[a_{m}, a_{n}\right]=\left[a_{m}^{\dagger}, a_{n}^{\dagger}\right]=0
$$

e que definem o operador número como $N=\sum_{n} a_{n}^{\dagger} a_{n}$.

Note, em particular, que utilizando a expressão do operador número e as propriedades de comutação acima, é possível escrever o operador densidade (2.1.2) como um produto de termos independentes [6]:

$$
\rho=\frac{e^{-\beta \sum_{n}\left(\epsilon_{n}-\mu\right) a_{n}^{\dagger} a_{n}}}{\operatorname{Tr}\left(e^{-\beta \sum_{n}\left(\epsilon_{n}-\mu\right) a_{n}^{\dagger} a_{n}}\right)}=\Pi_{n} \frac{e^{-\beta\left(\epsilon_{n}-\mu\right) a_{n}^{\dagger} a_{n}}}{\sum_{\nu_{n}=0}^{\infty} e^{-\beta \nu_{n}\left(\epsilon_{n}-\mu\right)}}=\Pi_{n} \frac{e^{-\beta\left(\epsilon_{n}-\mu\right) a_{n}^{\dagger} a_{n}}}{\left(1-e^{-\beta\left(\epsilon_{n}-\mu\right)}\right)^{-1}}
$$

em que a expressão após a última igualdade segue da fórmula da soma da série geométrica. Aqui a convergência desta série impõe uma restrição aos valores de $\mu$, que devem satisfazer $\epsilon_{n}-\mu>0$ para todo $n$, o que pode, portanto, ser interpretado também como a condição que define um limite superior de $\mu$ como sempre menor que o menor valor admitido pelas autoenergias $\epsilon_{n}$, denotado aqui de $\epsilon_{0}$. Sem perda de generalidade é possível tomar $\epsilon_{0}=0$ e reescrever ainda esta condição como $-\infty<\mu<0$.

A obtenção explícita do potencial químico, por sua vez, segue da condição subsidiária relacionada ao vínculo sobre o número das partículas do sistema, portanto,

$$
<N>=\operatorname{Tr}\left(\sum_{n} a_{n}^{\dagger} a_{n} \rho\right)=\sum_{n} \operatorname{Tr}\left(a_{n}^{\dagger} a_{n} \rho\right)=\sum_{n}<N_{n}>
$$

em que $\left\langle N_{n}>\right.$ corresponde ao número de partículas que ocupam o n-ésimo nível de energia e pode ser calculado em termos da fugacidade $z=e^{\beta \mu}$ como:

$$
\begin{aligned}
<N_{n}> & =\operatorname{Tr}\left(a_{n}^{\dagger} a_{n} \rho\right)=\left(1-e^{-\beta\left(\epsilon_{n}-\mu\right)}\right) \operatorname{Tr}\left(a_{n}^{\dagger} a_{n} e^{-\beta\left(\epsilon_{n}-\mu\right) a_{n}^{\dagger} a_{n}}\right)= \\
& =\left(1-e^{-\beta\left(\epsilon_{n}-\mu\right)}\right) \sum_{\nu=0}^{\infty} \nu e^{-\beta\left(\epsilon_{n}-\mu\right) \nu}=-\left(1-e^{-\beta\left(\epsilon_{n}-\mu\right)}\right) \frac{d}{d\left(\beta\left(\epsilon_{n}-\mu\right)\right)} \sum_{\nu=0}^{\infty} e^{-\beta\left(\epsilon_{n}-\mu\right) \nu}= \\
& =\frac{e^{-\beta\left(\epsilon_{n}-\mu\right)}}{1-e^{-\beta(\epsilon-\mu)}} \equiv \frac{z e^{-\beta \epsilon_{n}}}{1-z e^{-\beta \epsilon_{n}}} .
\end{aligned}
$$

Portanto, uma vez que a fugacidade é uma quantidade definida em termos do potencial químico, deve valer a condição $0<z<1$.

A partir daqui o cálculo das propriedades Termodinâmicas deste sistema pode ser realizado através do emprego das técnicas usuais da Mecânica Estatística. Entretanto, um dos ingredientes necessários para cumprir esta tarefa é justamente a informação sobre o espectro de energias do sistema, que por sua vez depende dos detalhes do potencial. Portanto, 
por questões de conveniência, o potencial será adotado aqui como o potencial harmônico anisotrópico, cuja expressão é dada por

$$
V(\vec{r}) \rightarrow \frac{m}{2}\left(\omega_{1} x_{1}^{2}+\omega_{2}^{2} x_{2}^{2}+\omega_{3}^{2} x_{3}^{2}\right)
$$

e que resulta no espectro

$$
\epsilon_{n} \rightarrow \epsilon_{n_{1} n_{2} n_{3}}=\hbar\left(\omega_{1} n_{1}+\omega_{2} n_{2}+\omega_{3} n_{3}\right), \quad n_{i}=0,1,2, . . \quad i=1,2,3 .
$$

Para esta escolha de potencial, o número médio das partículas em determinados níveis $n_{1}$, $n_{2}$ e $n_{3}$ de energias do sistema é dado por

$$
<N_{n_{1} n_{2} n_{3}}>=\sum_{\nu=1}^{\infty} z^{\nu} e^{-\beta \nu \hbar\left(n_{1} \omega_{1}+n_{2} \omega_{2}+n_{3} \omega_{3}\right)},
$$

de forma que a média do número total de partículas é escrita como

$$
<N>=\sum_{n_{1} n_{2} n_{3}=0}^{\infty}<N_{n_{1} n_{2} n_{3}}>=\sum_{\nu=1}^{\infty} \sum_{n_{1} n_{2} n_{3}=0}^{\infty} \Pi_{i=1}^{3} z^{\nu} e^{-\beta \nu n_{i} \hbar \omega_{i}}=\sum_{\nu=1}^{\infty} z^{\nu} \Pi_{i=1}^{3} \frac{1}{1-e^{-\nu \hbar \omega_{i} \beta}} .
$$

Este resultado permite a determinação numérica da fugacidade e portanto também a expressão completa do operador densidade $\rho$ do caso de um gás ideal de bósons presos por uma armadilha harmônica. Entretanto, para prosseguir com considerações analíticas acerca das propriedades do gás ideal preso por uma armadilha harmônica, e em especial aquelas relacionadas ao fenômeno da condensação, considere, por simplicidade, o caso em que o potencial harmônico é isotrópico, ou seja, $\omega_{1}=\omega_{2}=\omega_{3}=\omega$.

Nesta situação a expressão do número total de partículas (2.1.10) fica resumida como:

$$
<N>=\sum_{\nu=1}^{\infty} \frac{z^{\nu}}{\left(1-e^{-\beta \nu \hbar \omega}\right)^{3}} .
$$

A partir daí, o número de partículas que popula os estados excitados pode ser estimado a através da subtração na expressão acima da expressão do número de partículas que ocupa o estado fundamental. Em particular, esta última quantidade pode ser expressa de maneira muito simples através do uso da fugacidade como $\left\langle N_{0}\right\rangle=\frac{z}{1-z}$, de forma que o cálculo da ocupação dos estados excitados é realizado como

$$
\begin{aligned}
<N^{\prime}>=<N>-<N_{0}>=\sum_{n=1}^{\infty} \frac{e^{-\beta\left(\epsilon_{n}-\mu\right)}}{1-e^{-\beta\left(\epsilon_{n}-\mu\right)}}=\sum_{n=1}^{\infty} \frac{1}{e^{\beta\left(\epsilon_{n}-\mu\right)}-1}< \\
<\sum_{n=1}^{\infty} \frac{1}{e^{\beta \epsilon_{n}}-1} \equiv<N_{\max }>
\end{aligned}
$$

A desigualdade segue do fato que $z<1$. Portanto, se $<N>><N_{\max }>$, pelo menos $\left\langle N>-<N_{\max }>\right.$ partículas devem ocupar o estado de menor energia $\left.\epsilon_{0}[6] .<N_{\max }\right\rangle$ é a quantidade conhecida como número de saturação, e de forma geral é escrita em termos de uma integral da densidade de estados do sistema. Para o caso do gás ideal na armadilha harmônica isotrópica $<N_{\max }>$ corresponde a uma integral cujo resultado pode ser expresso 
em termos da função Zeta de Riemann ${ }^{5}$

$$
<N_{\max }>\rightarrow \frac{1}{2 \epsilon^{3}} \int_{\frac{\epsilon}{2}}^{\infty} \frac{(x+\epsilon)(x+2 \epsilon)}{e^{x}-1} d x
$$

e na qual $x=\beta n \hbar \omega$ e $\epsilon=\beta \hbar \omega$. Na situação em que $\hbar \omega \ll \frac{1}{\beta}$, esta integral tem uma boa estimativa dada por

$$
<N_{\max }>=1.202 . .\left(\frac{k_{B} T}{\hbar \omega}\right)^{3},
$$

cuja expressão corresponde exatamente à relação que ilustra a condensação, no sentido em que explicita o papel da temperatura no valor do número de saturação. De fato, a situação em que $<N_{\max }>$ se iguala ao número total de partículas é também a situação que fixa o valor da temperatura

$$
T_{c}=\frac{\hbar \omega}{k_{B}}\left(\frac{<N>}{1.202 . .}\right)^{\frac{1}{3}}
$$

abaixo da qual a ocupação dos bósons satura o estado correspondente ao nível de menor energia $\epsilon_{0}$, que por sua vez consiste na idéia da condensação como concebida por Einstein ${ }^{6}$.

\subsection{Definição geral da condensação de Bose-Einstein}

Durante mais de uma década após o trabalho de Einstein, e apesar de muito estudo ter sido realizado em sistemas de gases bosônicos, não foi obtido nenhum progresso real nesta área. $^{7}$ [7]. No ano de 1937, após conhecer os trabalhos experimentais que vinham sendo realizados no ${ }^{4} \mathrm{He}$, e em que foi caracterizado pela primeira vez o fenômeno de superfluidez, London propôs que um dos mecanismos por trás do comportamento superfluido do ${ }^{4} \mathrm{He}$ poderia ser justamente a ocorrência da condensação de Bose-Einstein. Para justificar esta hipótese, London mostrou que a estimativa da temperatura crítica prevista pela teoria de Einstein para um sistema em que as partículas tinham a massa do ${ }^{4} \mathrm{He}$ era próxima daquela em que se verificava a transição no laboratório [7], e com este resultado ${ }^{8}$ a teoria de Einstein ganhou força outra vez. A partir de então e até os dias de hoje, os fenômenos relacionados à condensação têm sido exaustivamente estudados.

Um passo muito importante para a teoria da condensação bosônica foi alcançado no ano de 1956, em um trabalho de Penrose e Onsager [23] em que os autores generalizam a definição da condensação de Bose-Einstein de forma a permitir o estudo de sistemas com interações arbitrárias entre as partículas e dispostos sob qualquer potencial. Esta é provavelmente a definição mais geral do fenômeno da condensação bosônica [3] e corresponde de fato à que

\footnotetext{
${ }^{5}$ Uma vez que o objetivo aqui é apenas o de ilustrar a idéia da condensação bosônica, os detalhes deste cálculo foram omitidos. No entanto, o leitor interessado pode encontrar o desenvolvimento de todas as passagens na seção 1 da referência [6].

${ }^{6}$ Apesar de a situação do gás aprisionado ter sido utilizada aqui para ilustrar a idéia da condensação como concebida por Einstein, o sistema estudado por ele compreendia o gás ideal livre. Na referência [6] é possível encontrar uma comparação entre estas duas situações bem como discussões sobre a influência da dimensão do sistema no fenômeno da condensação. A leitura desta referência é altamente recomendável porque expõe o fenômeno em diversas situações e de maneira muito clara.

${ }^{7}$ Aparentemente uma das principais razões deve-se à maneira como a teoria de Einstein foi inicialmente recebida pela comunidade científica. 'Uhlenbeck, por exemplo, argumentou contra a teoria pois discordava das predições da transição de fase, argumentando que esta não poderia ocorrer em sistemas finitos' [7]. Para um apanhado geral sobre o desenvolvimento histórico da pesquisa desta área, ver [7].

${ }^{8} \mathrm{E}$ também depois de um entendimento melhor da teoria de transições de fase de $2^{a}$ ordem do que aquele que se tinha na época do trabalho de Einstein [7].
} 
será será utilizada ao longo de todas as análises deste trabalho.

Para os desenvolvimentos a seguir é importante manter que a idéia básica do fenômeno da condensação consiste na ocupação de um estado de partícula independente por um número macroscópico de partículas (ou como definem Penrose e Onsager, 'a condensação ocorre quando o número de partículas que ocupam um estado de partícula independente se torna uma quantidade extensiva do sistema' [23]). Portanto, a generalização deste conceito a sistema sujeitos a condições arbitrárias de interação e potencial externo está relacionada com o entendimento das duas questões (a) o que significa um estado de partícula independente neste contexto e (b) como acessá-lo.

Considere então um sistema de $N$ bósons interagentes sujeitos a um potencial externo (que pode ou não ter dependência temporal) e descritos pelo Hamiltoniano de muitos corpos $H$, dado na representação de posição $\left\{x_{k}\right\}=\left\{x_{1}, x_{2}, \ldots, x_{N}\right\}$. Independentemente da expressão deste Hamiltoniano, é sempre possível encontrar um conjunto completo e ortonormal de autoestados que satisfazem a equação de autovalores

$$
H \phi_{i}\left(\left\{x_{k}\right\}\right)=\epsilon_{i} \phi_{i}\left(\left\{x_{k}\right\}\right)
$$

$\operatorname{com} \epsilon_{i}$ a energia de muitos corpos correspondente ao $i$-ésimo estado. Aqui os estados $\phi_{i}\left(\left\{x_{k}\right\}\right)$ são funções de onda puras e uma vez que compreendem uma base no espaço de Hilbert de muitos corpos, qualquer estado mais geral do sistema pode ser escrito como uma combinação linear destes estados como $\Phi_{\alpha}\left(\left\{x_{k}\right\}\right)=\sum_{i} p_{i} \phi_{i}\left(\left\{x_{k}\right\}\right)$, com os pesos $p_{i}$ adequados.

Para seguir com o estudo das propriedades do sistema relacionadas à condensação é necessário descobrir então como é que as partículas deste sistema de muitos corpos estão alocadas em estados individuais, e como será mostrado aqui, esta informação é obtida através do formalismo das matrizes de densidade ${ }^{9}$.

A construção da matriz densidade $\rho$ parte dos autoestados do Hamiltoniano de muitos corpos que caracterizam o sistema, como ilustrado na matriz densidade referente ao estado de muitos corpos $\phi_{i}\left(\left\{x_{k}\right\}\right)$

$$
\rho=\phi_{i}^{*}\left(\left\{x_{k}\right\}\right) \phi_{i}\left(\left\{x_{k}^{\prime}\right\}\right) .
$$

As informações referentes ao que acontece com um corpo neste sistema, por exemplo a partícula correspondente à coordenada $x_{1}{ }^{10}$, são obtidas quando todas as informações das $N-1$ partículas restantes contidas na matriz densidade são desconsideradas. O procedimento matemático correspondente a esta 'prosa' consiste em tomar $\left\{x_{k}^{\prime}\right\}=\left\{x_{k}\right\}$ para $k=2 \ldots N$ seguido de uma integração em todas as variáveis $\left\{x_{k}\right\}$ do sistema, com exceção à da partícula de interesse.

Portanto, de forma geral, $\rho^{(1)}$ é definido como:

$$
\rho^{(1)}=N \int d x_{2} d x_{3} \ldots d x_{N} \phi_{i}^{*}\left(\left\{x_{k}\right\}\right) \phi_{i}\left(\left\{x_{k}^{\prime}\right\}\right) .
$$

Agora, esta matriz densidade - denominada de matriz densidade reduzida de um corpo - desempenha papel análogo ao da função de onda de um corpo, mas com a diferença crucial de que tem hierarquia de uma distribuição de probabilidades e não de uma amplitude de probabilidades. Desta forma atribui-se a $\rho^{(1)}$ a interpretação de que esta quantidade representa a amplitude de probabilidade de que seja encontrada uma partícula na posição $x_{1}$ multiplicada pela amplitude de probabilidade de a partícula em questão esteja na coordenada $x_{1}^{\prime}$ quando

\footnotetext{
${ }^{9}$ Ver referência [6] para uma discussão completa sobre o uso das matrizes de densidade aplicado à descrição dos condensados bosônicos.

${ }^{10}$ Note que a escolha a coordenada $x_{1}$ é arbitrária; a escolha de qualquer $x_{j}$ seria igualmente boa para a definição de $\rho^{(1)}$.
} 
consideradas todas as possibilidades para as outras partículas do sistema [3]. Esta é, portanto, toda a informação de um corpo que se pode extrair do sistema, e que está codificada na expressão de $\rho^{(1)}$ na forma de probabilidades. Acontece, no entanto, que o interesse em identificar os estados de um corpo que de fato são populados pelas partículas do sistema requer um objeto com hierarquia de amplitude de probabilidade e que por consistência deve ser obtido a partir de $\rho^{(1)}$.

Portanto, a forma natural e mais imediata de alcançar este objetivo consiste na diagonalização de $\rho^{(1)}$. Devido às propriedades de hermiticidade de $\rho, \rho^{(1)}$ é também, por definição, hermiteana, de forma que sempre admite encontrar um conjunto completo e ortonormal de funções $\xi$ tais que

$$
\rho^{(1)}\left(x, x^{\prime}\right)=\sum_{\mu} n_{\mu} \xi_{\mu}^{*}\left(x^{\prime}\right) \xi_{\mu}(x),
$$

com as amplitudes de probabilidades $\xi$ correspondendo justamente aos estados de partícula independente procurados. Na expansão acima, os autovalores $n_{\mu}$ compreendem números no intervalo $[0, N]$ e representam o número de partículas que ocupam o respectivo estado $\xi(x)$. Desta forma, a ocorrência da condensação é caracterizada pela existência de $\mu$ tal que no limite em que $N \rightarrow \infty \frac{n_{\mu}}{N} \sim 1$, com esta quantidade representando então a fração de condensado e $\xi_{\mu}$ a função de onda do condensado. Note aqui que as conveniências desta definição residem na ausência da restrições quanto à existência e generalidade de potenciais externos ou sobre as interações do sistema, de forma o fenômeno pode ser caracterizado em um âmbito mais geral. 


\section{Capítulo 3}

\section{Superfluidez}

Cunhado por Kapitza em 1938, o termo superfluidez foi aplicado inicialmente para fazer referência a uma série de fenômenos experimentais emergentes em sistemas de ${ }^{4} \mathrm{He}$ quando à temperaturas menores que $\mathrm{T}=2.17 \mathrm{~K}$ e à pressão atmosférica. De forma geral, estes fenômenos estão relacionados às propriedades de fluxo de sistemas conhecidos como líquidos quânticos ${ }^{1}$ e incluem: fluxo sem fricção, correntes persistentes, propagação de ondas nas superfícies dos líquidos e outros efeitos cinéticos [24].

Poucos meses depois da descoberta da superfluidez no ${ }^{4} \mathrm{He}$, London sugeriu que este fenômeno consistia em uma manifestação da condensação de Bose-Einstein, e justificou esta hipótese apresentando o cálculo da temperatura de condensação para um gás ideal de átomos com massa igual a do ${ }^{4} \mathrm{He}$. No entanto, apesar de a temperatura obtida por London ( $\mathrm{T}=$ $3.3 \mathrm{~K}$ [25]) compreender de fato uma boa aproximação à temperatura experimental de aparecimento dos fenômenos relacionados à superfluidez no ${ }^{4} \mathrm{He}$, este sistema tem propriedades físicas muito diferentes das de um gás ideal, e portanto, o argumento utilizado por London não sustentou sua hipótese por muito tempo.

Depois da hipótese de London, a primeira tentativa de explicação teórica à superfluidez foi de autoria de L. Tisza. Em um modelo fenomenológico, denominado de modelo de dois fluidos, Tisza propôs que o Hélio líquido deveria ser descrito como se constituído de duas componentes: normal e superfluida, e que as propriedades relacionadas à superfluidez poderiam ser entendidas através de um modelo hidrodinâmico com as hipóteses adicionais para a parte superfluída (a) seu movimento se dá sem fricção tanto com a parte normal do fluido quanto com as paredes do recipiente e (b) esta componente do líquido não acrescenta nenhuma contribuição à entropia do sistema. Este modelo, apesar de resultar uma descrição qualitativa bastante satisfatória do comportamento do Hélio superfluido, foi bastante criticado por Landau ${ }^{2}$ que criou, em 1941, uma teoria própria para descrever os fenômenos relacionados à superfluidez.

Em um artigo entitulado 'A Teoria da Superfluidez do Hélio-II ${ }^{3}$, [27], Landau caracteriza o fenômeno a partir da natureza do espectro das excitações elementares do Hélio superfluido [27], mostrando que quando estas correspondem à excitações do tipo fônons não é possível

\footnotetext{
${ }^{1}$ Líquido quântico é o nome dado a um sistema de muitos corpos descrito, de forma geral, pelas regras da Mecânica Quântica e Mecânica Estatística [3].

${ }^{2}$ De fato, em um artigo entitulado 'Sobre a Teoria da Superfluidez' [26], Landau argumenta contra a teoria de Tisza com frases como esta: 'infelizmente, entretanto, ele obtém os resultados corretos através de hipóteses incorretas como a da proporcionalidade entre a entropia e a parte normal da densidade do Hélio líquido. Os esforços de Tisza para dar um fundamento termodinâmico para suas hipóteses são bastante não convincentes e as fórmulas que dão esta proporcionalidade não são apresentadas' para argumentar contra a teoria de Tisza.

${ }^{3}$ Hélio-II é como se denomina a fase superfluida no ${ }^{4} \mathrm{He}$.
} 
transferir ao sistema quantidades arbitrariamente pequenas de momento e energia [24], de forma que o fluxo ocorre sem fricção. Ainda, com considerações acerca do espectro das excitações elementares, Landau deduz que no limite de $\mathrm{T} \rightarrow 0$, o calor específico do ${ }^{4} \mathrm{He}$ deve ser proporcional a $\mathrm{T}^{3}$, mostrando a concordância entre os seus resultados e a teoria de Debye [27]. É interessante atentar aqui para o fato de que Landau não faz menção ao fenômeno da condensação na formulação de sua teoria, e ao que tudo indica, sempre permaneceu cético à hipótese de London [28].

De forma geral, o Hélio líquido pode ser estudado em três níveis diferentes [29]:

- Macroscópico: cuja principal representante é a teoria de dois fluidos;

- Semi-fenomenológico: que consiste na Teoria de Landau, cujo objetivo é relacionar certas quantidades macroscópicas com parâmetros microscópicos;

- Microscópico: que compreendem as abordagens mais modernas (a partir da década de 50) e em termos do formalismo de matéria condensada, cujo principal objetivo é calcular todas as propriedades macroscópicas ou semi-fenomenológicas a partir do modelo utilizado para descrever as interações entre os átomos de Hélio [29]. Em geral este tipo de teoria é construída com base na hipótese da existência de um modo condensado no sistema.

Cada uma destas abordagens vêm acompanhada de sua versão da definição de superfluidez, que apesar das diferenças conceituais acerca das hipóteses assumidas nos respectivos desenvolvimentos, sempre conectam o fenômeno às propriedades de de fluxo no sistema [30]. Acontece, no entanto, que inclusão da idéia física na formulação dos critérios não é por si só capaz de assegurar uma classificação unânime para todos os sistemas, e como escreve Leggett em [31], pode-se questionar a existência de um enunciado geral para a definição de superfluidez.

Neste trabalho a superfluidez é tomada em termos do critério de dois fluidos. Uma vez que este o único critério necessário ao entendimento dos resultados apresentados no capítulo 5, este capítulo segue com o seu enunciado e uma discussão. No entanto, como forma de complemento, uma descrição sobre a teoria de Landau pode ser encontrada no apêndice A.2.

\subsection{A superfluidez pelo critério de dois fluidos}

A idéia básica por trás do critério de dois fluidos é a de que um líquido quântico pode ser descrito como se constituído de duas componentes não interagentes - denominadas de normal e superfluida, representadas, respectivamente pelas densidades $\rho_{n}$ e $\rho_{s}$ e tais que a densidade do sistema é dada por $\rho=\rho_{s}+\rho_{n}$ - e que distinguem-se devido ao comportamento apresentado quando impõe-se um campo externo de velocidades ao sistema [32]. Neste formalismo, portanto, as densidades de fluido normal e superfluido exercem o papel das quantidades relevantes e são suficientes para determinar todas as características macroscópicas relacionadas ao fluxo do sistema.

Tradicionalmente, a inclusão dos efeitos de um campo externo de velocidades a este tipo de sistema para considerações relacionadas ao fenômeno da superfluidez é realizada através da imposição de condições de contorno torcidas ${ }^{4}$ no objeto que desempenha o papel da função de onda que contém informações sobre a componente superfluida. Uma vez que não faz sentido pensar no sistema como contendo um número de átomos na parte superfluida e o restante na parte normal com respectivas funções de onda de muitos corpos, o que se faz, usualmente, é assumir a hipótese de ocorrência da condensação bosônica

\footnotetext{
${ }^{4}$ Tradução adotada para twisted boundary conditions.
} 
e identificar a função de onda do condensado - também chamada de parâmetro de ordem - com o objeto que guarda informações sobre a superfluidez. Nestes desenvolvimentos o gradiente da fase do parâmetro de ordem é comumente associado a uma velocidade, denominada de velocidade de superfluido, de forma que a imposição das condições de contorno torcidas pode ser realizada através da introdução de uma variação linear nesta fase [30]. Estas resoluções são aplicadas para encontrar a diferença entre as energias do estado fundamental do sistema com e sem condições de contorno torcidas, que de acordo com o critério de dois fluidos, é proporcional à fração de superfluido. Nas referências $[30,33]$ é possível encontrar o estudo da superfluidez no modelo de Bose-Hubbard a partir do emprego destes métodos. Para mais detalhes em relação à definição da fração de superfluido, veja [34].

Neste trabalho, a obtenção das expressões para $\rho_{s}$ e $\rho_{n}$ segue um caminho alternativo ao do método citado acima. O campo externo de velocidades é colocado como a rotação das paredes do recipiente que contém o sistema ${ }^{5}$, cujos efeitos são incluídos diretamente na expressão usual do Hamiltoniano de muitos corpos através da aplicação de técnicas de cranking. Isto permite que a diferença entre as energias intrínsecas do sistema com e sem rotação seja obtida, portanto, sem invocar o uso do parâmetro de ordem ou de hipóteses adicionais acerca da condensação, de forma que é possível prosseguir aqui com as análises de cada um destes fenômenos independentemente. Ainda, uma vez que o modelo estudado nos capítulos 4 e 5 considera um sistema disposto em um container com geometria de anel, os desenvolvimentos abaixo serão realizados para este tipo de recipiente ${ }^{6}$.

\subsubsection{Considerações estatísticas sobre o cálculo de $\rho_{s}$}

Para que seja possível prosseguir com o estudo do sistema através do uso das técnicas padrões da Mecânica Estatística de equilíbrio, é preciso considerar o sistema em um referencial em que o Hamiltoniano é independente do tempo. No caso da rotação uniforme das paredes do recipiente que contém o sistema, o único referencial que satisfaz este requisito é aquele que rotaciona com a mesma velocidade angular $\omega$ de rotação do recipiente. Portanto, a dinâmica de $N$ partículas de massa $m$ dispostas em um recipiente com geometria de anel de raio $R$ que efetua rotação e sujeitas à ação de um potencial externo $V_{\text {ext }}$ que rotaciona junto com o anel, é descrita neste referencial e em termos dos operadores de campo através do Hamiltoniano

$$
H_{\omega}=\int d \phi \Psi^{\dagger}(\phi)\left(\frac{1}{2 m R^{2}}\left(\frac{\hbar}{i} \frac{d}{d \phi}-m \omega R^{2}\right)^{2}+V_{e x t}(\phi)\right) \Psi(\phi),
$$

em que a expressão de $V_{\text {ext }}(\phi)$ não apresenta dependência temporal e nem de $\omega^{7}$.

Para os cálculos efetuados a seguir, consideram-se duas hipóteses acerca do sistema:

- Todas as propriedades estatísticas de um sistema de muitos corpos cuja dinâmica é descrita pelo Hamiltoniano $H$ podem ser determinadas a partir da matriz densidade térmica $\rho=e^{-\beta H}[32]$.

\footnotetext{
${ }^{5}$ Note, entretanto, que estes métodos podem ser adaptados sem dificuldades adicionais para outros tipos de movimento, como por exemplo o movimento acelerado.

${ }^{6} E$ É importante chamar atenção, no entanto, que os métodos desenvolvidos aqui podem ser aplicados para sistemas gerais e com geometria diferente desta.

${ }^{7}$ Aqui a expressão do Hamiltoniano no referencial que efetua rotação é apenas enunciada, porque os desenvolvimentos a seguir utilizam explicitamente os termos do Hamiltoniano proporcionais a $\omega$. No entanto, o capítulo seguinte apresenta um estudo detalhado de cada um dos termos deste Hamiltoniano nos casos com e sem rotação.
} 
- As componentes normal e superfluida são determinadas experimentalmente a partir da sua resposta ao movimento imposto [32].

Portanto, o primeiro passo para avaliar a resposta ao movimento de rotação das paredes do recipiente que contém o sistema deve compreender o cálculo da matriz densidade (não normalizada). Para o referencial que rotaciona com $\omega$ tem-se:

$$
\rho_{\omega}=e^{-\beta H_{\omega}}
$$

com $H_{\omega}$ dado pela expressão (3.1.1). Agora, devido ao regime de baixíssimas temperaturas para o qual o estudo do sistema é considerado, é possível utilizar a aproximação:

$$
\rho_{w}=\sum_{n}\left|E_{n}^{(\omega)}\right\rangle e^{-\beta E_{n}^{(\omega)}}\left\langle E_{n}^{(\omega)}\left|=e^{-\beta E_{0}^{(\omega)}} \sum_{n}\right| E_{n}^{(\omega)}\right\rangle e^{-\beta\left(E_{n}^{(\omega)}-E_{0}^{(\omega)}\right)}\left\langle E_{n}^{(\omega)}\left|\simeq e^{-\beta E_{0}^{(\omega)}}\right| E_{0}^{(\omega)}\right\rangle\left\langle E_{0}^{(\omega)}\right|
$$

que ilustra o fato de que a matriz densidade depende essencialmente da energia do estado fundamental, denominada aqui como $E_{0}^{(\omega)}$

Da aplicação direta da definição de componente normal do fluido - como a única parte do sistema que de fato oferece resposta ao movimento [32] - obtêm-se:

$$
\frac{\rho_{n}}{\rho} N m R^{2} \omega=\left\langle L_{z}\right\rangle_{\omega}=\frac{\operatorname{Tr}\left[L_{z} \rho_{\omega}\right]}{\operatorname{Tr}\left[\rho_{\omega}\right]}=\frac{\int_{0}^{2 \pi} d \phi L_{z} e^{-\beta H_{\omega}}}{\int_{0}^{2 \pi} d \phi e^{-\beta H_{\omega}}},
$$

que pode ser reescrito da seguinte forma:

$$
\frac{\rho_{n}}{\rho} N m \omega R^{2}=\frac{1}{\beta} \frac{\partial}{\partial \omega} \ln \left(\operatorname{Tr}\left[\rho_{\omega}\right]\right)+N m R^{2} \omega
$$

Esta expressão, quando combinada com (3.1.2), $\operatorname{com} \operatorname{Tr} \rho_{\omega}=e^{-\beta E_{0}^{(\omega)}}$ e com a definição das componentes normal e superfluida do sistema - $\rho=\rho_{s}+\rho_{n}$, resulta uma expressão para a fração de superfluido a partir do parâmetro inercial

$$
\frac{\rho_{s}}{\rho}=\left.\frac{2}{N m R^{2}} \frac{\partial E_{0}^{(\omega)}}{\partial \omega^{2}}\right|_{\omega=0}
$$

\subsubsection{Relacionando fração inercial de superfluido com o espectro dos au- toestados do sistema $\operatorname{com} \omega=0$}

Considere mais uma vez o Hamiltoniano de muitos corpos no referencial em que gira com a mesma velocidade angular das paredes do container (3.1.1). Este Hamiltoniano leva à equação de Schrödinger $H_{\omega}\left|\Psi_{\omega}^{(0)}\right\rangle=E_{\omega}^{(0)}\left|\Psi_{\omega}^{(0)}\right\rangle$, cuja energia do estado fundamental é dada por $E_{\omega}^{(0)}$.

Agora, a partir da aplicação do teorema de Feynman-Hellman, é possível escrever o parâmetro inercial como:

$$
\left.\frac{\partial E_{\omega}^{(0)}}{\partial \omega^{2}}\right|_{\omega=0}=\lim _{\omega \rightarrow 0} \frac{1}{2 \omega} \frac{\partial E_{\omega}^{(0)}}{\partial \omega}=\lim _{\omega \rightarrow 0} \frac{1}{2 \omega}\left\langle\Psi_{\omega}^{(0)}\left|\frac{\partial H_{\omega}}{\partial \omega}\right| \Psi_{\omega}^{(0)}\right\rangle .
$$

Note aqui, em particular, que as derivadas em $\omega$ de $H_{\omega}$ podem ser expressas em termos do 
Hamiltoniano do sistema sem rotação $H_{\omega=0}$ como:

$$
\begin{aligned}
H_{\omega}-H_{0} & =\int d \phi \Psi^{\dagger}(\phi)\left(-\omega \frac{\hbar}{i} \frac{\partial}{\partial \phi}+\frac{m R^{2} \omega^{2}}{2}\right) \Psi(\phi) \\
\frac{\partial H_{\omega}}{\partial \omega} & =\int d \phi \Psi^{\dagger}(\phi)\left(-\frac{\hbar}{i} \frac{\partial}{\partial \phi}+m R^{2} \omega\right) \Psi(\phi)
\end{aligned}
$$

tal que $\frac{\partial H_{\omega}}{\partial \omega}=\frac{1}{\omega}\left(H_{\omega}-H_{0}+\hat{N} \frac{m R^{2} \omega^{2}}{2}\right)$.

Portanto,

$$
\begin{aligned}
\left.\frac{\partial E_{\omega}^{(0)}}{\partial \omega^{2}}\right|_{\omega=0} & =\lim _{\omega \rightarrow 0} \frac{1}{2 \omega^{2}}\left\langle\Psi_{\omega}^{(0)}\left|H_{\omega}-H_{0}+\hat{N} \frac{m R^{2} \omega^{2}}{2}\right| \Psi_{\omega}^{(0)}\right\rangle \\
& =\frac{N m R^{2}}{4}+\lim _{\omega \rightarrow 0}\left\langle\Psi_{\omega}^{(0)}\left|H_{\omega}-H_{0}\right| \Psi_{\omega}^{(0)}\right\rangle
\end{aligned}
$$

Agora, a partir da introdução de um conjunto completo de autoestados do sistema com $\omega=0, H_{\omega=0}\left|\Psi_{0}^{(\nu)}\right\rangle=E_{0}^{(\nu)}\left|\Psi_{0}^{(\nu)}\right\rangle$ no último elemento de matriz:

$$
\left\langle\Psi_{\omega}^{(0)}\left|H_{\omega}-H_{0}\right| \Psi_{\omega}^{(0)}\right\rangle=\sum_{\nu}\left(E_{\omega}^{(0)}-E_{0}^{(\nu)}\right)\left|\left\langle\Psi_{\omega}^{(0)} \mid \Psi_{0}^{(\nu)}\right\rangle\right|^{2}
$$

é possível obter a expressão

$$
\left.\frac{\partial E_{\omega}^{(0)}}{\partial \omega^{2}}\right|_{\omega=0}=\frac{N m R^{2}}{4}+\lim _{\omega \rightarrow 0} \frac{1}{2 \omega^{2}} \sum_{\nu}\left(E_{\omega}^{(0)}-E_{0}^{(\nu)}\right)\left|\left\langle\Psi_{\omega}^{(0)} \mid \Psi_{0}^{(\nu)}\right\rangle\right|^{2},
$$

que pode finalmente ser tratada a partir do emprego da teoria de perturbações. A expressão perturbativa da energia deve ser calculada até segunda ordem enquanto que a dos autoestados é calculada até primeira ordem. Usando notação $L_{z}=\int d \phi \Psi^{\dagger}(\phi) \frac{h}{i} \frac{\partial}{\partial \phi} \Psi(\phi)$ é possível escrever:

$$
\begin{gathered}
E_{\omega}^{(0)} \simeq E_{0}^{(0)}+\frac{N m R^{2} \omega^{2}}{2}+\omega^{2} \sum_{\nu \neq 0} \frac{\left|\left\langle\Psi_{0}^{(0)}\left|\hat{L_{z}}\right| \Psi_{0}^{(\nu)}\right\rangle\right|^{2}}{E_{0}^{(0)}-E_{0}^{(\nu)}}, \\
\left|\Psi_{\omega}^{(0)}\right\rangle \simeq\left|\Psi_{0}^{(0)}\right\rangle+\omega \sum_{\nu \neq 0} \frac{\left|\Psi_{0}^{(\nu)}\right\rangle\left\langle\Psi_{0}^{(\nu)}\left|\hat{L}_{z}\right| \Psi_{0}^{(0)}\right\rangle}{E_{0}^{(0)}-E_{0}^{(\nu)}},
\end{gathered}
$$

de onde obtém-se uma expressão para o parâmetro inercial em termos das excitações do sistema:

$$
\left.\frac{\partial E_{\omega}^{(0)}}{\partial \omega^{2}}\right|_{\omega=0}=\frac{N m R^{2}}{2}+\sum_{\nu \neq 0} \frac{\left|\left\langle\Psi_{0}^{(0)}\left|\hat{L}_{z}\right| \Psi_{0}^{(\nu)}\right\rangle\right|^{2}}{E_{0}^{(0)}-E_{0}^{(\nu)}}
$$

Nesta fórmula estão embutidas diversas propriedades do fenômeno da superfluidez relacionadas diretamente com a física do sistema. Em primeiro lugar note a dependência do espectro (e autoestados) de $H_{\omega=0}$ na expressão da somatória acima. Esta dependência faz com que a fração de superfluido dependa também de características tais como interação entre as partículas e presença de um potencial externo, e que incorpore efeitos de rotação das paredes do container contidas na expressão das autoenergias do sistema. Além disso, esta somatória consiste em uma quantidade negativa. Portanto, uma vez que esse é justamente o termo que introduz uma dependência explícita dos estados excitados na expressão da fração de superfluido, é possível concluir que o acoplamento com estes estados excitados induz a supressão da superfluidez [30]. Note ainda que a dependência das excitações é crucial na 
determinação das propriedades relacionadas à superfluidez, e portanto os resultados sobre o fenômeno obtidos a partir de observáveis relacionados apenas com o estado fundamental, como por exemplo a fração de condensado e padrões de interferência, não devem ser capazes de descrever o sistema de forma completa [30].

Obtida a expressão acima para o parâmetro inercial, sua correspondência com o cálculo estatístico $\rho_{s}$ segue diretamente. De fato, a partir da substituição de (3.1.5) em (3.1.4) vem:

$$
\frac{\rho_{s}}{\rho}=1+\frac{2}{N m R^{2}} \sum_{\nu \neq 0} \frac{\left|\left\langle\Psi_{0}^{(0)}\left|\hat{L}_{z}\right| \Psi_{0}^{(\nu)}\right\rangle\right|^{2}}{E_{0}^{(0)}-E_{0}^{(\nu)}}, \quad \frac{\rho_{n}}{\rho}=-\frac{2}{N m R^{2}} \sum_{\nu \neq 0} \frac{\left|\left\langle\Psi_{0}^{(0)}\left|\hat{L}_{z}\right| \Psi_{0}^{(\nu)}\right\rangle\right|^{2}}{E_{0}^{(0)}-E_{0}^{(\nu)}}
$$

tal que o resultado compreende justamente as expressões de $\rho_{n}$ e $\rho_{s}$ em termos do espectro das excitações do Hamiltoniano de muitos corpos do sistema sem rotação. 


\section{Capítulo 4}

\section{Apresentação do modelo}

Como já foi mencionado anteriormente, o presente trabalho tem como objetivo realizar o estudo da condensação de Bose-Einstein e da superfluidez em um gás de bósons muito diluído disposto em um potencial periódico com geometria de anel e que efetua rotação. Considerações sobre a rotação do potencial são especialmente importantes para a caracterização das propriedades relacionadas ao fenômeno da superfluidez e serão tratadas neste capítulo após uma discussão inicial realizada para explicitar a derivação do Hamiltoniano do sistema a partir da expressão geral em termos dos operadores de campo do Hamiltoniano de problemas de muitos corpos. Neste capítulo são obtidas as expressões segundo quantizadas dos Hamiltonianos que serão utilizados nos desenvolvimentos ao longo do trabalho, e para finalizar, é apresentada uma pequena discussão sobre o modelo de Bose-Hubbard, que consiste, de fato, no modelo usualmente empregado no estudo de gases frios e diluídos em redes ópticas.

\subsection{Considerações gerais sobre Hamiltonianos de sistemas de gases bosônicos}

De forma geral, a dinâmica de um gás de $\mathrm{N}$ bósons dispostos em um potencial externo é descrita pelo Hamiltoniano

$$
H=\sum_{i=1}^{N}\left(\frac{p_{i}^{2}}{2 m}+V_{\text {ext }}\left(\overrightarrow{r_{i}}\right)\right)+V_{i n t}\left(\overrightarrow{r_{i}}, \overrightarrow{r_{j}}\right)
$$

com o termo livre: $\frac{p_{i}^{2}}{2 m}$ e o termo devido à ação de um potencial externo: $V_{\text {ext }}\left(\overrightarrow{r_{i}}\right)$ representando contribuições individuais de cada uma das partículas do sistema, enquanto que efeitos coletivos - que surgem como consequência das interações entre as partículas - são representados pelo termo $V_{\text {int }}$. Na situação ideal $V_{\text {int }}$ deve ser capaz de descrever todas as interações presentes no sistema, resultado de processos de colisões de dois corpos, três corpos, e assim por diante. Entretanto, na prática, não é isso o que acontece. Aliás, a solução exata de problemas de muitos corpos pode ser encontrada apenas em situações muito particulares, e de forma geral, nenhuma das teorias existentes até os dias de hoje consegue dar um tratamento exato às interações em sistemas quânticos realistas de muitos corpos. No entanto, o que é possível fazer e de fato é posto em prática, é restringir a generalidade deste potencial de interação à descrição das interações relevantes do sistema tratado e que nas condições 
em que este se encontra são por si só suficientes para garantir uma boa aproximação da realidade experimental. Neste trabalho, por exemplo, realiza-se o estudo das propriedades relacionadas à superfluidez e à condensação bosônica em um gás muito diluído disposto em um potencial periódico com geometria de anel, como ilustrado na figura abaixo.

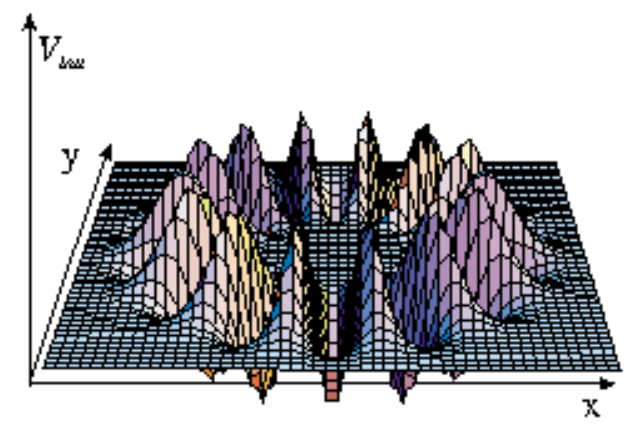

Figura 4.1: Ilustração da implementação de uma rede óptica com geometria de anel. Existe uma proposta experimental para a realização deste sistema, que está descrita na referência [35], que é também a fonte desta imagem.

Por sua vez, um gás muito diluído no regime de condensação compreende um sistema com temperatura próxima de $0 \mathrm{~K}$ em que a distância entre os átomos - fixada pela densidade do gás e dada pela razão $n=\frac{N}{V} \operatorname{com} N$ o número de átomos e $V$ o volume disponível de ocupação - é muito grande. No laboratório isto corresponde a sistemas de gases atômicos fabricados com densidades da ordem de $10^{-5}$ átomos por $\mathrm{cm}^{3}$ e temperaturas entre $10^{-7} \mathrm{~K} \mathrm{e} 10^{-5} \mathrm{~K}$ [3]. Exatamente por estarem sob estas condições, uma boa aproximação das interações no sistema pode ser obtida considerando que as interações que de fato ocorrem se restringem aos resultados de processos de colisões de dois corpos [36]. Ainda, como consequência das baixas densidades praticadas, 'a distância entre duas partículas nestes sistemas é sempre grande o suficiente para justificar o uso da expressão assintótica da função de onda do movimento relativo, fixada pela amplitude de espalhamento' [36]. Isso dispensa, portanto, qualquer análise mais detalhada desta interação, porque agora todas as informações do sistema ficam armazenadas na amplitude de espalhamento.

A obtenção da amplitude de espalhamento de processos de dois corpos no regime de condensação segue diretamente da aplicação da teoria padrão do espalhamento de baixas energias, como será comentado na seção a seguir, em que é discutida a origem da expressão do potencial efetivo $V_{\text {int }}$. Desta forma, para prosseguir com a caracterização do sistema é necessário identificar ainda a expressão de $V_{\text {ext }}$ e adotar condições de contorno adequadas à sua descrição. Da geometria anelar segue imediatamente que este é um problema com condições de contorno periódicas e com período igual a $2 \pi$; da escolha do potencial externo como um potencial periódico - é natural que seja satisfeita a condição $V_{e x t}(\vec{r})=V_{\text {ext }}(\vec{r}+n p)$, em que $p$ corresponde ao período do potencial e $n$ a um inteiro qualquer. Juntando a isso a expressão de $V_{\text {int }}$, que sabe-se ser obtida a partir da amplitude de de espalhamento, é possível proceder com a construção de cada um dos termos do Hamiltoniano do sistema, que de forma geral, em termos dos operadores do campo, é dada por

$$
H=\int d^{3} r d^{3} r^{\prime} \Psi^{\dagger}(\vec{r})\left(\frac{p^{2}}{2 m}+V_{\text {ext }}(\vec{r})+\Psi^{\dagger}\left(\overrightarrow{r^{\prime}}\right) V_{i n t} \Psi\left(\overrightarrow{r^{\prime}}\right)\right) \Psi(\vec{r}) .
$$




\subsubsection{Comprimento de espalhamento de onda-s e interação efetiva}

O entendimento de como ocorrem as colisões entre duas partículas em sistemas diluídos de gases muito frios é extremamente importante porque estes processos estão diretamente relacionados tanto com fatores que determinam a realização experimental dos condensados - como o processo de condensação por evaporação [6, 37], quanto com sua estabilidade [37].

Aqui, uma circunstância que simplifica enormemente o tratamento de interações nestes sistemas, é que a situação de baixas energias do regime de condensação - quando o comprimento de onda de de Broglie $\lambda_{T}=\frac{h}{k_{T}}\left(\operatorname{com} k_{T}\right.$ o momento das partículas à temperatura $T$ ) é aproximadamente do tamanho do espaçamento entre as partículas - permite que os processos de espalhamento sejam aproximados pelo espalhamento de onda-s $[3,6]$.

De forma geral, interações entre partículas são caracterizadas pela seção de choque que descreve o processo de colisão entre as mesmas. Para os processos considerados por meio do espalhamento de onda-s, como é o caso de interesse aqui, a seção de choque do centro de massa de duas partículas em um estado de momento relativo $\vec{k}$ pode ser caracterizada em termos do deslocamento de fase $\delta_{0}(k) \operatorname{como}^{1}[6]$

$$
\frac{d \sigma}{d \Omega}=\frac{\sin ^{2}\left(\delta_{0}(k)\right)}{k^{2}}
$$

tal que $a$ é uma quantidade com dimensões de comprimento.

Acontece, no entanto, que o contexto dos processos de interação que pretendem ser descritos através da seção de choque acima compreende, em particular, o limite $k \rightarrow 0$. Neste caso, o denominador de (4.1.3) requer o anulamento linear da função $\sin \left(\delta_{0}(k)\right)$ para qualquer $k$ e portanto $\delta_{0}(k)$ não pode mais ser considerado uma boa quantidade para caracterizar estas seções de choque. Uma forma de corrigir esta inequabilidade consiste na introdução do comprimento de espalhamento de onda-s $a$, definido como

$$
\lim _{k \rightarrow 0} \frac{k}{\sin \left(\delta_{0}(k)\right)} \equiv-\frac{1}{a}
$$

Aqui, a menos da escolha do sinal, o comprimento de espalhamento de onda-s a corresponde à mesma quantidade do parâmetro de comprimento introduzido na equação (4.1.3) [6].

Para refinar a descrição para descrever a dependência da seção de choque com o momento relativo, esta última expressão é considerada como o primeiro termo de uma expansão em potências de $k$ da quantidade $k \cot \left(\delta_{0}(k)\right)$, escrita como [6]

$$
k \cot \left(\delta\left(k_{0}\right)\right)=-\frac{1}{a}+\frac{r_{0}}{2} k^{2}+\ldots
$$

e denominada, devido ao alcance efetivo $r_{0}$, de equação de alcance efetivo. Desta forma, ao invés de utilizarem os deslocamentos de fase, os processos de espalhamento de onda-s a baixas energias passam a ser caracterizados por apenas dois parâmetros: o comprimento de espalhamento de onda-s $a$ e o alcance efetivo $r_{0}$. Isto implica, portanto, que independente da forma do potencial, diferentes potenciais com os mesmos valores de $a$ e $r_{0}$ dão origem aos mesmos processos de interação.

A determinação do valor de $a$ segue diretamente da teoria padrão de espalhamento cujos métodos não serão discutidos aqui ${ }^{2}$. O objetivo, agora, é descrever como se implementa, a partir do conhecimento dos processos de interação entre duas partículas do sistema, a

\footnotetext{
${ }^{1}$ Os desenvolvimentos daqui são baseados na seção 2.1 da referência [6].

${ }^{2}$ Ver referência [38].
} 
extensão dos efeitos da interação para o sistema global através de um potencial efetivo.

De forma geral, a aproximação utilizada para sistemas de gases rarefeitos a baixas temperaturas consiste em substituir o potencial 'real' de interação $U\left(\overrightarrow{r_{i}}, \overrightarrow{r_{j}}\right)$ por uma interação efetiva de contato $V_{i n t}=\lambda \delta\left(\overrightarrow{r_{i}}-\overrightarrow{r_{j}}\right)$, cuja constante de acoplamento é proporcional a $\frac{2 \pi \hbar^{2} a}{\mu}$ e em que $\mu$ é a massa reduzida das partículas envolvidas no processo. Consequentemente, para o caso de partículas idênticas de massa $m$, a expressão do potencial efetivo de interação é dada por

$$
V_{i n t}\left(\overrightarrow{r_{i}}, \overrightarrow{r_{j}}\right)=\frac{4 \pi \hbar^{2} a}{m} \delta\left(\overrightarrow{r_{i}}-\overrightarrow{r_{j}}\right),
$$

que corresponde à expressão que será adotada para o termo de interação do Hamiltoniano (4.1.1). Da mesma forma, segue abaixo a expressão segundo quantizada deste termo do Hamiltoniano:

$$
V_{\text {int }}=\frac{4 \pi \hbar^{2} a}{m} \int d^{3} r \Psi^{\dagger}(\vec{r}) \Psi^{\dagger}(\vec{r}) \Psi(\vec{r}) \Psi(\vec{r})
$$

\subsubsection{A física por trás da escolha do potencial periódico}

Esta seção discute a estrutura de bandas do espectro de energias de sistemas sujeitos à ação de potenciais periódicos. Uma vez que as propriedades físicas de um sistema de muitos corpos podem ser qualitativamente entendidas através do estudo do problema de KronigPenney de um corpo [19], a resolução deste problema será desenvolvida aqui explicitamente.

O problema de Kronig-Penney consiste no estudo da dinâmica de uma partícula sujeita a um potencial periódico e que satisfaz condições de contorno periódicas [39]. Para um arranjo unidimensional com período $d$ e com barreiras de potencial de largura $b$, este modelo pode ser esquematizado como na figura 4.2, e é representado pelo Hamiltoniano

$$
H=\frac{p^{2}}{2 m}+V(x)
$$

$\operatorname{com} V(x)=V(x+d)$.

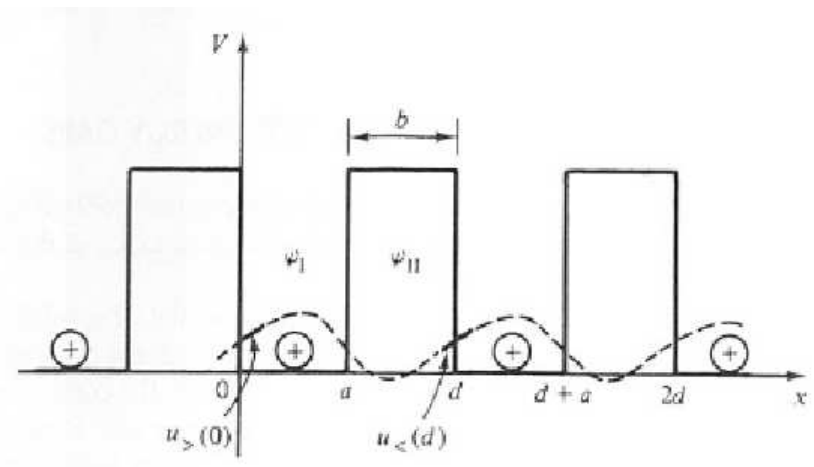

Figura 4.2: Ilustração esquemática com os parâmetros do modelo de Kronig-Penney considerados na resolução do problema. Esta figura foi adaptada de uma figura da referência [39].

A adição do termo de potencial periódico ao Hamiltoniano é responsável pela quebra da invariância translacional contínua do sistema. Consequentemente perde-se a conservação de momento e portanto as autofunções do problema de autovalores não podem mais ser tomadas como os autoestados de momento. Entretanto, devido à natureza periódica do potencial, existe aqui uma outra quantidade que se conserva, usualmente denominada quasi-momento 
(ou momento modular). Este quasi-momento exerce um papel análogo ao do momento em sistemas livres, e pode ser tomado como a quantidade que se conserva em um sistema invariante por translações espaciais discretas. Mantendo as analogias, e da mesma forma que acontece com o momento nos sistemas livres, os valores admitidos pelo quasi-momento podem ser empregados para rotular as autofunções do sistema sujeito a uma rede periódica de potenciais.

Uma forma de se obter as autofunções do problema de autovalores de (4.1.8) é através da aplicação direta do Teorema de Bloch [40]. Este teorema enuncia justamente que as autofunções de um sistema disposto em um potencial periódico são funções de Bloch, definidas como

$$
\psi(x)=e^{i q x} u(x)
$$

com $u(x)$ uma função periódica e que tem a mesma periodicidade do potencial. Fisicamente o que o teorema afirma é que as autofunções deste problema são as mesmas ondas planas do problema livre mas com uma modulação adicional que dá conta de incluir os efeitos do potencial nestas autofunções.

De forma alternativa, existe um processo intuitivo que permite a obtenção das autofunções deste problema, desenvolvido a partir do uso direto da propriedade de conservação do quasi-momento. A idéia básica por trás deste processo é a seguinte: uma vez que $T_{S}$ representa o gerador de translações discretas no sistema, vale a propriedade $\left[H, T_{S}\right]=0$. Consequentemente, existe um conjunto completo de autofunções simultâneas de $T_{S}$ e $H$ e portanto o problema de se encontrar as autofunções de $H$ fica restrito ao de se encontrar as autofunções de $T_{S}$.

Matematicamente, este argumento se traduz da seguinte forma: Seja a ação de $T_{S}$ a adição de um vetor genérico $S$ à coordenada de uma função, ou seja,

$$
T_{S} f(x)=f(x+S)
$$

com $f(x)$ uma função qualquer. Daí segue que

$$
T_{S} H(x) f(x)=T_{S} H(x) T_{-S} T_{S} f(x),
$$

e uma vez que $T_{-S}=T_{S}^{-1}$,

$$
T_{S} H(x) f(x)=T_{S} H(x) T_{S}^{-1} T_{S} f(x)=H(x+S) T_{S} f(x) .
$$

Com a invariância do sistema à translações discretas, vale ainda que $H(x+S)=H(x)$ e portanto a propriedade de comutação segue imediatamente.

Outra propriedade que será utilizada no processo de identificação das autofunções de $T_{S}$ é propriedade de adição das translações discretas, que segue diretamente da lei de composição de grupo. Explicitamente, $T_{S+S^{\prime}}=T_{S} T_{S^{\prime}}$, com $S$ e $S^{\prime}$ dois vetores quaisquer ao longo dos quais as translações são realizadas. A verificação desta propriedade também é imediata:

$$
T_{S+S^{\prime}} f(x)=f\left(x+S+S^{\prime}\right)=T_{S^{\prime}} f(x+S)=T_{S^{\prime}} T_{S} f(x) .
$$

Considere agora a equação de autovalores:

$$
T_{S} F(x)=a(S) F(x) .
$$

Daí vem a relação $T_{S} T_{S^{\prime}} F(x)=a\left(S^{\prime}\right) T_{S} F(x)=a\left(S^{\prime}\right) a(S) F(x)$ e também $T_{S+S^{\prime}} F(x)=$ $a\left(S+S^{\prime}\right) F(x)$. Devido à propriedade aditiva da translação, deve valer ainda que $a\left(S^{\prime}\right) a(S)=$ $a\left(S^{\prime}+S\right)$ e, como translações ao longo de diferentes vetores se adicionam, a ação deste operador pode ser caracterizada por autovalores exponenciais. Suponha aqui $a(S)=e^{i \tilde{q} S}$. Portanto,

$$
T_{S} F(x)=F(x+S)=e^{i \tilde{q} S} F(x) .
$$


A expressão acima é tida como uma maneira alternativa a (4.1.9) de enunciar o Teorema de Bloch [39], e como informação adicional ao enunciado tradicional já mostra a propriedade de que as autofunções do operador de translação podem ser determinadas para todo o seu domínio a partir do comportamento das mesmas em um período. Em outras palavras, estas auto-funções são funções periódicas cuja periodicidade é a mesma do potencial. Em geral este período que se escolhe para o ajuste das constantes na expressão das autofunções é o que corresponde à chamada célula primária do sistema.

A equivalência entre as duas formas de se enunciar o Teorema de Bloch segue da periodicidade de $u(x)$. Explicitamente, de (4.1.10) é imediato ver que $F(x)$ é uma função com a mesma periodicidade do potencial. Agora, de acordo com (4.1.9), $\psi(x)=e^{i q x} u(x)$, e portanto $\psi(x+S)=e^{i q x} e^{i q S} u(x+S)$. Daqui vem que $e^{-i q S} \psi(x+S)=e^{i q x} u(x+S)$. Mas por outro lado, $e^{-i q S} \psi(x+S)=\psi(x)$. Logo, $\psi(x)=e^{i q x} u(x+S)=e^{i q x} u(x)$, o que implica na igualdade $u(x)=u(x+S)$. Para concluir note que $\psi(x+S)=e^{i q(x+S)} u(x)=$ $e^{i q S} \psi(x)$ e portanto, a obtenção do enunciado (4.1.10) a partir do enunciado (4.1.9) é suficiente para verificar as equivalências entre eles.

Uma vez conhecida a forma geral das funções de Bloch, é possível construir explicitamente as autofunções e autoenergias do problema de Kronig-Penney de um corpo em um anel de raio $\mathrm{R}$ com $\mathrm{M}$ barreiras de potencial de largura $b$. Devido à geometria anelar, a variável azimutal relevante será denotada por $\phi$, e as funções de Bloch como $\psi(\phi)=e^{i q \phi} u(\phi)$.

Começando pela imposição das condições de contorno (periódicas) tem-se

$$
\psi(\phi)=\psi(\phi+2 \pi)=e^{2 \pi i q} \psi(\phi)
$$

de onde segue que $e^{2 \pi i q}=1,2 \pi i q=2 n \pi$, com $n=0, \pm 1, \pm 2 .$. , o que implica que os valores admitidos pela variável de quasi-momento $q$ devem restringir-se a inteiros. Uma vez que $q$ será utilizado para rotular as auto-funções do sistema - e consequentemente terá também uma relação um-a-um com os seus autovalores - esta restrição dos valores possíveis de $q$ já destaca o caráter discreto do espectro de energias do sistema.

Agora, é conveniente resolver separadamente cada uma das regiões que constituem um período: o espaço livre (para $0 \leq \phi \leq a$ ) e a região das barreiras (para $a \leq \phi \leq d$ ).

No intervalo em que $0 \leq \phi \leq a$, o problema de autovalores do Hamiltoniano (4.1.8) se resume ao próprio problema livre. Portanto, as autofunções compreendem ondas planas e que serão tomadas aqui como

$$
\psi_{I}(\phi)=A e^{i k_{1} \phi}+B e^{-i k_{1} \phi}
$$

com energias dadas por $E=\frac{\hbar^{2} k_{1}^{2}}{2 m}$.

Para a região que compreende o domínio da barreira, no intervalo $a \leq \phi \leq d$, existem duas soluções a serem consideradas, uma para a situação em que $E \leq V$ e a outra para $E \geq V$. No primeiro caso, em que $E \leq V$, as funções de Bloch são dadas em termos de exponenciais reais

$$
\psi_{I I}(\phi)=C e^{k_{2} \phi}+D e^{-k_{2} \phi},
$$

em que as energias satisfazem $\frac{\hbar^{2} k_{2}^{2}}{2 m}=E-V$. Já no outro caso, em que $E \geq V$, assim como na região entre duas barreiras, as soluções do problema compreendem ondas planas. Esta situação foi desconsiderada nas resoluções deste trabalho e portanto, assume-se aqui, que no domínio das barreiras a função de onda que caracteriza o sistema tem expressão dada por $\psi_{I I}(\phi)$ acima.

A determinação das expressões que definem os coeficientes $A, B, C$ e $D$ é realizada através da imposição de condições de continuidade. Em um problema de Kronig-Penney em que as barreiras têm largura definida, por exemplo, as funções de Bloch devem ser contínuas e 
ter derivadas contínuas ao longo de todo o domínio do período [39]. Consequentemente, tanto a parte periódica das funções de Bloch, $u(\phi)$, quanto suas derivadas, $u^{\prime}(\phi)$ devem variar continuamente dentro de cada período e portanto satisfazem as seguintes condições de continuidade:

$$
\begin{aligned}
& u_{I}(0)=u_{I I}(d) \\
& u_{I}^{\prime}(0)=u_{I I}^{\prime}(d)
\end{aligned}
$$

que em termos das funções de Bloch podem ser reescritas como

$$
\begin{gathered}
\psi_{I}(0)=\psi_{I}(d) e^{-i q d} \\
\psi_{I}^{\prime}(0)=\psi_{I I}^{\prime}(d) e^{-i q d} .
\end{gathered}
$$

A determinação dos coeficientes das funções de Bloch exige ainda outras duas equações e que são obtidas a partir da imposição da continuidade das funções de Bloch para o ponto em que $\phi=a$. Explicitamente,

$$
\begin{aligned}
& \psi_{I}(a)=\psi_{I I}(a) \\
& \psi_{I}^{\prime}(a)=\psi_{I I}^{\prime}(a) .
\end{aligned}
$$

A partir da aplicação das condições de continuidade (4.1.12), (4.1.13), (4.1.16) e (4.1.17) nas expressões de $\psi_{I}$ e $\psi_{I I}$, resultam as quatro equações abaixo:

$$
\begin{gathered}
A+B=e^{-i q d}\left(C e^{k_{2} d}+D e^{-k_{2} d}\right) \\
i k_{1}(A-B)=k_{2} e^{-i q d}\left(C e^{k_{2} d}-D e^{-k_{2} d}\right) \\
A e^{i k_{1} a}+B^{-i k_{1} a}=C e^{k_{2} a}+D e^{-k_{2} a} \\
i k_{1}\left(A e^{i k_{1} a}-B e^{-i k_{1} a}\right)=k_{2}\left(C e^{k_{2} a}-D e^{-k_{2} a}\right)
\end{gathered}
$$

que quando escritas em notação matricial

$$
\left(\begin{array}{cccc}
1 & 1 & -e^{d\left(k_{2}-i q\right)} & -e^{-d\left(k_{2}+i q\right)} \\
k_{1} & -i k_{1} & -k_{2} e^{d\left(k_{2}-i q\right)} & k_{2} e^{-d\left(k_{2}+i q\right)} \\
e^{i k_{1} a} & -i e^{-i k_{1} a} & -e^{-k_{2} a} & -e^{-k_{2} a} \\
i k_{1} e^{i k_{1} a} & -i k_{1} e^{-k_{1} a} & -k_{2} e^{k_{2} a} & i k_{2} e^{-k_{2} a}
\end{array}\right)\left(\begin{array}{c}
A \\
B \\
C \\
D
\end{array}\right)=0
$$

compõem um sistema de equações lineares homogêneas cuja solução é diferente da trivial apenas na situação em que o determinante da matriz for igual a zero [39].

Do cálculo do determinante obtêm-se então a chamada relação de dispersão: que consiste em uma equação dependente das variáveis $k_{1}, k_{2}$ e de $q$, responsável por exprimir os momentos livres da partícula em termos do quasi-momento das funções de Bloch. Para este problema, a relação de dispersão é dada por

$$
\cos \left(k_{1} a\right) \cosh \left(k_{2} b\right)-\frac{k_{1}^{2}-k_{2}^{2}}{2 k_{1} k_{2}} \sin \left(k_{1} a\right) \sinh \left(k_{2} b\right)=\cos (q d)
$$

$\operatorname{com} k_{1}^{2}+k_{2}^{2}=\frac{2 m V}{\hbar^{2}}$.

Note, em particular, que esta expressão revela diversas das propriedades do espectro de energias do sistema. Além deste apresentar natureza discreta - característica que já foi mencionada, mas que aqui se faz explícita - o lado direito da equação, que consiste em uma função cosseno, impõe restrições nos valores das autoenergias. De fato, estes devem limitar-se ao intervalo $[-1,1]$ e compreendem os pontos de intersecção entre a curva representada pelo 
lado esquerdo da relação de dispersão com a do cosseno com o valor de quasi-momento de interesse, que representa o lado direito da equação. É justamente por causa desta condição que o espectro de energia de sistemas com potenciais periódicos têm uma estrutura de bandas. Explicitamente, estas bandas correspondem às diferentes faixas em que é possível encontrar soluções para as autoenergias do sistema.

No limite em que as barreiras correspondem a potenciais do tipo $\delta$-Dirac ${ }^{3}$, em que $V \rightarrow$ $\infty, b \rightarrow 0$ com o produto $V b$ constante, a relação de dispersão é dada pela expressão

$$
\cos (d k)+\frac{V_{0}}{2 k} \sin (d k)=\cos (2 q d),
$$

cujas soluções e estrutura de bandas do espectro do sistema estão ilustradas na figura 4.3.
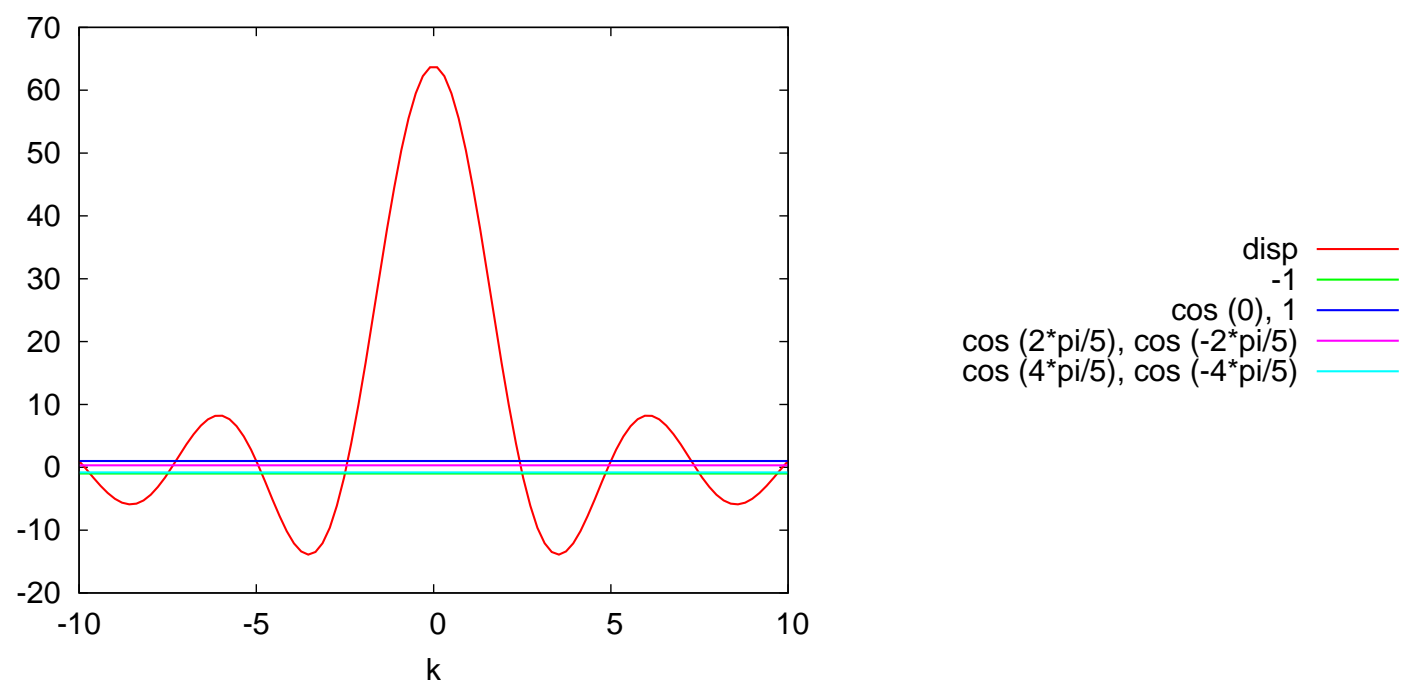

Figura 4.3: Este gráfico representa um sistema com 5 barreiras igualmente espaçadas em um anel de raio $R$. Aqui $V_{0}$ é o parâmetro que determina a intensidade da força repulsiva das barreiras em unidades de $\frac{h^{2}}{m R^{2}}$ e foi tomado como $V_{0}=100$. As intersecções entre a curva que representa a relação de dispersão e os diferentes plots da função $\cos (2 q d)$ são as soluções para os vetores de onda do sistema, $k$, que estão relacionados com as respectivas energias. Finalmente, a estrutura de bandas corresponde aos diferentes agrupamentos (separados horizontalmente) em que as soluções de $k$ podem ser obtidas.

Para concluir, os coeficientes das funções de Bloch foram obtidos a partir da resolução do sistema linear e a expressão destas funções é dada, a menos de uma constante de normalização, por:

$$
\begin{gathered}
\psi_{B}(\phi)=\gamma\left(\left(\frac{k_{1}+i k_{2}}{k_{1}-i k_{2}}\right)\left(\frac{e^{-d\left(k_{2}+i q\right)}-e^{-a\left(k_{2}+i k_{2}\right)}}{e^{a\left(k_{2}-i k_{1}\right)}-e^{d\left(k_{2}-i q\right)}}\right) e^{k_{2} \phi}+e^{-k_{2} \phi}\right)+ \\
(1-\gamma)\left(\frac{k_{1}-i k_{2}}{2 k_{1}}\right)\left(\frac{e^{-2 k_{2} d}-e^{-2 k_{2} a}}{e^{d\left(k_{2}-i q\right)}-e^{-a\left(k_{2}-i q\right)}}\right)\left(\left(\frac{-i k_{2}-k_{1}}{-i k_{2}+k_{1}}\right)\left(\frac{e^{d\left(i q-k_{2}\right)}-e^{-a\left(i k_{1}+k_{2}\right)}}{e^{d\left(i q-k_{2}\right)}-e^{-a\left(k_{2}-i k_{1}\right)}}\right) e^{i k_{1} \phi}+e^{-k_{1} \phi}\right)
\end{gathered}
$$

em que $\gamma$ é igual à parte inteira da divisão $\frac{\phi}{a}$.

\footnotetext{
${ }^{3}$ A solução completa do problema de Kronig-Penney com potenciais do tipo $\delta$-Dirac está desenvolvida explicitamente no Apêndice A.
} 


\subsubsection{Segunda quantização do Hamiltoniano e o modelo de Bose-Hubbard}

Uma vez discutida e conhecida a origem física dos potenciais $V_{\text {int }}$ e $V_{\text {ext }}$, basta escolher uma base adequada para seguir com o processo da segunda quantização do Hamiltoniano (4.1.1).

De forma geral, uma boa base para a expansão do Hamiltoniano de um problema de muitos corpos pode ser construída em termos das autofunções da parte de um corpo do Hamiltoniano de muitos corpos. Para as situações em que $V_{\text {ext }}$ é um potencial periódico, estas autofunções correspondem às funções de Bloch, definidas neste caso no espaço tridimensional como $\psi_{\alpha}(\vec{r})=e^{i \overrightarrow{q r}} u_{\alpha}(\vec{r})$, com $\alpha$ o índice responsável pela rotulação das bandas. Nos desenvolvimentos deste trabalho, será utilizada a hipótese de que a separação entre as energias da primeira e segunda bandas é grande o suficiente para garantir uma boa aproximação para a descrição do sistema quando a ocupação dos bósons é limitada às funções de Bloch da primeira banda. Consequentemente, o índice $\alpha$ será omitido nos cálculos seguintes.

Considere então o problema de autovalores de um corpo

$$
\left(\frac{p^{2}}{2 m}+V_{e x t}\right) \psi_{\vec{q}}(\vec{r})=\epsilon_{\vec{q}} \psi_{\vec{q}}(\vec{r})
$$

com $\psi_{\vec{q}}(\vec{r})=e^{i \vec{q} r} u_{\vec{q}}(\vec{r})$ a função de Bloch da primeira banda de um bóson no estado de quasi-momento $\vec{q}$; e os operadores de criação $A_{\vec{q}}^{\dagger}$ e aniquilação $A_{\vec{q}}^{\dagger}$, responsáveis por, respectivamente, criar e destruir na posição $\vec{r}$ uma partícula com função de Bloch da primeira banda com estado de quasi-momento $\vec{q}$ :

$$
\begin{aligned}
& \Psi^{\dagger}(\vec{r})=\sum_{\vec{q}} \psi_{\vec{q}}^{*}(\vec{r}) A_{\vec{q}}^{\dagger} \\
& \Psi(\vec{r})=\sum_{\vec{q}} \psi_{\vec{q}}(\vec{r}) A_{\vec{q}} .
\end{aligned}
$$

Todas as informações sobre a natureza bosônica destas partículas estão embutidas nas relações de comutação que estes operadores obedecem, dadas por:

$$
\left[\Psi^{\dagger}(\vec{r}), \Psi\left(\overrightarrow{r^{\prime}}\right)\right]=\delta\left(\vec{r}-\overrightarrow{r^{\prime}}\right), \quad\left[\Psi^{\dagger}(\vec{r}), \Psi^{\dagger}\left(\overrightarrow{r^{\prime}}\right)\right]=\left[\Psi(\vec{r}), \Psi\left(\overrightarrow{r^{\prime}}\right)\right]=0 .
$$

Agora, a partir da fórmula geral ${ }^{4}$ que relaciona os operadores de um corpo de energia cinética e potencial (externo) e o operador de interação de dois corpos de (4.1.1) com a expressão do Hamiltoniano em termos dos operadores de campo $\Psi_{\vec{q}}(\vec{r})$ e $\Psi_{\vec{q}}^{\dagger}(\vec{r})$ segue:

$$
H=\int d^{3} r \Psi^{\dagger}(\vec{r})\left(\frac{p^{2}}{2 m}+V_{e x t}\right) \Psi(\vec{r})+\frac{1}{2} \int d^{3} r d^{3} r^{\prime} \Psi^{\dagger}(\vec{r}) \Psi^{\dagger}\left(\overrightarrow{r^{\prime}}\right) V_{i n t}\left(\vec{r}-\overrightarrow{r^{\prime}}\right) \Psi\left(\overrightarrow{r^{\prime}}\right) \Psi(\vec{r}) .
$$

Nas situações em que a diferença entre as energias das excitações na direção transversa e na própria direção do potencial periódico é grande, o estudo do sistema pode ser reduzido ao estudo do caso unidimensional [41]. Portanto, considerando desacoplados e/ou congelados os graus de liberdade transversais ao deste potencial [19], o Hamiltoniano pode ser simplificado como

$$
H=\int d \phi d \phi^{\prime} \Psi^{\dagger}(\phi)\left(-\frac{\hbar^{2}}{2 m R^{2}} \frac{d^{2}}{d^{2} \phi}+V_{e x t}(\phi)+\Psi^{\dagger}\left(\phi^{\prime}\right) V_{i n t} \Psi\left(\phi^{\prime}\right)\right) \Psi(\phi),
$$

\footnotetext{
${ }^{4}$ Ver fórmulas da página 398 da referência [38].
} 
com o ângulo $\phi$ a variável azimutal relevante. A partir daqui, a menos que explicitado o contrário, todas as análises serão baseadas na expressão unidimensional do Hamiltoniano.

Nestes termos, a expressão segundo quantizada do Hamiltoniano do problema de muitos corpos na representação construída em termos das funções de Bloch da primeira banda é obtida a partir da substituição direta de expressões unidimensionais correspondentes a (4.1.23) e (4.1.24) no Hamiltoniano acima, que resulta:

$$
H=\sum_{q} \epsilon A_{q}^{\dagger} A_{q}+\frac{\lambda}{2} \sum \Lambda\left(q_{1}, q_{2}, q_{3}, q_{4}\right) A_{q_{1}}^{\dagger} A_{q_{2}}^{\dagger} A_{q_{3}} A_{q_{4}},
$$

com $\lambda$ o parâmetro que caracteriza o equivalente unidimensional da interação efetiva e

$$
\Lambda\left(q_{1}, q_{2}, q_{3}, q_{4}\right)=\int d \phi \psi_{q_{1}}^{\dagger}(\phi) \psi_{q_{2}}^{\dagger}(\phi) \psi_{q_{3}}(\phi) \psi_{q_{4}}(\phi)
$$

uma integral de quatro funções de Bloch. A partir daqui, esta expressão do Hamiltoniano será chamada, ao longo do texto, de Hamiltoniano da primeira banda.

O Hamiltoniano utilizado ao longo do trabalho será uma versão modificada do Hamiltoniano da primeira banda, adaptado para incluir os efeitos de rotação que são especialmente relevantes para os fenômenos que pretendem ser estudados aqui. No entanto, a dinâmica de sistemas de gases diluídos é comumente representada pelo Hamiltoniano do modelo de Bose-Hubbard:

$$
H_{B H}=-J \sum_{<i, j>}\left(a_{i}^{\dagger} a_{j}+a_{j}^{\dagger} a_{i}\right)+\sum_{i} \epsilon_{i} a_{i}^{\dagger} a_{i}+\frac{U}{2} \sum_{i} a_{i}^{\dagger} a_{i}^{\dagger} a_{i} a_{i} \quad J, U>0,
$$

obtido heuristicamente a partir da expressão geral do Hamiltoniano de muitos corpos (4.1.2) utilizando-se da representação construída em termos das funções de Wannier da primeira banda $\Phi_{\alpha}\left(x-x_{0}\right)$ e com a hipótese adicional de que a interação entre partículas só acontece quando elas estão no mesmo sítio, por exemplo, o sítio $i$. Em um potencial periódico com $M$ sítios, $U=U_{i i i i}$ e $J$ são dados explicitamente pelas expressões:

$$
U_{i j k l}=\int d x d x^{\prime} \Phi^{*}\left(x-R_{i}\right) \Phi^{*}\left(x^{\prime}-R_{j}\right) V_{i n t} \Phi\left(x^{\prime}-R_{k}\right) \Phi\left(x-R_{l}\right)
$$

e $J=t_{i j}+t_{j i}, \mathrm{com}$

$$
t_{i j}=\int d x \Phi^{*}\left(x-R_{i}\right)\left(\frac{p^{2}}{2 m}+V_{l a t t}\left(x_{i}\right)\right) \Phi\left(x-R_{j}\right)=\frac{1}{M} \sum_{q} e^{i q\left(R_{i}-R_{j}\right)} \epsilon_{q},
$$

de onde vem

$$
J=\sum_{q} 2 \cos \left(q\left(R_{i}-R_{j}\right)\right) \epsilon_{q}
$$

Neste Hamiltoniano, o primeiro termo - chamado de termo de hopping - é responsável por destruir uma partícula em um sítio e criá-la no sítio vizinho; o segundo termo representa as diferentes energias de cada sítio devido à imposição de um potencial externo, incluído para dar conta do fato de que, em situações comumente realizadas, a rede está imersa em um potencial confinante global; e o último termo representa a repulsão efetiva devido a interação de dois corpos em cada sítio [19]. Particularmente, a inclusão do termo que representa os efeitos de armadilha destaca o caráter altamente heurístico da derivação deste Hamiltoniano uma vez que o potencial externo destrói a regularidade da rede que é usada ao invocar as funções de Wannier. Note, no entanto, que as funções de Wannier não são as autofunções de problemas com potenciais periódicos, mas constituem um conjunto de funções equivalentes às funções de Bloch, autofunções destes Hamiltonianos, 
e são definidas em termos destas como:

$$
\Phi_{\alpha}\left(x-x_{0}\right)=\frac{1}{\sqrt{M}} \sum_{q} \psi_{\alpha q}(x)
$$

com $\alpha$ o índice de banda. A grande diferença aqui, em relação às funções de Bloch se deve ao caráter mais local das funções de Wannier, evidenciado pela propriedade

$$
\int \Phi_{\alpha}^{*}\left(x-x_{0}\right) \Phi_{\alpha^{\prime}}\left(x-x_{0}^{\prime}\right)=\delta_{\alpha \alpha^{\prime}} \delta_{x_{0} x_{0}^{\prime}}
$$

de forma que a descrição do sistema em termos destas funções é considerada como uma versão complementar (local) da descrição obtida em termos das funções de Bloch (deslocalizada). Isto se deve, principalmente, porque a descrição dos sistemas obtida através das funções de Wannier evidencia propriedades físicas de caráter mais local que muitas vezes ficam escondidas no retrato deslocalizado do sistema.

Nas situações em que as $M$ barreiras de potencial do sistema estão arranjadas com geometria em formato de anel, é conveniente adotar uma outra representação para o Hamiltoniano de Bose-Hubbard, em termos dos operadores de quasi-momento, definidos pela transformação unitária:

$$
A_{q}=\frac{1}{\sqrt{M}} \sum_{n=1}^{M} e^{\frac{2 \pi}{M} n q} a_{n}
$$

Nesta representação o Hamiltoniano adquire a expressão

$$
H \rightarrow-2 J \sum_{q=0}^{M-1} \cos \left(\frac{2 \pi q}{M}\right) A_{q}^{\dagger} A_{q}+\frac{U}{2 M} \sum_{q_{j}} \delta_{M}\left(q_{q}+q_{2}-q_{3}-q_{4}\right) A_{q_{3}}^{\dagger} A_{q_{4}}^{\dagger} A_{q_{2}} A_{q_{1}}
$$

em que $\delta_{M}(q)$ é igual a 1 se $q$ for um múltiplo inteiro de $M$, e zero caso contrário. Note aqui que a periodicidade genuína da geometria anelar dispensa a adição do termo heurístico $\sum_{q} \epsilon_{q} a_{q}^{\dagger} a_{q}$ na expressão do Hamiltoniano acima. Ainda, esta expressão guarda uma analogia com aquela do Hamiltoniano da primeira banda, no sentido em que assim como os operadores de quasi-momento, as funções de Bloch têm a propriedade de diagonalizar exatamente a parte de um corpo do Hamiltoniano escrito em termos dos operadores de campo (4.1.28). Os resultados obtidos por meio desta descrição mostram que no limite de barreiras de potencial altas, esta e a descrição do sistema em termos das funções de Bloch são essencialmente equivalentes. No entanto, com o abaixamento destas barreiras, as energias de Bloch de partícula independente incluem efeitos adicionais à descrição do sistema, como será mostrado nos próximos capítulos.

\subsection{Considerações sobre o Hamiltoniano do sistema que efe- tua rotação}

Considerações envolvendo containers sob rotação são teoricamente relevantes para a confirmação das propriedades da superfluidez em sistemas bosônicos frios [19]. É exatamente por esta razão que o sistema de estudo deste trabalho utiliza um Hamiltoniano modificado daquele da primeira banda - que será adaptado a partir do emprego de técnicas de cranking - para que o modelo possa incorporar os efeitos da rotação. Este tratamento tem a vantagem de que, além do objetivo mais direto que compreende o estudo da superfluidez através do critério de dois fluídos, possibilita a caracterização do condensado quando sujeito à rotação. 


\subsubsection{Sobre a rotação, os referenciais e os Hamiltonianos}

A dificuldade do estudo e tratamento de sistemas sob rotação está estreitamente vinculada à escolha dos referenciais utilizados para descrevê-los. É imediato perceber, que para tanto, existem duas escolhas mais naturais do que pode ser chamado um bom referencial: um que gira com a mesma velocidade angular do sistema, e outro fixo no referencial do laboratório. Nesta seção será desenvolvido um estudo sobre as expressões do Hamiltoniano do sistema nos dois referenciais mencionados acima e para um container com geometria de anel de raio $R$ que efetua rotação com velocidade angular $\omega$ em torno do eixo $z$. Uma vez que utiliza-se aqui a expressão do Hamiltoniano na representação construída em termos das funções de Bloch da primeira banda (autofunções da parte de um corpo do Hamiltoniano) é suficiente prosseguir com o estudo do problema de um corpo.

Considere então o Hamiltoniano que descreve o problema de um corpo sujeito a um potencial com dependência temporal:

$$
h_{l a b}=-\frac{\hbar^{2}}{2 m R^{2}} \frac{\partial^{2}}{\partial \phi^{2}}+V(\phi, t)=-\frac{\hbar^{2}}{2 m R^{2}} \frac{\partial^{2}}{\partial \phi^{2}}+U(t) V(\phi) U^{\dagger}(t),
$$

ou seja, a expressão do Hamiltoniano no referencial do laboratório e em que para a situação de rotação tem-se $U(t)=e^{-\frac{i}{\hbar} L_{z} \omega t}$, com $L_{z}$ o gerador de rotações infinitesimais no eixo $z$. A dinâmica deste sistema é descrita pela equação de Schrödinger dependente do tempo

$$
i \hbar \frac{\partial \psi}{\partial t}=h_{l a b} \psi=\left(-\frac{\hbar^{2}}{2 m R^{2}} \frac{\partial^{2}}{\partial \phi^{2}}+U(t) V(\phi) U^{\dagger}(t)\right) \psi
$$

Aqui, em particular, a re-rotulação $\tilde{\psi}=U^{\dagger}(t) \psi$ permite que a equação acima seja escrita como

$$
i \hbar \frac{\partial \tilde{\psi}}{\partial t}=\left(-\frac{\hbar^{2}}{2 m R^{2}} \frac{\partial^{2}}{\partial \phi^{2}}+V(\phi)-L_{z} \omega\right) \tilde{\psi}
$$

mas com a diferença de que agora o potencial não depende mais do tempo. Portanto, daí segue que para um observador no referencial do laboratório, a equação de Schrödinger para o sistema no referencial que efetua rotação é dada por:

$$
h_{\text {rot }} \tilde{\psi}=\left(-\frac{\hbar^{2}}{2 m R^{2}} \frac{\partial^{2}}{\partial \phi^{2}}+V(\phi)-L_{z} \omega\right) \tilde{\psi}=\epsilon^{(r o t)} \tilde{\psi},
$$

$\operatorname{com} \epsilon^{(r o t)}$ as autoenergias correspondentes aos autoestados $\tilde{\psi}$.

Para as situações em que o tempo $t=0$ ou para tempos especiais em que o referencial que efetua rotação coincide com o referencial no laboratório, é possível ainda escrever a correspondência entre os Hamiltonianos como:

$$
h_{r o t}=h_{l a b}-L_{z} \omega
$$

Agora, uma vez que considerações acerca da superfluidez do sistema requerem o conhecimento das energias intrínsecas nos referenciais com e sem movimento, é preciso utilizar a expressão do Hamiltoniano no referencial que efetua rotação e para um observador neste mesmo referencial. Para o container com geometria anelar, em particular, a expressão deste Hamiltoniano é obtida através da adição de $\frac{m \omega^{2} R^{2}}{2}$ na expressão de $h_{\text {rot }}$. De fato, este procedimento define o termo que contém a dependência do momento angular neste referencial 
como

$$
-\frac{\hbar^{2}}{2 m R^{2}} \frac{\partial^{2}}{\partial \phi^{2}} \rightarrow \frac{1}{2 m R^{2}}\left(\frac{\hbar}{i} \frac{\partial}{\partial \phi}-m \omega R^{2}\right)^{2}
$$

de onde segue então que

$$
h_{\omega}=h_{r o t}+\frac{m \omega^{2} R^{2}}{2}=\frac{1}{2 m R^{2}}\left(\frac{h}{i} \frac{\partial}{\partial \phi}-m \omega R^{2}\right)^{2}+V(\phi) .
$$

A partir daqui a expressão adequada para o Hamiltoniano do sistema no referencial sob rotação será representada por $h_{\omega}$ [3], e é tal que a equação de Schrödinger

$$
h_{\omega} \psi^{(\omega)}=\epsilon^{(\omega)} \psi^{(\omega)}
$$

corresponde à equação de autovalores em que as energias $\epsilon^{(\omega)}$ de $\psi^{(\omega)}$ representam as energias intrínsecas do sistema neste referencial. Note aqui, em particular, que $\epsilon^{(\omega)}$ e $\epsilon^{(r o t)}$ diferem apenas por uma constante.

Conhecida a expressão da parte de um corpo do Hamiltoniano no referencial que efetua rotação, a extensão para a expressão do Hamiltoniano de muitos corpos é imediata. De fato, em termos dos operadores de campo têm-se

$$
H_{\omega}=\int d \phi \Psi^{\dagger}(\phi)\left(\frac{1}{2 m R^{2}}\left(\frac{\hbar}{i} \frac{d}{d \phi}-m \omega R^{2}\right)^{2}+V(\phi)+\Lambda \Psi^{\dagger}(\phi) \Psi(\phi)\right) \Psi(\phi),
$$

que é exatamente a expressão utilizada para as considerações sobre rotação ao longo do trabalho.

\subsubsection{Adaptação de técnicas de cranking ao Hamiltoniano da primeira banda e obtenção da expressão segundo quantizada}

A seção acima contém uma discussão sobre a inclusão de efeitos de rotação no Hamiltoniano do problema de Kronig-Penney. Nesta seção serão analisadas as consequências surtidas por estes efeitos nas autofunções do sistema e suas autoenergias.

A adaptação de técnicas de cranking a um modelo físico consiste na inclusão de efeitos de rotação ao Hamiltoniano responsável por sua descrição. No caso tratado aqui, em que o Hamiltoniano do problema de muitos corpos está escrito na representação construída em termos das autofunções do problema de um corpo, a inclusão dos efeitos de rotação é realizada por meio destas próprias autofunções, porque agora o Hamiltoniano de um corpo diagonalizado já inclui tais efeitos. Isso implica, portanto, que o problema de Kronig-Penney de um corpo, com cranking, em um anel de raio $R$ com $M$ barreiras de largura $b$ e altura $V_{0}$ igualmente espaçadas, deve ser descrito justamente pela expressão (4.2.38) de $h_{\omega}$ discutida na seção acima.

Consequentemente, as autofunções do problema com cranking, chamadas aqui de $\psi^{(\omega)}$ devem satisfazer a equação de autovalores

$$
h_{\omega} \psi^{(\omega)}=\epsilon^{(\omega)} \psi^{(\omega)}
$$

com solução dada pelas funções de Bloch $\psi^{(\omega)}(\phi)=e^{i q \phi} u^{(\omega)}(\phi)$. Note, em particular, que agora a parte periódica destas autofunções também deve depender da velocidade angular de rotação $\omega . q$ representa o quasi-momento do sistema, que como consequência do uso de condições de contorno periódicas deve compreender os inteiros. 
As condições de continuidade e periodicidade satisfeitas pelas funções de Bloch neste caso são análogas à do problema sem rotação (4.1.12), (4.1.13), (4.1.16) e (4.1.17) e dadas aqui por:

$$
\begin{gathered}
u_{I}^{(\omega)}(0)=u_{I I}^{(\omega)}\left(\frac{2 \pi}{M}\right) \\
u_{I}^{\prime(\omega)}(0)=u_{I I}^{\prime(\omega)}\left(\frac{2 \pi}{M}\right) \\
\psi_{I}^{(\omega)}(0)=\psi_{I I}^{(\omega)}\left(\frac{2 \pi}{M}\right) e^{-\frac{2 \pi}{M} i q} \\
\psi_{I}^{\prime(\omega)}(0)=\psi_{I I}^{\prime(\omega)}\left(\frac{2 \pi}{M}\right) e^{-\frac{2 \pi}{M} i q} .
\end{gathered}
$$

Desta forma, a imposição das condições acima para as funções que resolvem cada parte do período: no domínio entre duas barreiras $(0 \leq \phi \leq a)$

$$
\psi_{I}^{(\omega)}(\phi)=A e^{i\left(k_{1}+\frac{\omega}{\omega_{0}}\right) \phi}+B e^{-i\left(k_{1}-\frac{\omega}{\omega_{0}}\right) \phi}
$$

e no domínio da barreira $\left(a \leq \phi \leq \frac{2 \pi}{M}\right) \operatorname{com} \epsilon_{\omega}<V_{o}$

$$
\psi_{I I}^{(\omega)}(\phi)=A e^{\left(k_{2}+i \frac{\omega}{\omega_{0}}\right) \phi}+B e^{\left(k_{2}+i \frac{\omega}{\omega_{0}}\right) \phi}
$$

resulta na equação matricial necessária para a determinação dos coeficientes $A, B, C$ e $D$

$$
\left(\begin{array}{cccc}
1 & 1 & -e^{\frac{2 \pi}{M}\left(k_{2}-i \tilde{q}\right)} & -e^{-\frac{2 \pi}{M}\left(k_{2}+i \tilde{q}\right)} \\
-i\left(k_{1}-\tilde{q}\right) & -i\left(k_{1}+\tilde{q}\right) & -\left(k_{2}-i \tilde{q}\right) e^{\frac{2 \pi}{M}\left(k_{2}-i \tilde{q}\right)} & \left(k_{2}-i \tilde{q}\right) e^{-\frac{2 \pi}{M}\left(k_{2}-i \tilde{q}\right)} \\
e^{i k_{1} a} & e^{-i k_{1} a} & -e^{-k_{2} a} & -e^{-k_{2} a} \\
i\left(\frac{\omega}{\omega_{0}}+k_{1}\right) e^{i k_{1} a} & i\left(\frac{\omega}{\omega_{0}}-k_{1}\right) e^{-k_{1} a} & \left(i \frac{\omega}{\omega_{0}}+k_{2}\right) e^{k_{2} a} & -\left(i \frac{\omega}{\omega_{0}}+k_{2}\right) e^{-k_{2} a}
\end{array}\right)\left(\begin{array}{c}
A \\
B \\
C \\
D
\end{array}\right)=0
$$

em que $\tilde{q}=q-\frac{\omega}{\omega_{0}}$. Daqui segue, portanto, que a menos de uma constante de normalização, as funções de Bloch que resolvem o problema de Kronig-Penney com cranking são dadas pela expressão:

$$
\psi_{B}(\phi)=\gamma\left(c_{1} e^{\left(k_{2}+i \frac{\omega}{\omega_{0}}\right) \phi}+e^{-\left(k_{2}-i \frac{\omega}{\omega_{0}}\right) \phi}\right)+(1-\gamma) c_{2}\left(c_{3} e^{i\left(k_{1}+\frac{\omega}{\omega_{0}}\right) \phi}+e^{-i\left(k_{1}-\frac{\omega}{\omega_{0}}\right) \phi}\right)
$$

com

$$
\begin{aligned}
& c_{1}=\left(\frac{i k_{1}+k_{2}}{i k_{1}-k_{2}}\right)\left(\frac{e^{-\frac{2 \pi}{M}\left(k_{2}+i\left(q-\frac{\omega}{\omega_{0}}\right)\right)}-e^{a\left(-k_{2}+i k_{1}\right)}}{e^{a\left(k_{2}+i k_{1}\right)}-e^{\frac{2 \pi}{M}\left(k_{2}-i\left(q-\frac{\omega}{\omega_{0}}\right)\right)}}\right) \\
& c_{2}=-\left(\frac{k_{2}-i k_{1}}{2 i k_{1}}\right)\left(\frac{e^{-4 k_{2} \frac{\pi}{M}}-e^{-2 k_{2} a}}{e^{\frac{2 \pi}{M}\left(k_{2}-i\left(q-\frac{\omega}{\omega_{0}}\right)\right)}-e^{-a\left(k_{2}+i k_{1}\right)}}\right) \\
& c_{3}=\left(-\frac{k_{2}+i k_{1}}{k_{2}-i k_{1}}\right)\left(\frac{e^{\frac{2 \pi}{M}\left(i\left(q-\frac{\omega}{\omega_{0}}\right)+k_{2}\right)}-e^{-a\left(i k_{1}-k_{2}\right)}}{e^{\frac{2 \pi}{M}\left(k 2+i\left(q-\frac{\omega}{\omega_{0}}\right)\right)}-e^{a\left(k_{2}+i k_{1}\right)}}\right) .
\end{aligned}
$$

Da mesma forma como nos desenvolvimentos do problema de Kronig-Penney sem rotação, as funções de Bloch acima podem ser empregadas para definir os operadores de aniquilação e criação

$$
\Psi(\phi)^{(\omega) \dagger}=\sum_{q} \psi^{(\omega) *}(\phi) A_{q}^{(\omega) \dagger}
$$




$$
\Psi(\phi)^{(\omega)}=\sum_{q} \psi^{(\omega)}(\phi) A_{q}^{(\omega)},
$$

que com o truncamento na primeira banda, são utilizados para derivar a expressão segundo quantizada do Hamiltoniano da primeira banda com cranking:

$$
H_{\omega}=\sum_{q=0}^{M-1} \epsilon_{q}^{(\omega)} A_{q}^{(\omega) \dagger} A_{q}^{(\omega)}+\frac{1}{2} \sum_{q_{i}} \Lambda_{\left\{q_{i}\right\}}^{(\omega)} A_{q_{1}}^{(\omega) \dagger} A_{q_{2}}^{(\omega) \dagger} A_{q_{3}}^{(\omega)} A_{q 4}^{(\omega)}
$$

em que aqui as energias $\epsilon_{q_{i}}^{(\omega)}$ são obtidas a partir da relação de dispersão, enquanto que $\Lambda\left(\left\{q_{i}\right\}\right)$ é o termo proporcional à integral de quatro funções de Bloch. Igualando a zero o determinante da matriz em (4.2.2) obtém-se então a relação de dispersão

$$
\cos \left(k_{1} a\right) \cosh \left(k_{2} b\right)-\frac{k_{1}^{2}-k_{2}^{2}}{2 k_{1} k_{2}} \sin \left(k_{1} a\right) \sinh \left(k_{2} b\right)=\cos \left(\left(q-\frac{\omega}{\omega_{0}}\right) \frac{2 \pi}{M}\right),
$$

em que $k_{1}^{2}+k_{2}^{2}=\frac{2 m V_{0}}{\hbar^{2}}$. Aqui é interessante atentar para o fato de que a dependência dos momentos livres com a velocidade angular de rotação impõe uma dependência em $\omega$ para as energias do problema de um corpo, como ilustrado em 4.4(a), 4.4(b),4.4(c) e 4.4(d). Particularmente para o sistema de muitos corpos que está sendo caracterizado, os valores assumidos pelas energias do problema de um corpo (referentes ao problema de muitos corpos) estão diretamente relacionados com as propriedades da condensação bosônica. Por causa disso, a variação dos valores destas energias com a velocidade angular de rotação terá implicações diretas nas propriedades deste fenômeno, como será mostrado com detalhes nas resoluções do capítulo 5 . 


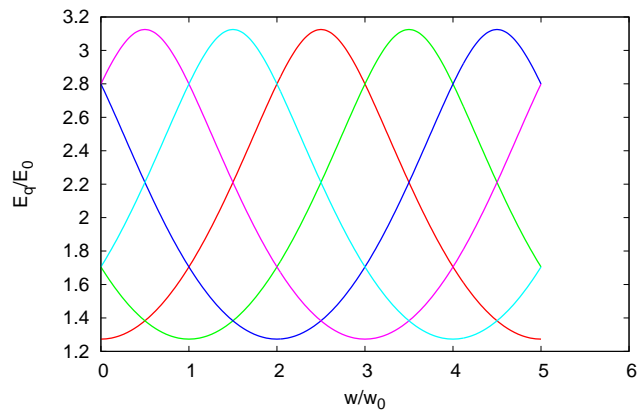

(a) Potenciais $\delta$-Dirac com $V_{0}=5$

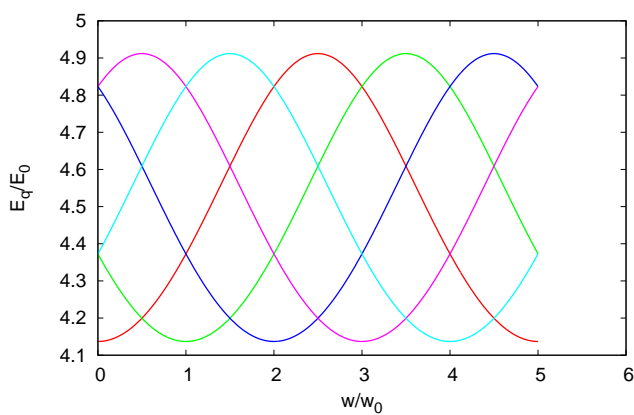

(c) Barreira de largura $\frac{\pi}{M} \operatorname{com} V_{0}=13$.

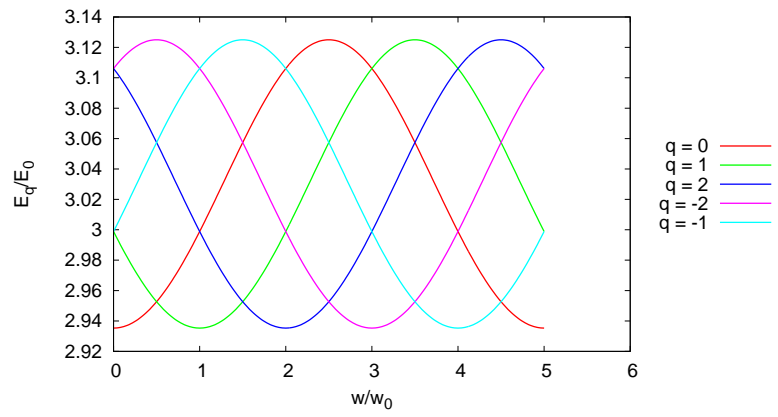

(b) Potenciais $\delta$-Dirac com $V_{0}=100$
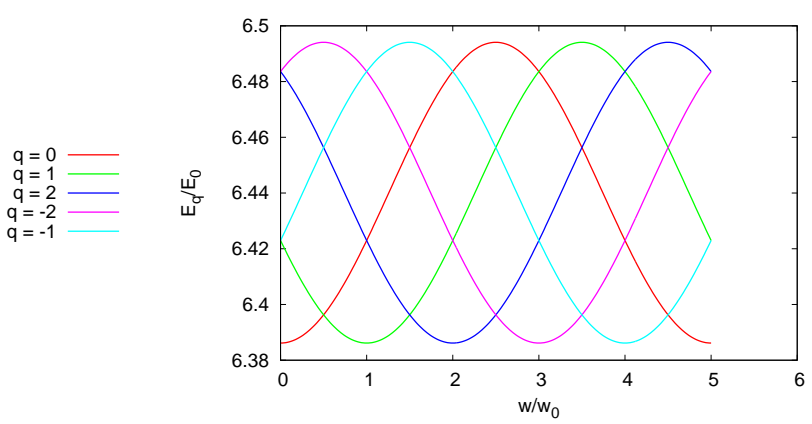

(d) Barreira de largura $\frac{\pi}{M} \operatorname{com} V_{0}=35$.

Figura 4.4: Este gráfico ilustra a dependência de $\omega$ nos valores das energias de partícula independente, consideradas em unidades de $\frac{\hbar^{2}}{m R^{2}}$. As curvas representam estas energias para os diferentes valores de quasi-momento $(-2,-1,0,1,2)$ de um sistema com 5 barreiras igualmente distribuídas em um anel. Note, em particular o cruzamento dos níveis de energia e a mudança com $\omega$ do estado de partícula independente de menor energia. Ainda, é possível observar aqui que a diferença entre o maior e o menor valor da energia depende também da largura da barreira de potencial. 


\section{Capítulo 5}

\section{Apresentação da resolução numérica e dos resultados}

Todos os desenvolvimentos a seguir são baseados na expressão do Hamiltoniano da primeira banda com cranking

$$
H_{\omega}=\sum_{q=0}^{M-1} \epsilon_{q}^{(\omega)} A_{q}^{(\omega) \dagger} A_{q}^{(\omega)}+\frac{1}{2} \sum_{q_{i}} \Lambda_{\{q i\}}^{(\omega)} A_{q_{1}}^{(\omega) \dagger} A_{q_{2}}^{(\omega) \dagger} A_{q_{3}}^{(\omega)} A_{q 4}^{(\omega)}
$$

obtido a partir da segunda quantização da expressão usual do Hamiltoniano de muitos corpos (4.1.27) em termos dos operadores de criação e aniquilação construídos na representação das funções de Bloch da primeira banda (4.2.48) e (4.2.49).

$\mathrm{Na}$ expressão do Hamiltoniano acima, as energias $\epsilon_{q}^{(\omega)}$ do primeiro termo correspondem às próprias energias do problema de um corpo referente ao Hamiltoniano (4.2.40), enquanto que o o segundo termo envolve uma integral de quatro funções de Bloch $\Lambda_{\left\{q_{i}\right\}} \sim$ $\int d \phi \psi_{q_{1}}^{(\omega) *} \psi_{q_{2}}^{(\omega) *} \psi_{q_{3}}^{(\omega)} \psi_{q_{4}}^{(\omega)}$. Esta integral pode ser reescrita como

$$
\Lambda_{\{q i\}}^{(\omega)} \sim \delta_{M}\left(q_{1}+q_{2}-q_{3}-q_{4}\right) \int d \phi \psi_{q_{1}}^{(\omega) *} \psi_{q_{2}}^{(\omega) *} \psi_{q_{3}}^{(\omega)} \psi_{q_{4}}^{(\omega)}
$$

com $\delta_{M}\left(\left\{q_{i}\right\}\right)$ (igual a 1 quando o argumento for múltiplo de $M$ e zero caso contrário) o delta de Kronecker modular, e portanto, além de tornar explícita a conservação modular do quasi-momento, a presença do $\delta_{M}\left(\left\{q_{i}\right\}\right)$ evidencia a propriedade de que este Hamiltoniano inclui termos referentes a processos de Umklapp ${ }^{1}$ da mesma forma em que inclui os termos relacionados propriamente com a conservação do quasi-momento.

Devido à propriedade de conservação modular do quasi-momento total,

$$
Q_{T}=\bmod \left(\sum_{q} q A_{q}^{(\omega) \dagger} A_{q}^{(\omega)}\right)
$$

satisfaz $\left[H_{\omega}, Q_{T}\right]=0$, e portanto constitui um bom número quântico para rotular os autoestados do sistema de muitos corpos. Mais ainda, isso implica o desacoplamento dos autoestados de $H_{\omega}$ com diferentes valores de quasi-momento total, de forma que nesta re-

\footnotetext{
${ }^{1} \mathrm{O}$ termo processo de Umklapp é comumente empregado no estudo de propriedades do estado sólido e remete aos espalhamentos em que os resultados do processo levam à criação de uma partícula de quasimomento definido além da primeira zona de Brillouin, ou seja, quando $q_{1}+q_{2}-q_{3}-q_{4}$ compreende um múltiplo de $M$.
} 
presentação o Hamiltoniano pode ser escrito como uma matriz diagonal por blocos em que cada bloco remete a um dos sub-espaços de quasi-momento total definido.

Neste capítulo será caracterizado o comportamento das propriedades do sistema relacionadas aos fenômenos da condensação e superfluidez, com o objetivo principal de entender um pouco mais de afirmações como: 'a superfluidez é uma consequência da condensação' [3] ou 'a condensação implica superfluidez' [42]; usualmente acreditadas pela comunidade científica [43] mas que no entanto nunca foram de fato demonstradas ${ }^{2}$ e demandam uma análise mais cuidadosa. Para tanto, será analisada a resposta do sistema com a variação dos seguintes parâmetros:

- U: responsável por caracterizar a força de interação repulsiva de dois corpos no sistema em unidades de $\epsilon_{0}=\frac{\hbar^{2}}{m R^{2}}$;

- $\omega$ : corresponde à velocidade angular em unidades de $\omega_{0}=\frac{\hbar}{m R^{2}}$;

- $\frac{N}{M}$ : define a comensurabilidade da ocupação dos sítios da rede periódica em que $N$ representa o número de partículas e $M$ o número de barreiras;

- $J$ : responsável por parametrizar a altura ou a força de interação repulsiva das barreiras, também em unidades de $\epsilon_{0}$.

É importante atentar ainda para o fato de que a expressão de $H_{\omega}$ não contém nenhum termo explícito responsável por incluir a dependência da altura das barreiras. De fato, esta dependência está implícita nos valores assumidos pelas energias do problema de um corpo $\epsilon_{q}^{(\omega)}$, e o parâmetro utilizado para expressar a sua variação é tomado como

$$
J=\frac{1}{4}\left(\max \left(\epsilon_{q}^{(\omega)}\right)-\min \left(\epsilon_{q}^{(\omega)}\right)\right) .
$$

Este parâmetro é definido como uma analogia ao parâmetro $J=-2 \cos \left(\frac{2 \pi}{M}\left(q-\frac{\omega}{\omega_{0}}\right)\right)$ do Hamiltoniano de Bose-Hubbard, e foi escolhido desta forma apenas para facilitar comparações entre os resultados dos dois modelos (nas referências [19, 30] é possível encontrar um estudo de algumas da propriedades estudadas aqui no contexto do modelo de Bose-Hubbard). Para valores suficientemente altos das barreiras no problema de um corpo, as curvas definidas pelos diferentes valores de $q$ de $J$ são muito próximas daquelas obtidas a partir do cosseno do modelo de Bose-Hubbard. Entretanto o abaixamento das barreiras faz com que estas curvas percam a característica de cosseno, de forma a indicar que a descrição do sistema via Hamiltoniano da primeira banda inclui efeitos adicionais em relação ao modelo de Bose Hubbard. Esta propriedade está ilustrada na figura 5.1.

Existe ainda uma outra propriedade deste sistema que aparece naturalmente no limite de barreiras baixas, referente às interações de dois corpos representadas por $\Lambda_{\left\{q_{i}\right\}}$. Explicitamente, o que se observa é que neste limite os termos de $\Lambda_{\left\{q_{i}\right\}}$ que correspondem a processos de Umklapp têm valores menores (que dependendo do valor de $J$ podem diferir, inclusive, por duas ordens de grandeza) do que os termos de interação que envolvem a conservação do quasi-momento, conforme ilustrado com alguns exemplos na tabela 5.1. As implicações desta propriedade nos fenômenos de condensação e superfluidez do sistema ainda estão sendo investigadas.

Todos os resultados apresentados aqui foram obtidos através de resoluções numéricas para as quais foi confeccionado um programa em Haskell ${ }^{3}$ que efetua a diagonalização do

\footnotetext{
${ }^{2}$ Existe uma prova de Lieb e colaboradores que mostra que no limite específico tratado naquele trabalho as frações de condensado e de superfluido são ambas 100\% [44].

${ }^{3}$ Todos os códigos estão disponíveis em http://cecm.usp.br/fepinheiro/Haskell.
} 


\begin{tabular}{|l|l|}
\hline Processos com 'Umklapp' & Processos sem 'Umklapp' \\
\hline$(-2,-2,0,1) 5.77798 \mathrm{e}-2$ & $(0,0,0,0) 0.1603227$ \\
$(-2,-1,0,2) 5.77798 \mathrm{e}-2$ & $(1,1,0,2) 0.1609982$ \\
$(-2,-1,1,1) 4.61256 \mathrm{e}-2$ & $(1,2,1,2) 0.1626699$ \\
$(2,2,1,-2) 7.101903 \mathrm{e}-2$ & $(2,3,1,-1) 0.1626699$ \\
\hline
\end{tabular}

Tabela 5.1: Valores adquiridos pelas integrais que caracterizam a interação de dois corpos em um sistema com 5 barreiras de altura $V_{0}=1 \epsilon_{0}$. A notação acima é utilizada para representar $\left(q_{1}, q_{2}, q_{3}, q_{3}\right)=\int d \phi \psi_{q_{1}}^{*}(\phi) \psi_{q_{2}}^{*}(\phi) \psi_{q_{3}}(\phi) \psi_{q_{4}}(\phi)$ com $q_{i}$ o quasi-momento correspondente à respectiva função de Bloch.

Hamiltoniano $H_{\omega}$. Os autoestados deste Hamiltoniano são rotulados pelos valores de quasimomento total e portanto uma base completa no espaço de Fock pode ser definida pelas combinações dos números de partículas que podem ocupar cada um dos estados de Bloch com valores de quasi-momento definido, ou seja, $\left\{\left|\underline{n}_{q=-i}, \ldots, \underline{n}_{q=-1}, \underline{n}_{q=0}, \underline{n}_{q=1} \ldots, \underline{n}_{q=i}\right\rangle\right\}$, com $i=\frac{M}{2}$ para $M$ par e $i=\frac{M-1}{2}$ para $M$ ímpar, e tal que $\sum_{q} n_{q}=N$. Portanto, a menos do truncamento das funções de Bloch à primeira banda, o que segue são os resultados da solução exata do modelo de muitos corpos.

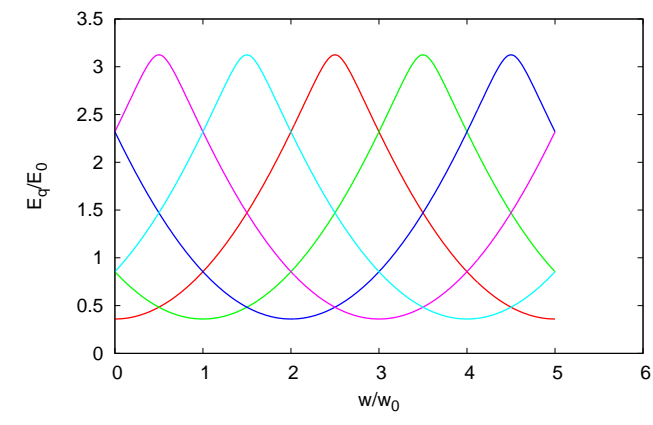

(a) $\delta$-Dirac com $V_{0}=1$

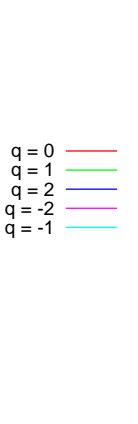

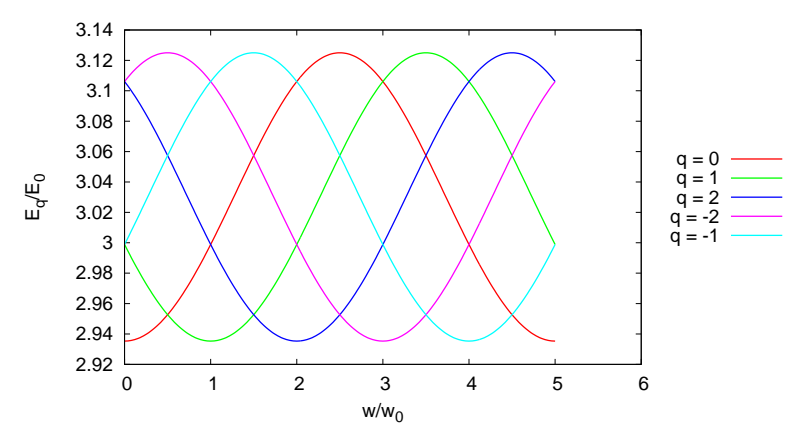

(b) $\delta$-Dirac com $V_{0}=100$

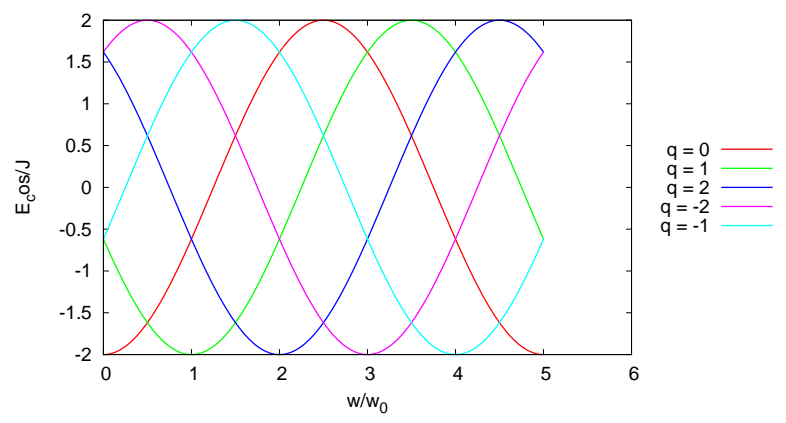

(c) $\cos \left(\frac{2 \pi}{M}\left(q-\frac{\omega}{\omega_{0}}\right)\right)$ do modelo de Bose-Hubbard

Figura 5.1: Os gráficos acima ilustram as energias de partícula independente do modelo do Hamiltoniano da primeira banda para $V_{0}=1 \epsilon_{0}$ em 5.1 (a) e $V_{0}=100 \epsilon_{0}$ em 5.1(b), e o análogo no modelo de Bose-Hubbard em 5.1(c). Note que assim como 5.1(c), 5.1(b) apresenta curvas semelhantes à de uma função cosseno enquanto que com o abaixamento das barreiras em 5.1(a), as energias de partícula independente perdem esta característica. 


\subsection{Diagrama de fases do estado fundamental}

A descrição destes sistemas em termos do modelo de Bose-Hubbard [18] prevê a ocorrência de dois tipos diferentes de estado fundamental, denominados de superfluido e isolante de Mott, cuja transição é determinada por um valor definido da razão $\frac{J}{U}$. Esta propriedade é revelada a partir do tratamento perturbativo do Hamiltoniano (como realizado nas referências $[45,46]$ ), e o resultado é apresentado na forma de um diagrama de fases do estado fundamental que mostra o comportamento das diferenças de energias de adição de partículas $E_{N+1}-E_{N}$ com a variação do parâmetro $J$ para um valor determinado de $U$. Em sistemas com número de partículas definido, esta quantidade exerce papel análogo ao do potencial químico ${ }^{4}$.

Da mesma forma, a aplicação destas técnicas perturbativas ao Hamiltoniano da primeira banda permite a obtenção dos diagramas de fase que revelam a estrutura do estado fundamental desta descrição através das diferenças de energias de adição de partículas. Estas diferenças foram computadas aqui através da diagonalização de $H_{\omega}$ para cada um dos casos correspondentes.

Neste processo, é possível perceber que o valor da velocidade angular exerce um papel determinante na definição do sub-espaço de quasi-momento total que contém o estado fundamental. Isto acontece porque a dependência em $\omega$ na expressão das energias de partícula independente provoca um cruzamento de níveis, de forma a mudar a ordenação energética dos estados de partícula independente (como comentado na seção 4.2.2), e portanto, a cada reordenação, as partículas devem se redistribuir nos novos estados fundamental e excitados.

Para situações em que $\omega=0$, o estado fundamental do sistema compreende sempre um dos estados do sub-espaço de quasi-momento total $Q_{T}=0$. No entanto, para valores de $\omega \neq 0$ isto deixa de ser verdade, e em geral, no intervalo em que o estado fundamental do problema de um corpo corresponde à função de Bloch de quasi-momento $q$, o estado fundamental do sistema de muitos corpos estará no sub-espaço correspondente ao valor de quasi-momento total $Q_{T}=[N q] \bmod M[19]$.

As figuras 5.2(a) e 5.2(b) mostram o resultado do diagrama de fases em algumas situações. De forma geral, é possível identificar que a separação de energias dá origem à formação dos lobos de Mott para valores pequenos de $J$, portanto no limite em que as barreiras são bastante altas. Com o aumento do valor de $J$ acontece uma mudança na estrutura diagrama de fases do estado fundamental, que passa a mostrar agora um agrupamento de linhas paralelas igualmente espaçadas [19]. Esta mudança na estrutura do diagrama de fases sugere, justamente, que um sistema de muitos corpos caracterizado por este Hamiltoniano deve sofrer a transição de fase isolante de Mott - superfluido no limite Termodinâmico, e que esta transição é governada pela razão $\frac{J}{U}$.

\footnotetext{
${ }^{4} \mathrm{O}$ tratamento estatístico do Hamiltoniano de Bose-Hubbard no limite Termodinâmico está desenvolvido na referência [46]
} 


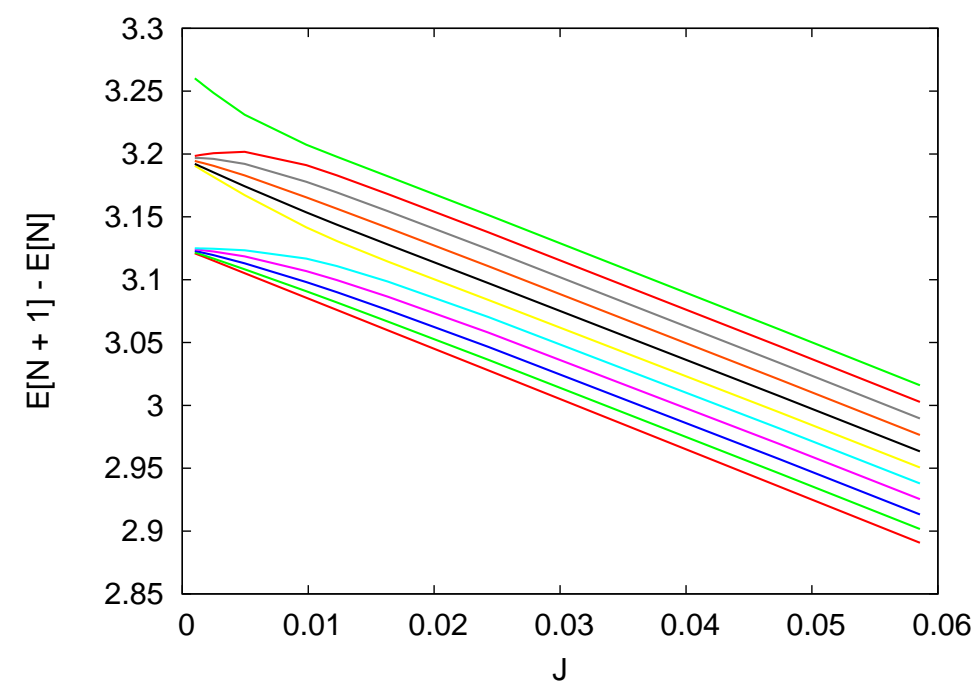

(a) $U=0.06 \epsilon_{0}$ e $\omega=0$

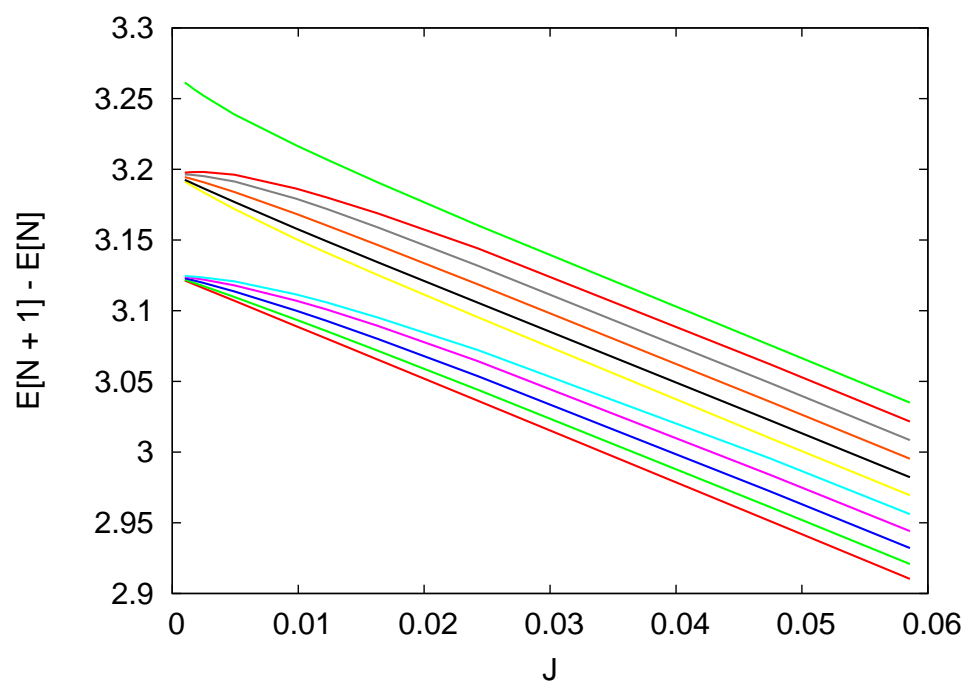

(b) $U=0.06 \epsilon_{0}$ e $\omega=0.48 \omega_{0}$

Figura 5.2: Diagrama de fase à $\mathrm{T}=0 \mathrm{~K}$ para 5 barreiras do tipo $\delta$-Dirac. Observe em (a), situação em que $\omega=0$, que o fechamento dos lobos de Mott ocorre nas proximidades de $J=0.012 \epsilon_{0}$ e que na situação com $\omega \neq 0$, em (b), o fechamento dos lobos de Mott ocorre para valores maiores de $J$, em torno de $J=0.05 \epsilon_{0}$. 


\subsection{A condensação de Bose-Einstein}

Como discutido na seção (4.1.2), a condensação de Bose-Einstein em um sistema de muitos corpos com interações e sujeitos a um potencial externo, deve ser estudada no contexto da definição dada por Penrose e Onsager [23]. Portanto, o primeiro passo para descrever a condensação corresponde à identificação dos estados de partícula independente, obtidos a partir da diagonalização da matriz densidade reduzida de um corpo $\rho^{(1)}$, que por sua vez, é obtida a partir da matriz densidade do sistema de muitos corpos $\rho$.

Aqui os autoestados do Hamiltoniano de muitos corpos $|E(N)\rangle$ são rotulados pelos valores do quasi-momento total e portanto a densidade reduzida de um corpo é diagonal na representação dos quasi-momentos. Explicitamente,

$$
\left\langle E(N)\left|A_{q}^{(\omega) \dagger} A_{q^{\prime}}^{(\omega)}\right| E(N)\right\rangle=\rho_{q}^{(1)} \delta q q^{\prime},
$$

com $\operatorname{Tr} \rho^{(1)}=N$. Desta forma, os autoestados da matriz densidade reduzida correspondem às próprias funções de Bloch que resolvem o problema de um corpo, e a condensação é caracterizada pelo aparecimento de um autovalor dominante que acompanha a decomposição de $\rho^{(1)}$ em termos destas funções.

Por se tratar de um sistema à temperatura $0 \mathrm{~K}$, a função de onda que caracteriza o problema de muitos corpos corresponde ao estado fundamental do Hamiltoniano $H_{\omega}$. Entretanto, como já comentado na seção acima, a determinação deste estado fundamental depende crucialmente dos valores da velocidade angular e das propriedades de comensurabilidade da ocupação da rede periódica, de forma que por questões de organização, é conveniente realizar o estudo da condensação nos sistemas com ocupação comensurável separado daquele das situações de incomensurabilidade.

Para valores comensuráveis da ocupação da rede (quando $\frac{N}{M}$ é um múltiplo de $M$ ) e independente do valor de $\omega$, o estado fundamental do sistema de muitos corpos estará sempre no sub-espaço definido pelo valor de quasi-momento total $Q_{T}=0$. Nas figuras 5.5, 5.6 e 5.7 é possível perceber que os estados de partícula independente partem de uma situação totalmente degenerada no limite em que $J \rightarrow 0$, e definem diferentes números de ocupação com o aumento de $J$. Esta degenerescência inicial é uma consequência do caráter repulsivo da interação efetiva de dois corpos [19]. Com o abaixamento da altura das barreiras, o comportamento do condensado dependerá da velocidade angular de rotação. Nas situações em que $\omega=0$, os estados com valores simétricos de quasi-momento permanecem degenerados para todos os valores de $J$, enquanto que para valores de $\omega \neq 0$, cada um destes estados responde independentemente ao aumento de $J$, obedecendo apenas a hierarquia de que os estados de partícula independente de menor energia têm sempre as maiores ocupações. Os gráficos das figuras 5.5, 5.6 e 5.7 ilustram justamente esta propriedade. Observe as ocupações dos diferentes estados de quasi-momento nas situações em que $\omega=0.48 \omega_{0}$ e $\omega=0.52 \omega_{0}$, que correspondem, respectivamente, a situações ligeiramente antes e depois do cruzamento de níveis. Note, em particular, que para $\omega=0.52 \omega_{0}$ existe uma migração da ocupação para o novo estado fundamental que se estabelece após este cruzamento. Para complementar, os gráficos abaixo mostram a variação da ocupação dos estados de partícula independente com a variação da velocidade angular e com valor fixo para a altura das barreiras. Note que exatamente nos pontos em que ocorrem os cruzamentos nos gráficos 5.1(a), a população do condensado nos gráficos da figura 5.3 reage à mudança de estado fundamental, migrando para o novo estado de menor energia que se estabelece após os cruzamentos destes níveis. $\mathrm{O}$ mesmo ocorre para os gráficos da figura 5.4, mas agora o cruzamento dos níveis ocorre de 
acordo com o gráfico 5.1(b).

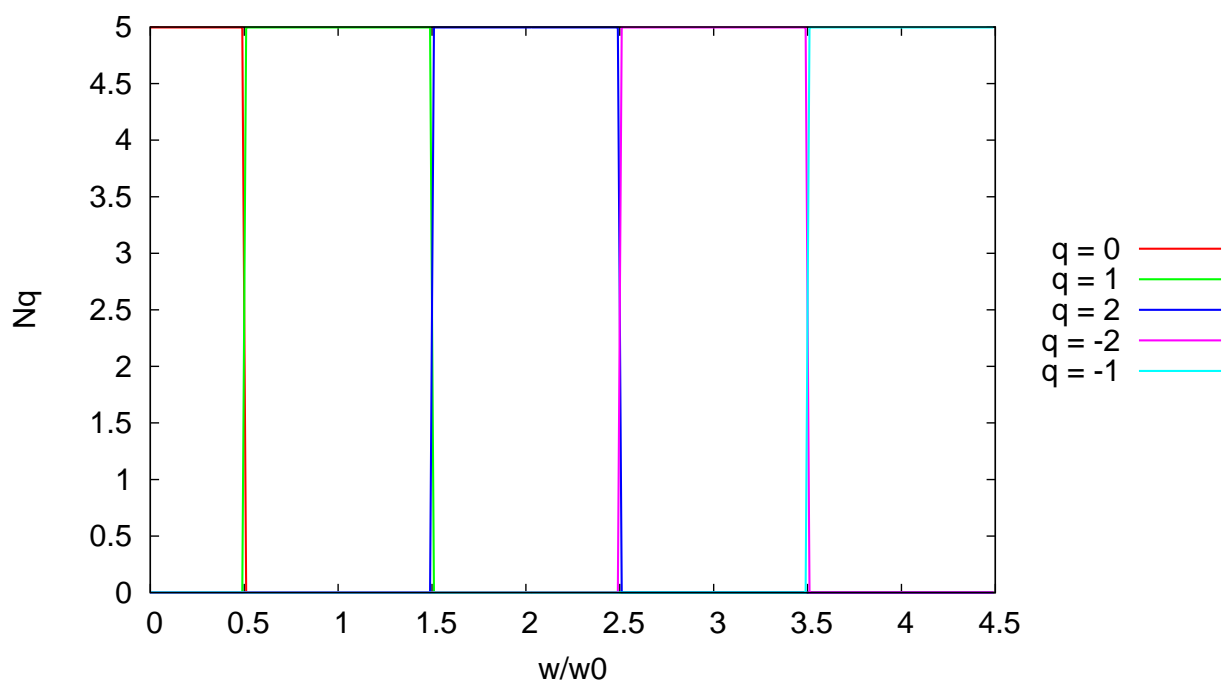

(a) $U=0.06 \epsilon_{0}$

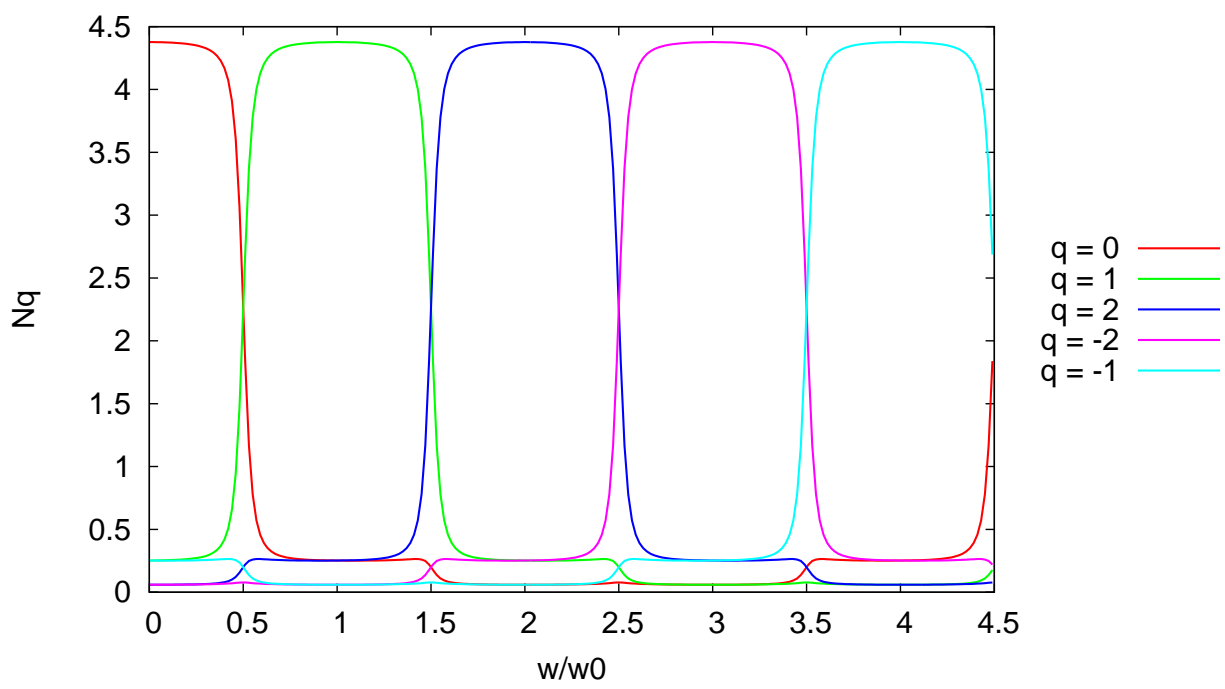

(b) $U=2.4 \epsilon_{0}$

Figura 5.3: Estes gráficos ilustram o comportamento da condensação com a variação da velocidade angular em que as barreiras de potencial do tipo $\delta$-Dirac têm altura dada por $1 \epsilon_{0} .5 .3$ (a) corresponde à situação em que $U=0.06 \epsilon_{0}$ e em 5.3 (b) $U=2.4 \epsilon_{0}$. 


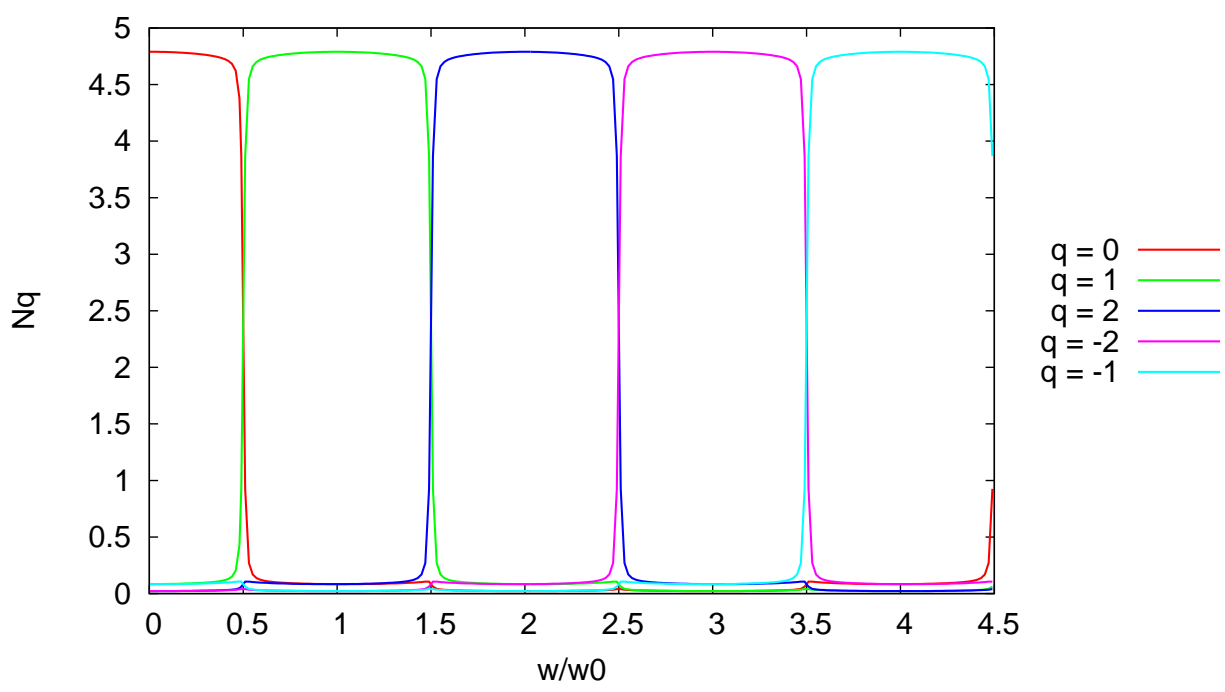

(a) $U=0.06 \epsilon_{0}$

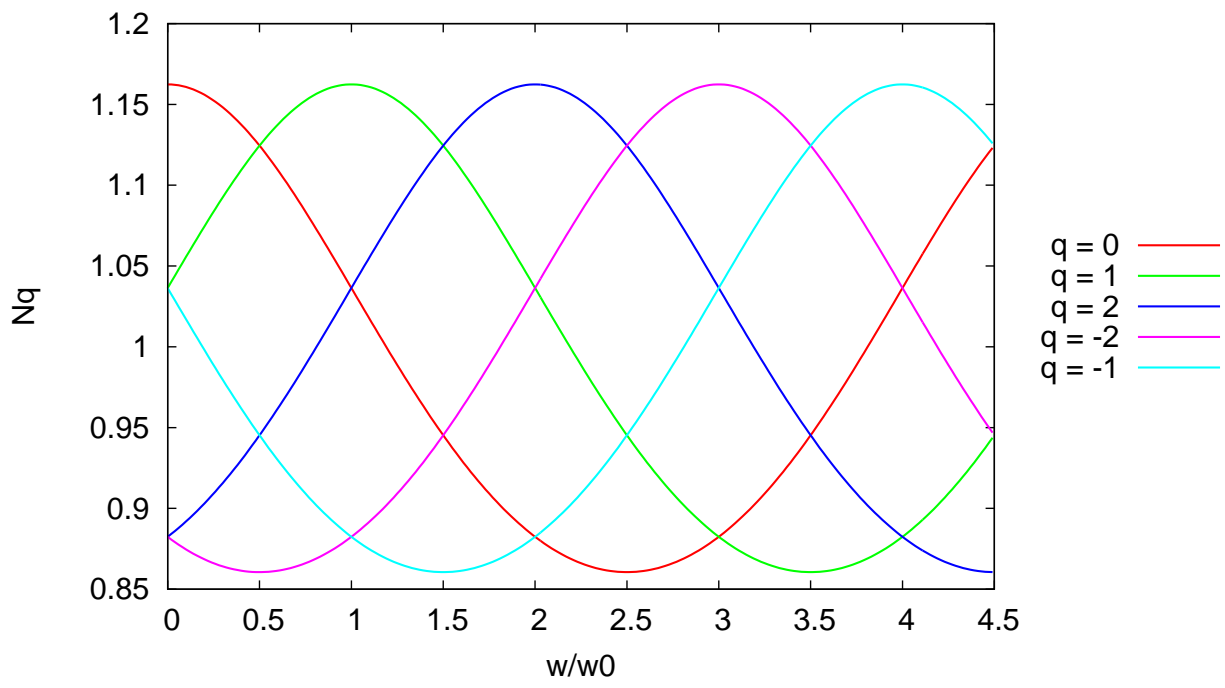

(b) $U=2.4 \epsilon_{0}$

Figura 5.4: Estes gráficos ilustram o comportamento da condensação com a variação da velocidade angular para um sistema de 5 partículas e 5 barreiras do tipo $\delta$-Dirac de altura $100 \epsilon_{0} .5 .4$ (a) corresponde à situação em que $U=0.06 \epsilon_{0}$ e em 5.4 (b) $U=2.4 \epsilon_{0}$. Note, no segundo caso, que a combinação da intensidade repulsiva da força de interação entre as partículas com a altura das barreiras não permite a formação do estado condensado. 


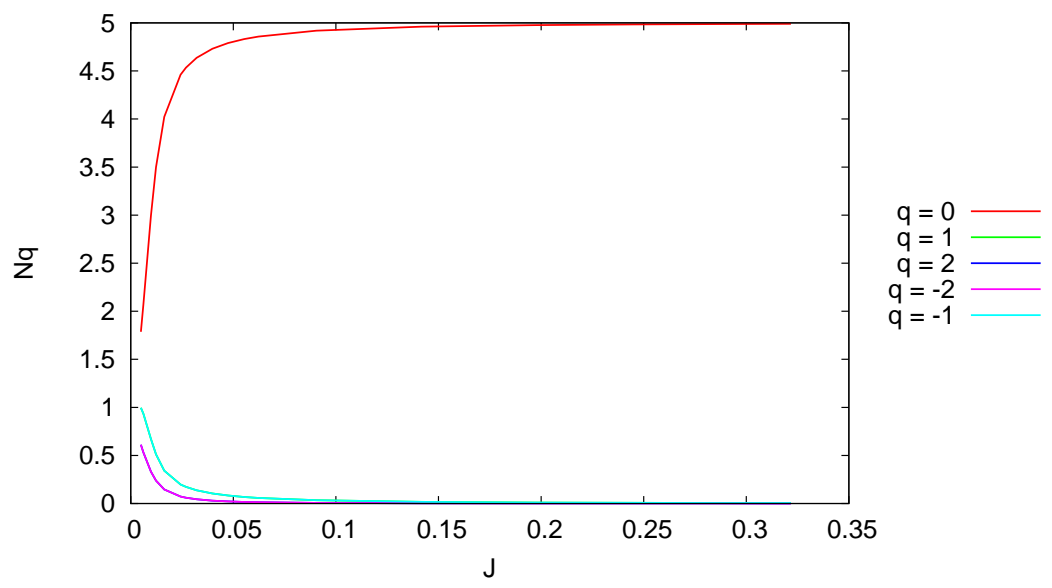

(a) $\omega=0$

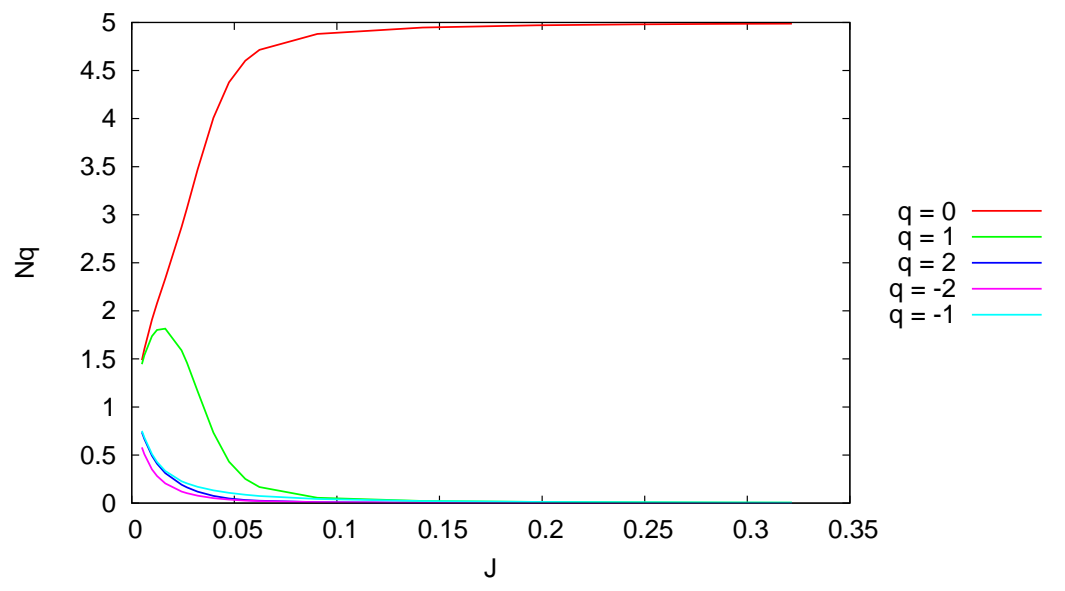

(b) $\omega=0.48 \omega_{0}$

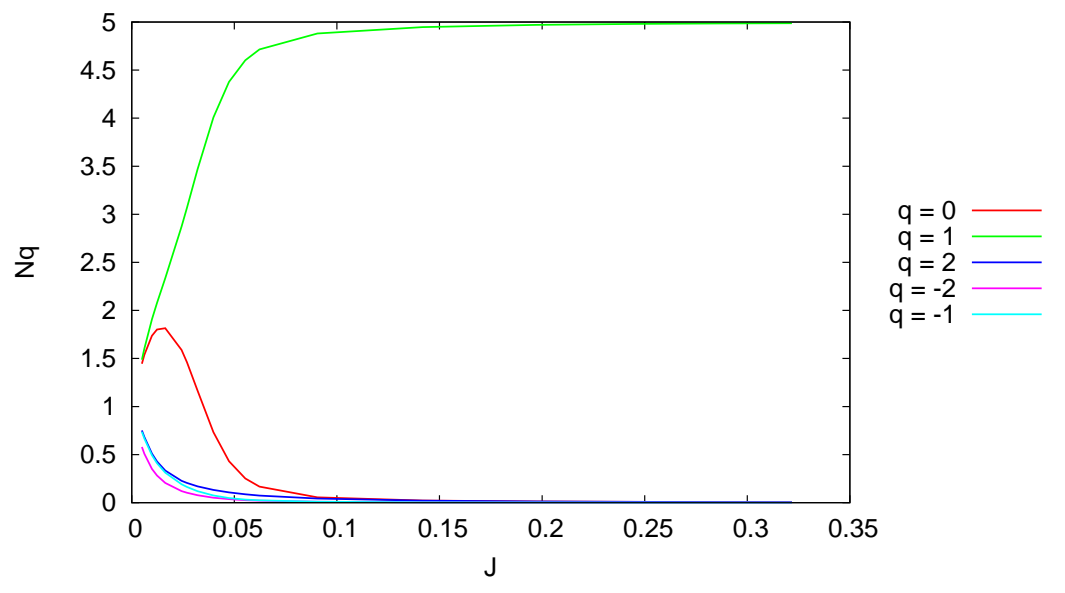

(c) $\omega=0.52 \omega_{0}$

Figura 5.5: Aqui está representado o comportamento das ocupações dos estados de partícula independente para um sistema de 5 partículas e 5 barreiras do tipo $\delta$-Dirac, com a variação da altura das barreiras parametrizada por $J$. Os resultados acima correspondem ao sistema com velocidades $\omega=0, \omega=0.48 \omega_{0}$ e $\omega=0.52 \omega_{0}$ e com a força de interação repulsiva entre as partículas dada por $U=0.06 \epsilon_{0}$. 


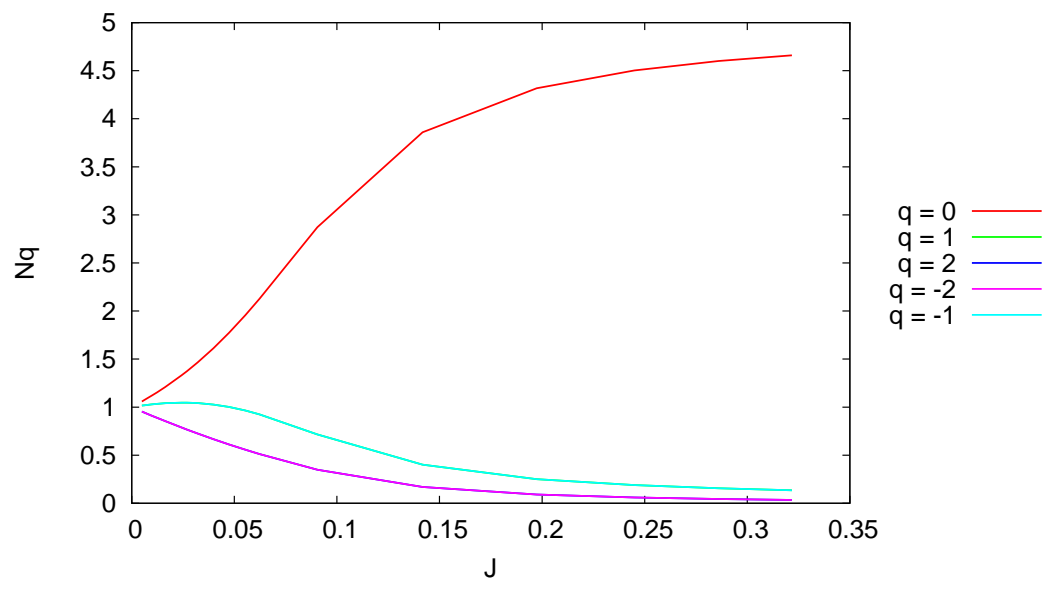

(a) $\omega=0$

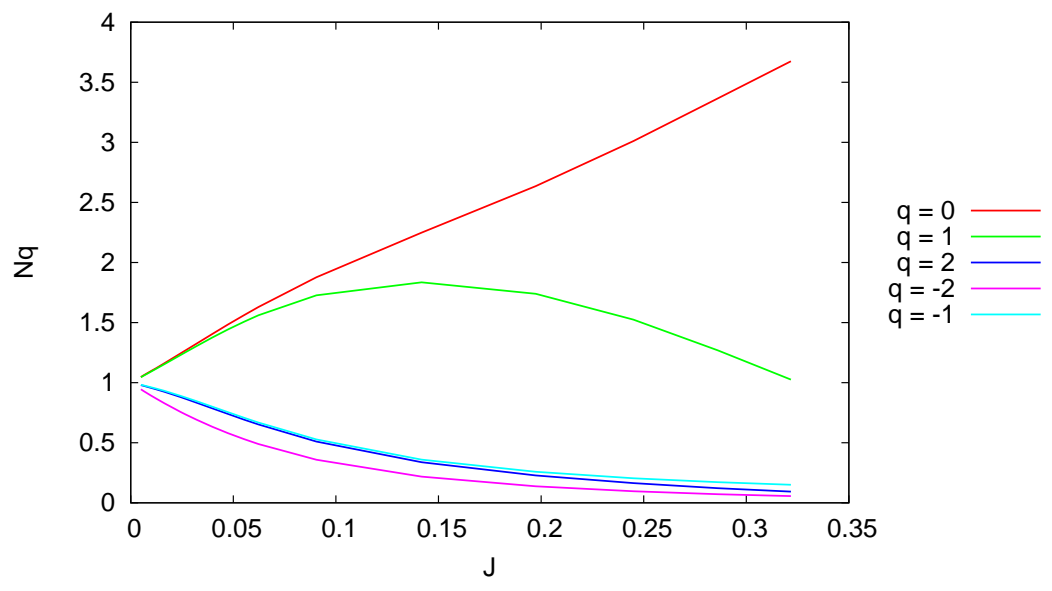

(b) $\omega=0.48 \omega_{0}$

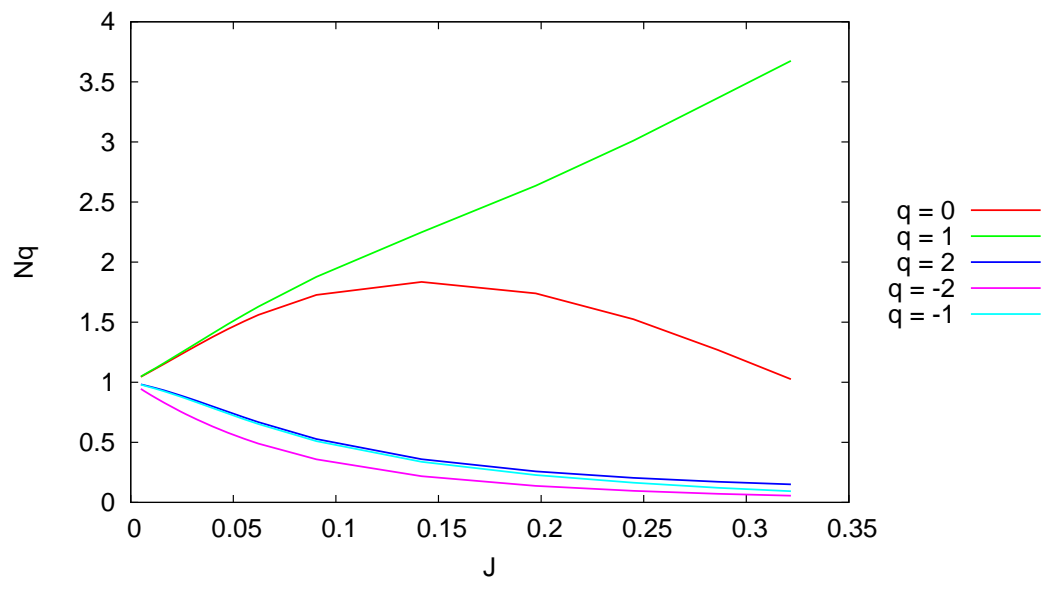

(c) $\omega=0.52 \omega_{0}$

Figura 5.6: Aqui está representado o comportamento das ocupações dos estados de partícula independente para um sistema de 5 partículas e 5 barreiras do tipo $\delta$-Dirac, com a variação da altura das barreiras parametrizada por $J$. Os resultados acima correspondem ao sistema com velocidades $\omega=0$, $\omega=0.48 \omega_{0}$ e $\omega=0.52 \omega_{0}$ e com a força de interação repulsiva entre as partículas dada por $U=0.6 \epsilon_{0}$. Note aqui, em relação à situação anterior em 5.5, que como consequência do aumento da intensidade da força repulsiva de interação entre as partículas a ocupação do estado fundamental de partícula independente satura sempre para valores maiores de $J$, ou seja, quando a altura das barreiras é cada vez mais baixa. 


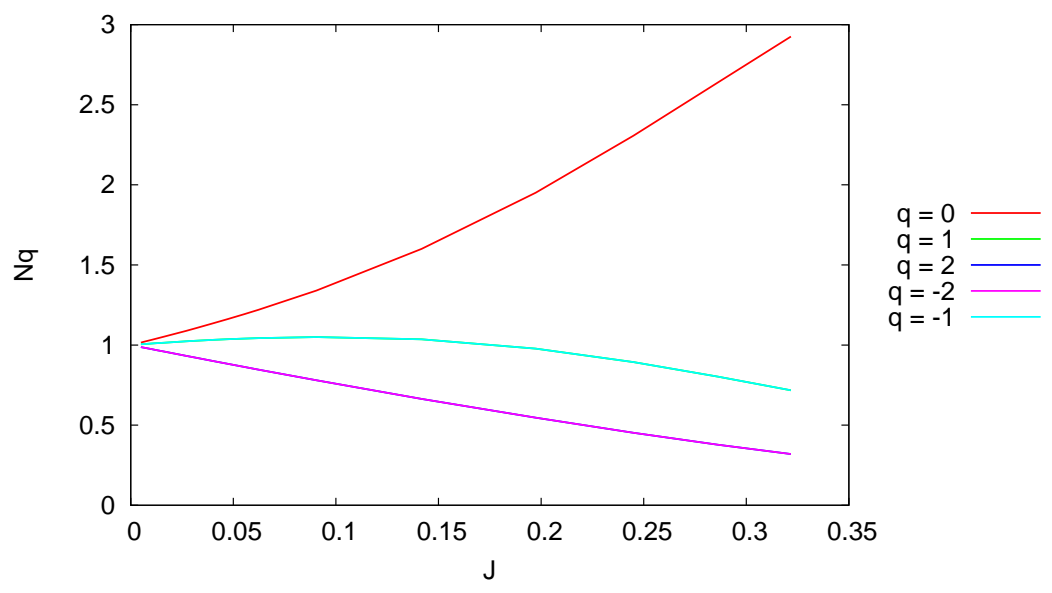

(a) $\omega=0$

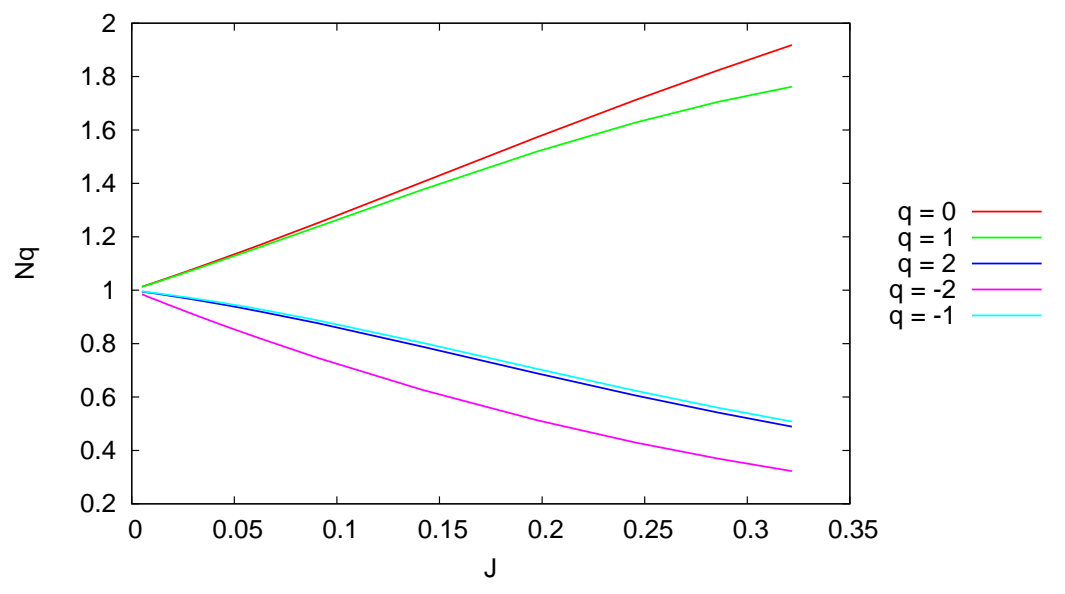

(b) $\omega=0.48 \omega_{0}$

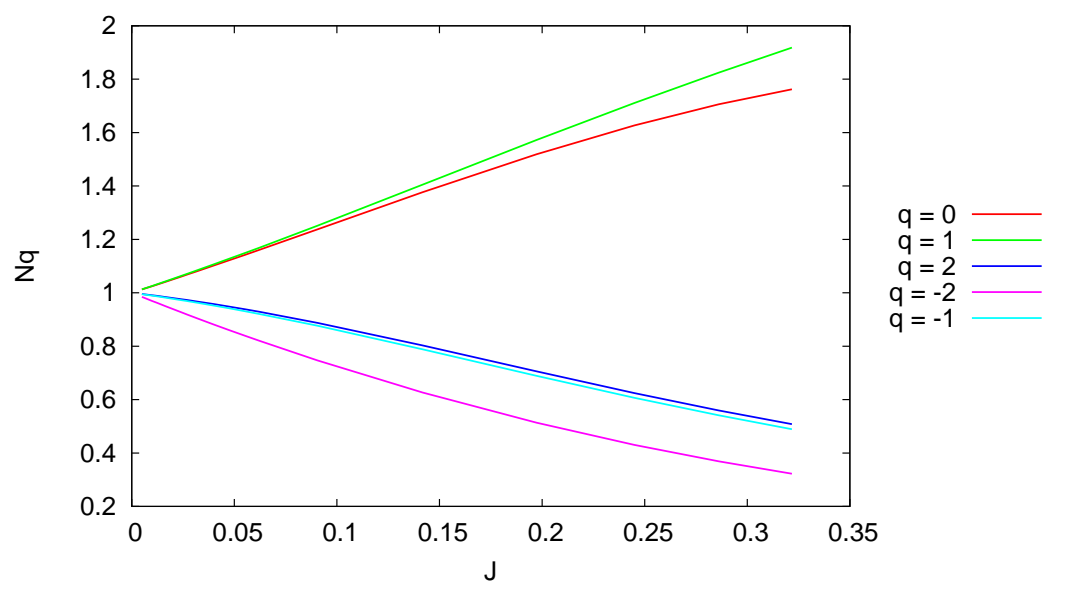

(c) $\omega=0.52 \omega_{0}$

Figura 5.7: Aqui está representado o comportamento das ocupações dos estados de partícula independente para um sistema de 5 partículas e 5 barreiras do tipo $\delta$-Dirac, com a variação da altura das barreiras parametrizada por $J$. Os resultados acima correspondem ao sistema com velocidades $\omega=0, \omega=0.48 \omega_{0}$ e $\omega=0.52 \omega_{0}$ e com a força de interação repulsiva entre as partículas dada por $U=2.4 \epsilon_{0}$. Agora a intensidade da força respulsiva de interação entre as partículas é muito maior do que nos dois casos anteriores, e a ocupação do estado fundamental de partícula independente satura quando as barreiras são muito mais baixas do que nas outras situações, evidenciando a dificuldade de se definir a ocupação do estado fundamental sob estas condições. 
Para valores incomensuráveis de ocupação da rede periódica, o sub-espaço que contém o estado fundamental de muitos corpos não fica restrito ao de quasi-momento total $Q_{T}=0$, e é modificado para todos os valores de $\omega$ em que ocorrem os cruzamentos de níveis. Nestes casos, as partículas tendem a ocupar o estado de partícula independente correspondente ao menor valor das energias de Bloch, e como já foi mencionado, o espaço de quasi-momento total que contém o estado fundamental fica vinculado à relação $[N q] \bmod M$. Esta propriedade está ilustrada nos gráficos da figura 5.8.

Diferente dos casos em que a ocupação da rede é comensurável, o limite em que $J \rightarrow 0$ das situações de ocupação incomensurável não é caracterizado pela degenerescência total dos estados de quasi-momento. O que se tem, de forma geral, é uma degenerescência dos estados conjugados de quasi-momento nos casos em que $\omega=0$ mas que no entanto não se preserva quando $\omega \neq 0$. Como ilustrado nos gráficos em que $\omega \neq 0$ das figuras 5.9, 5.10 e 5.11, cada um dos estados de quasi-momento apresenta resposta independente ao abaixamento das barreiras (aumento de $J$ ).

Ainda, outra característica do sistema ilustrada nestas figuras é que o aumento da intensidade da força repulsiva de interação entre as partículas dificulta a ocupação do estado fundamental de partícula independente. Note, em particular, que em relação aos gráficos da figura 5.9, os gráficos da figura 5.11 apresentam a saturação da ocupação do estado fundamental de quasi-momento para valores muito maiores de $J$. 


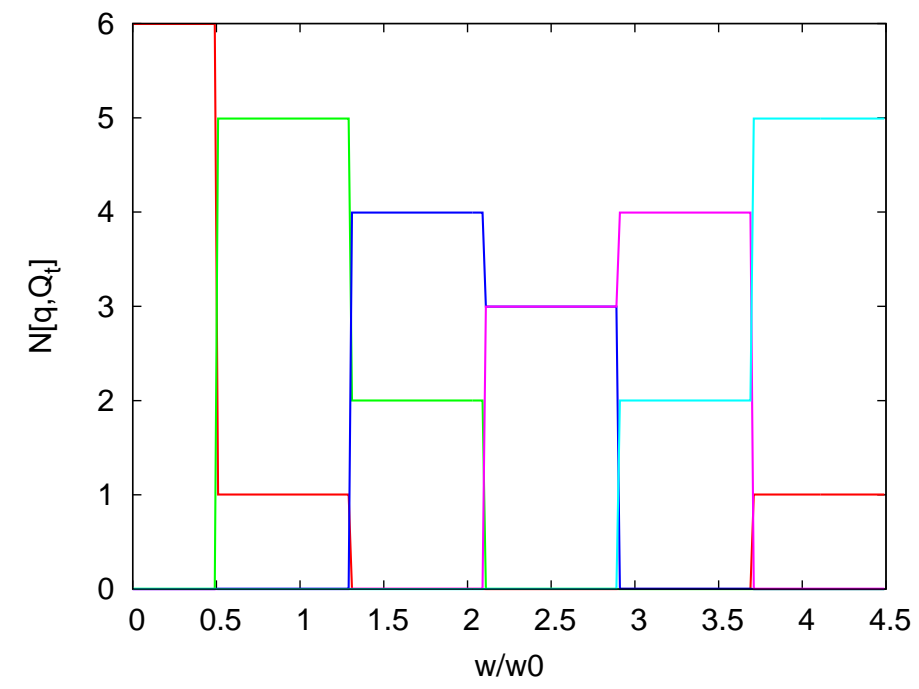

$$
\begin{aligned}
& q=0, Q_{t}=0 \\
& q=1, Q_{t}=0 \\
& q=2, Q_{t}=0 \\
& q=-2, Q_{t}=0 \\
& q=-1, Q_{t}=0
\end{aligned}
$$

(a) $Q_{T}=0$

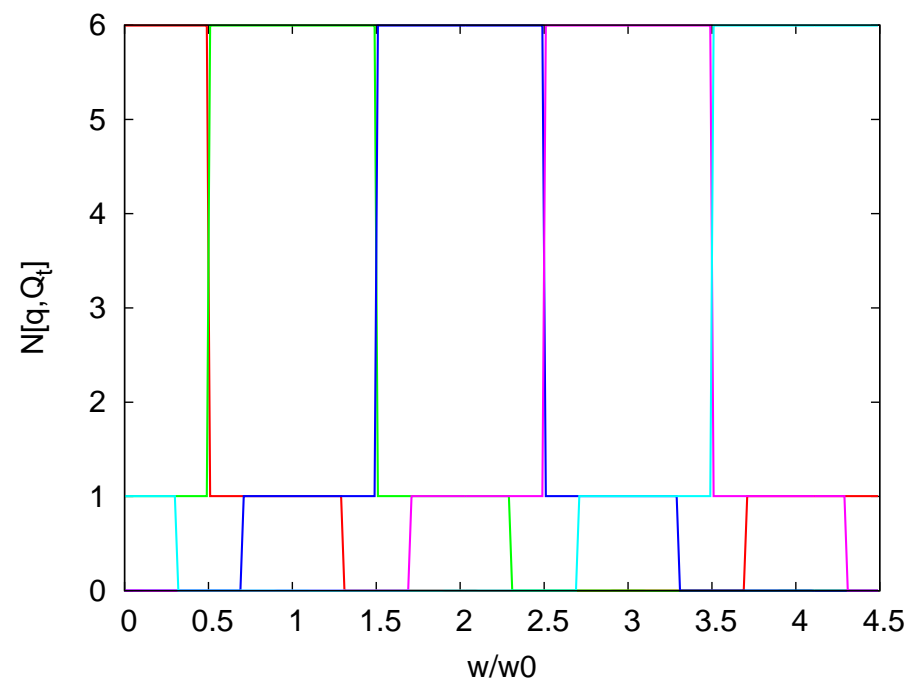

$$
\begin{array}{r}
q=0, Q_{t}=0 \\
q=1, Q_{t}=1 \\
q=2, Q_{t}=2 \\
q=-2, Q_{t}=-2 \\
q=-1, Q_{t}=-1
\end{array}
$$

(b) Diferentes valores de $Q_{T}$

Figura 5.8: Estes gráficos ilustram a variação da ocupação dos estados de quasi-momento para a situação incomensurável com 6 partículas e 5 barreiras do tipo $\delta$-Dirac de altura $V_{0}=1 \epsilon_{0}$. Em (a) estão representadas as ocupações de todos os estados de quasi-momento do sub-espaço de quasimomento total $Q_{T}=0$. Note, em particular, que para $\omega>0.5 \omega_{0}$ não existe mais a ocupação máxima de um estado de quasi-momento, como na situação do intervalo em que $0<\omega<0.5 \omega_{0}$. Acontece, no entanto, que devido ao cruzamento de níveis que ocorre para $\omega=0.5 \omega_{0}$ e para valores da velocidade angular maiores do que esta (e menores do que o valor em que ocorre o próximo cruzamento de níveis), o estado de Bloch de menor energia muda do sub-espaço de quasi-momento total 0 para o sub-espaço de quasi-momento total 1. Uma mudança análoga de sub-espaço de quasi-momento total também ocorre para nos outros pontos que correspondem ao cruzamento de níveis (conforme o texto acima) e o resultado está ilustrado em (b). Explicitamente, este gráfico mostra que a população do estado fundamental (que depende dos valores de $\omega$ ) é preservada. 


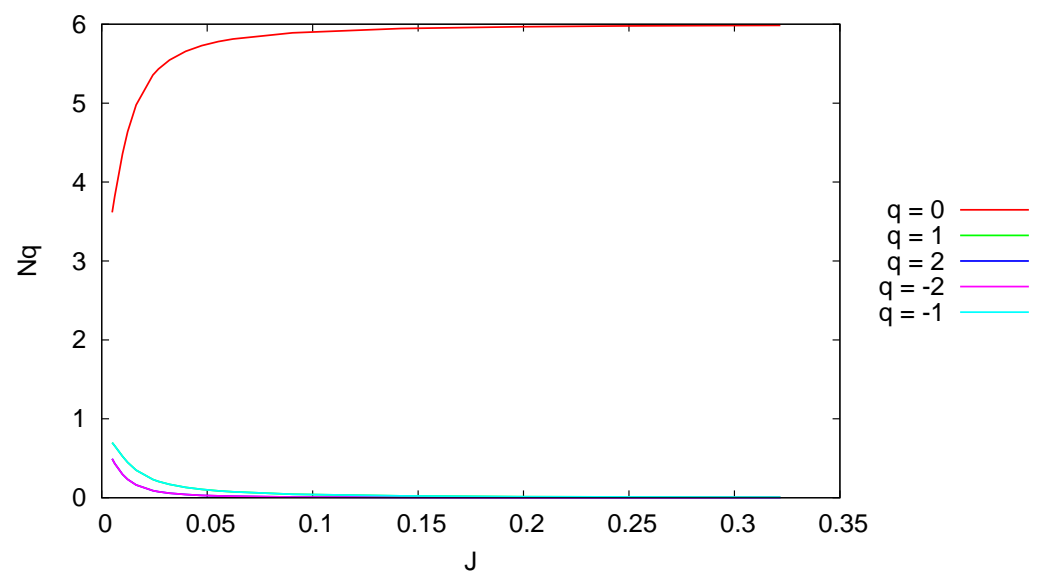

(a) $\omega=0$

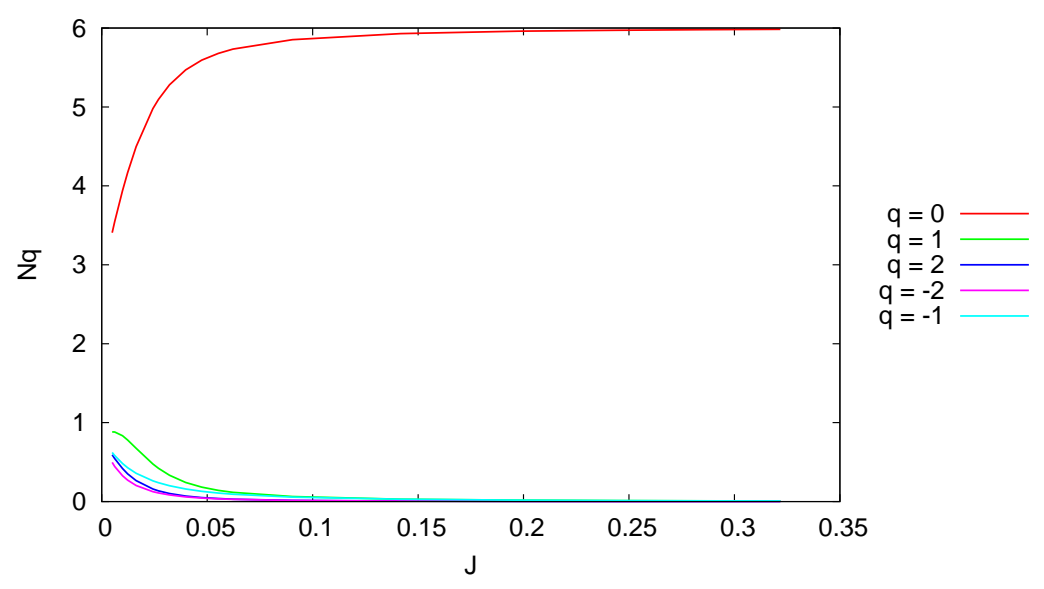

(b) $\omega=0.48 \omega_{0}$

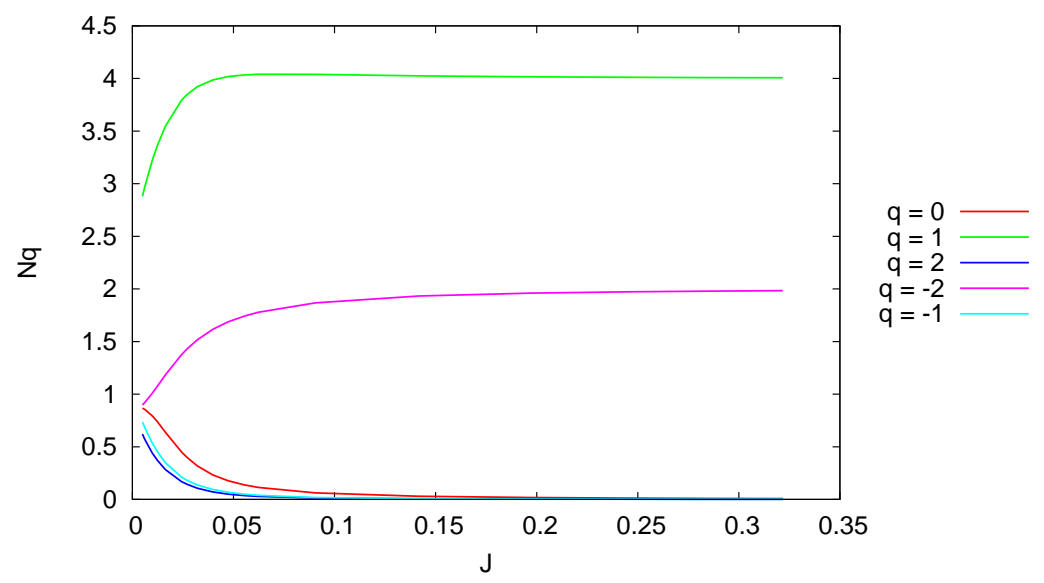

(c) $\omega=0.52 \omega_{0}$

Figura 5.9: Aqui está representado o comportamento das ocupações dos estados de partícula independente para a situação incomensurável de um sistema com 6 partículas e 5 barreiras do tipo $\delta$-Dirac, com a variação da altura das barreiras parametrizada por $J$. Os resultados acima correspondem ao sistema com velocidades $\omega=0, \omega=0.48 \omega_{0}$ e $\omega=0.52 \omega_{0}$ e com a força de interação repulsiva entre as partículas dada por $U=0.06 \epsilon_{0}$. Nos gráficos (a) e (b) os estados de quasi-momento ilustrados estão no sub-espaço de quasi-momento total $Q_{T}=0$ (pois no intervalo em que se encontram estas velocidades angulares não há cruzamento dos níveis). (c), por sua vez, compreende a situação logo após o cruzamento dos níveis e portanto o os estados de quasi-momento representados neste gráfico correspondem aos do sub-espaço de quasi-momento total $Q_{T}=1$. 


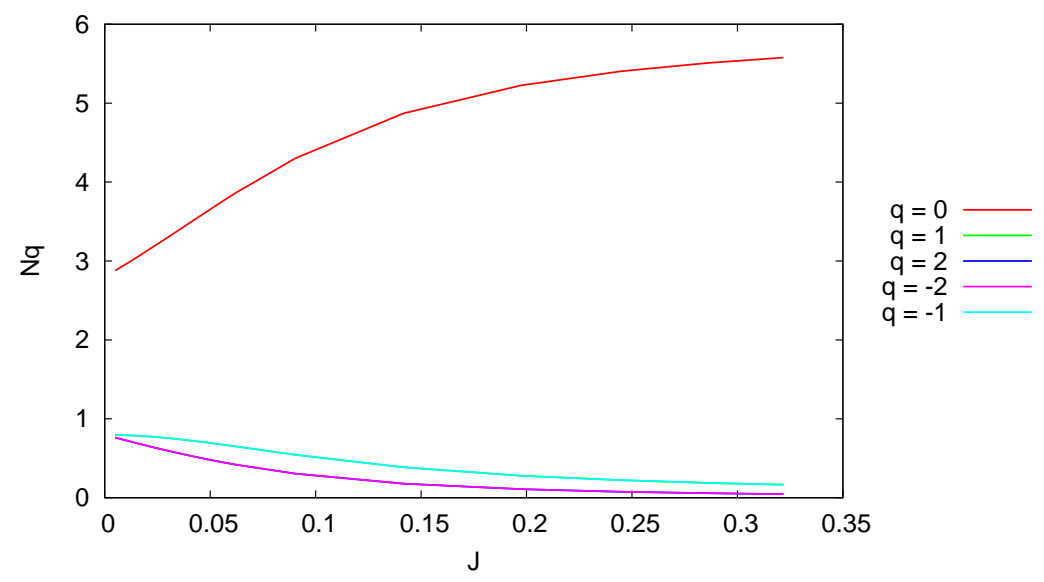

(a) $\omega=0$

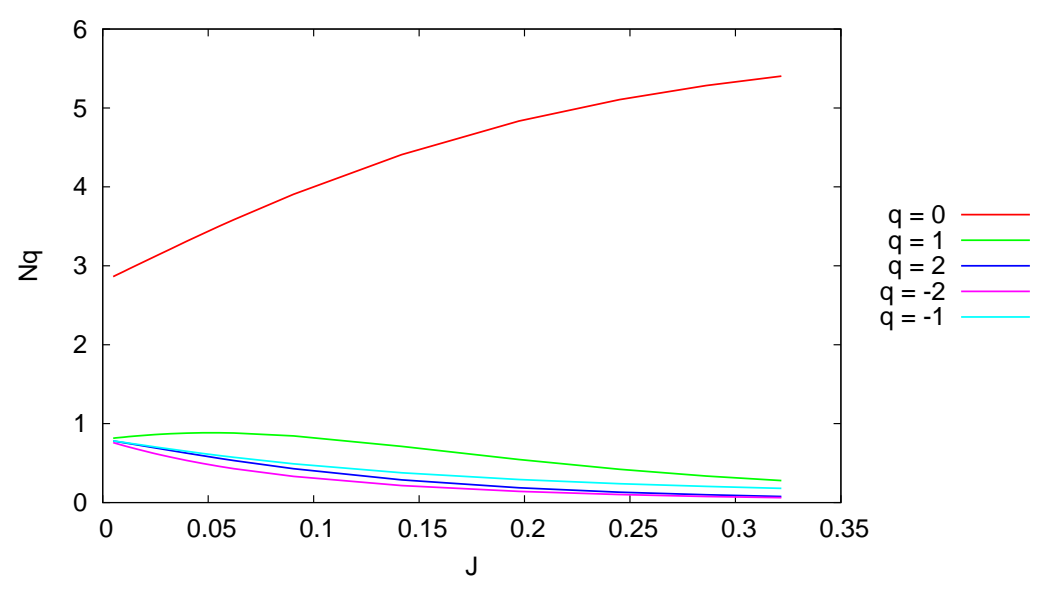

(b) $\omega=0.48 \omega_{0}$

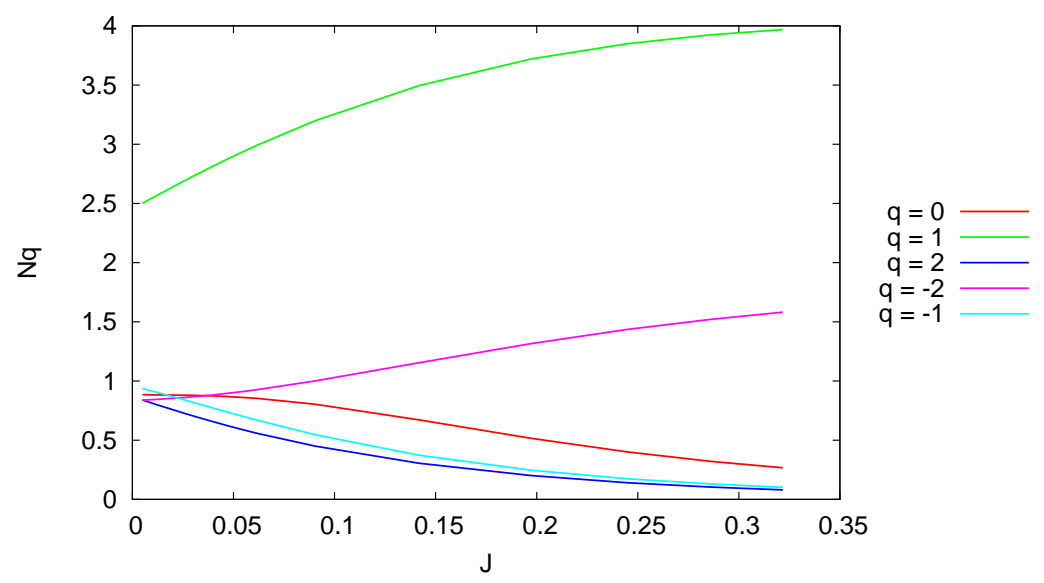

(c) $\omega=0.52 \omega_{0}$

Figura 5.10: Aqui está representado o comportamento das ocupações dos estados de partícula independente para a situação incomensurável de um sistema com 6 partículas e 5 barreiras do tipo $\delta$-Dirac, com a variação da altura das barreiras parametrizada por $J$. Os resultados acima correspondem ao sistema com velocidades $\omega=0, \omega=0.48 \omega_{0}$ e $\omega=0.52 \omega_{0}$ e com a força de interação repulsiva entre as partículas dada por $U=0.6 \epsilon_{0}$. Assim como nos gráficos da figura 5.9, (a) e (b) ilustram as ocupações dos estados de quasi-momento do sub-espaço de quasi-momento total 0 enquanto que em (c) o sub-espaço de quasi-momento total representado é 1 . Note, em relação ao caso anterior, que a ocupação do estado fundamental de partícula independente começa a saturar para valores maiores de $J$ e o valor de saturação atingido é também mais baixo. 


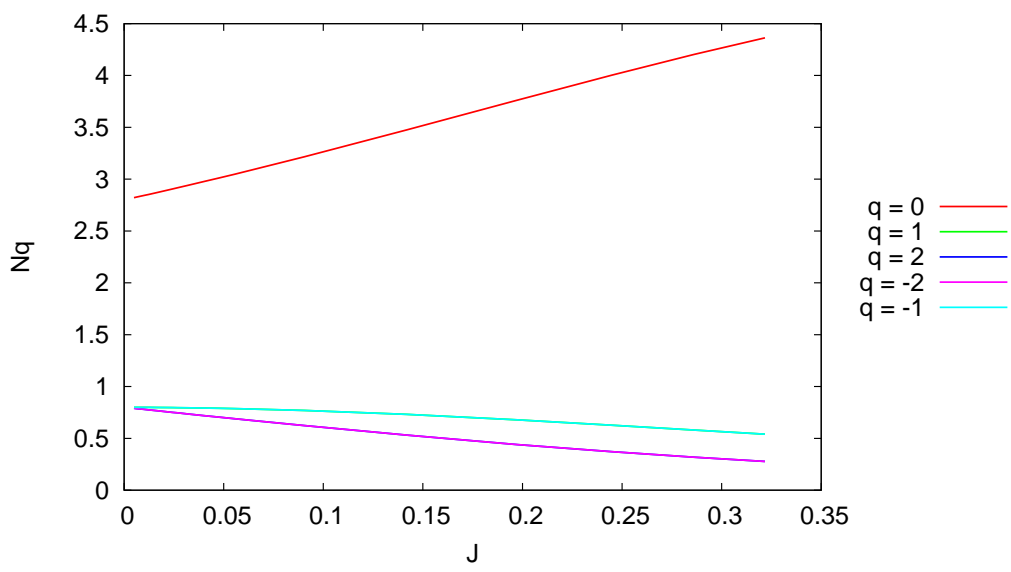

(a) $\omega=0$

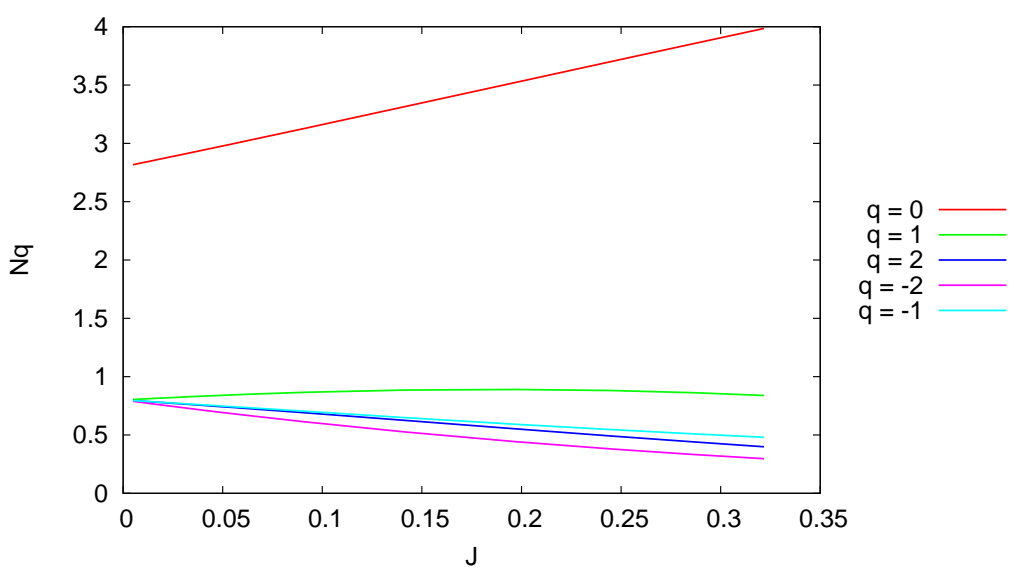

(b) $\omega=0.48 \omega_{0}$

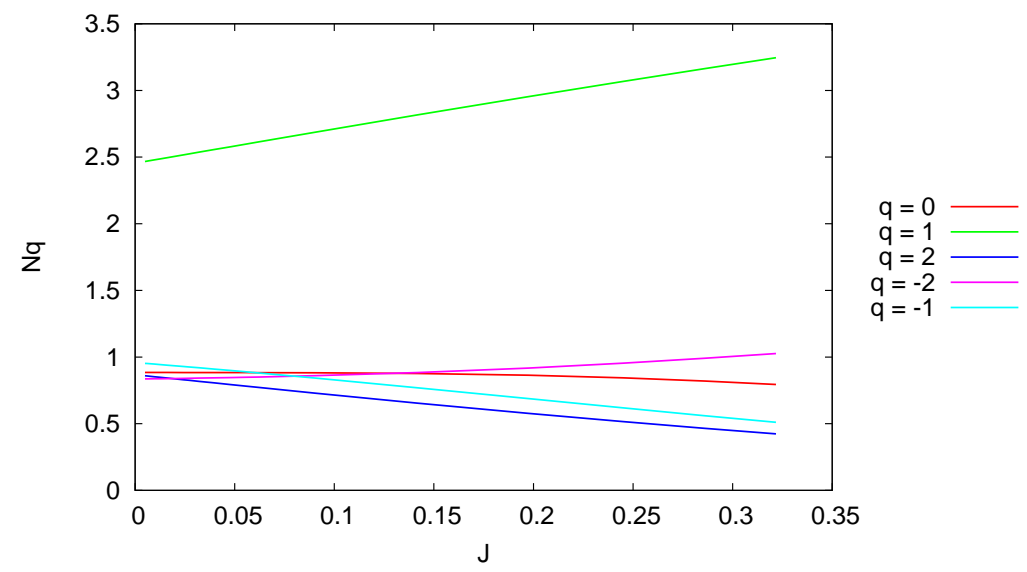

(c) $\omega=0.52 \omega_{0}$

Figura 5.11: Aqui está representado o comportamento das ocupações dos estados de partícula independente para a situação incomensurável de um sistema com 6 partículas e 5 barreiras do tipo $\delta$-Dirac, com a variação da altura das barreiras parametrizada por $J$. Os resultados acima correspondem ao sistema com velocidades $\omega=0, \omega=0.48 \omega_{0}$ e $\omega=0.52 \omega_{0}$ e com a força de interação repulsiva entre as partículas dada por $U=2.4 \epsilon_{0}$. Assim como nas figuras anteriores que contém os gráficos da situação de ocupação incomensurável (a) e (b) ilustram as ocupações dos estados de quasi-momento do sub-espaço de quasi-momento total $Q_{T}=0$ enquanto que em (c) o sub-espaço de quasi-momento total representado é $Q_{T}=1$. Ainda, no que diz respeito à ocupação do estado fundamental de partícula independente, aqui a saturação inicia para valores ainda maiores de $J$ e atinge valores consideravelmente menores dos que nos gráficos ilustrados em 5.9 e 5.10. 
Em relação à largura das barreiras de potencial, o que se mostra é que o comportamento do sistema quando disposto em um arranjo de barreiras periódicas do tipo $\delta$-Dirac reproduz qualitativamente bem o comportamento do sistema quando sujeito a um potencial periódico com barreiras de largura definida. A ocupação dos estados de quasi-momento para um arranjo de potenciais que simula de forma aproximada as funções utilizadas na implementação das redes ópticas (porque aqui a função cosseno é substituída por um arranjo de barreiras retangulares de potenciais cuja largura ocupa metade do período) está ilustrada nos gráficos 5.12 e 5.13 e em 5.14 e 5.15 os resultados da ocupação do estado fundamental deste arranjo são comparados com os obtidos para o arranjo de potenciais $\delta$.

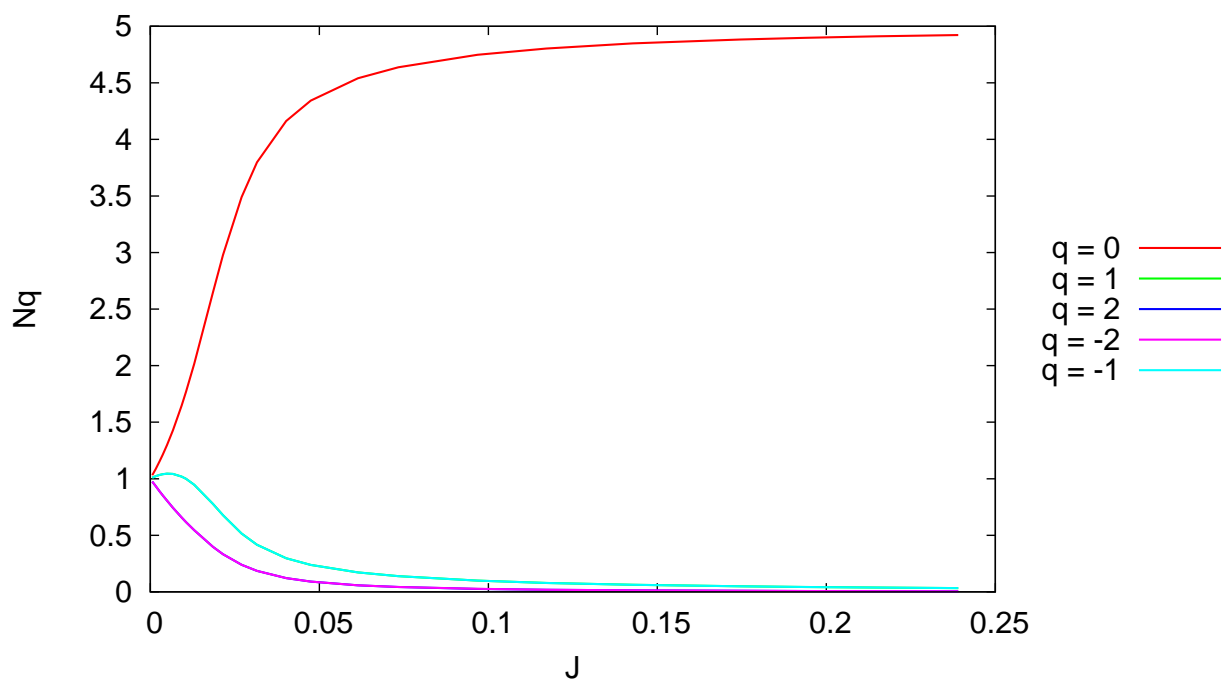

(a) Situação comensurável com $\omega=0$

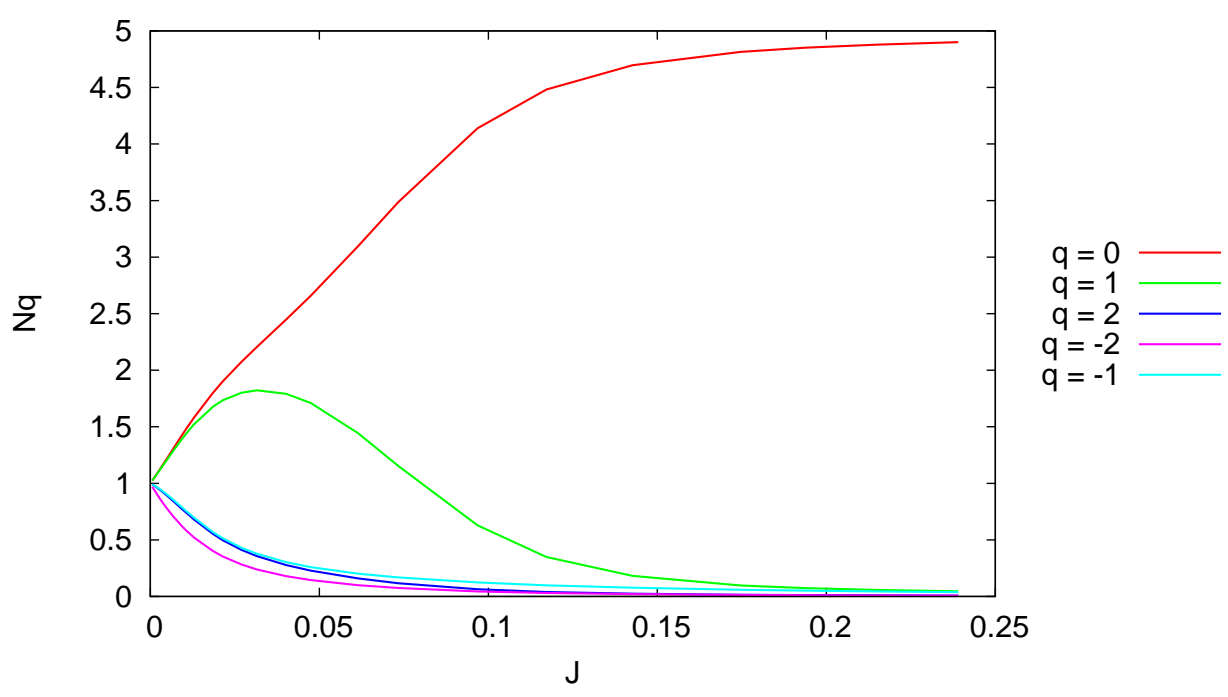

(b) Situação comensurável com $\omega=0.048 \omega_{0}$

Figura 5.12: Estes gráficos ilustram a ocupação dos estados de partícula independente para um arranjo de 5 barreiras retangulares de potencial e em que estas compreendem metade do período (aqui a largura das barreiras é dada por $b=\frac{\pi}{5}$ ). Ainda, a intensidade da força repulsiva de interação entre as partículas foi utilizada aqui como $U=0.06 \epsilon_{0}$. 


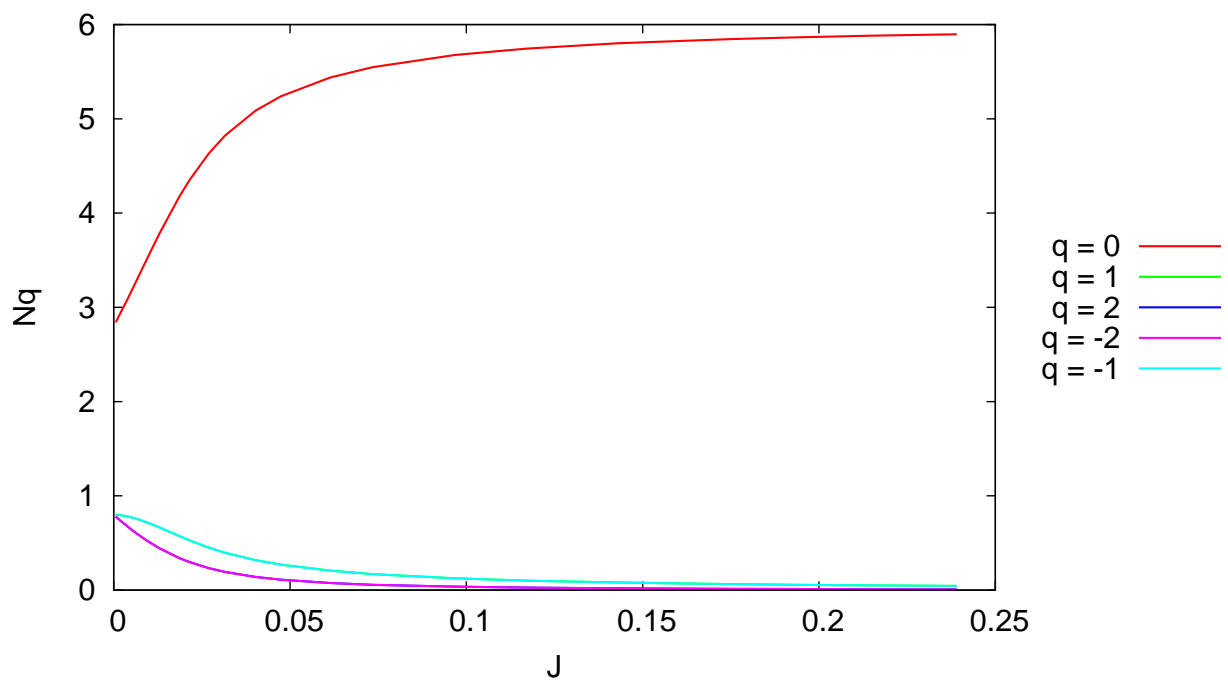

(a) Situação incomensurável com 6 partículas e $\omega=0$

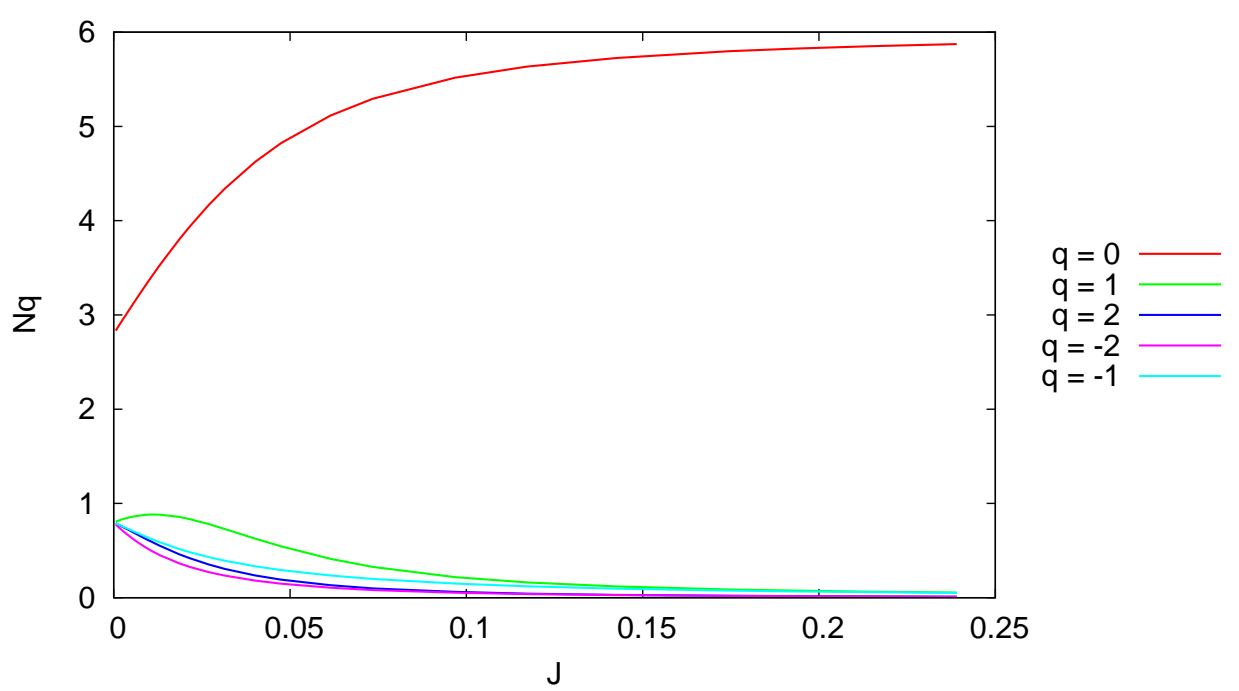

(b) Situação incomensurável com 6 partículas e $\omega=0.048 \omega_{0}$

Figura 5.13: Estes gráficos ilustram a ocupação dos estados de partícula independente para a situação incomensurável de um arranjo com 5 barreiras retangulares de potencial, com 6 partículas, e em que estas compreendem metade do período (aqui a largura das barreiras é dada por $b=\frac{\pi}{5}$ ). Ainda, a intensidade da força repulsiva de interação entre as partículas foi utilizada aqui como $U=0.06 \epsilon_{0}$. 


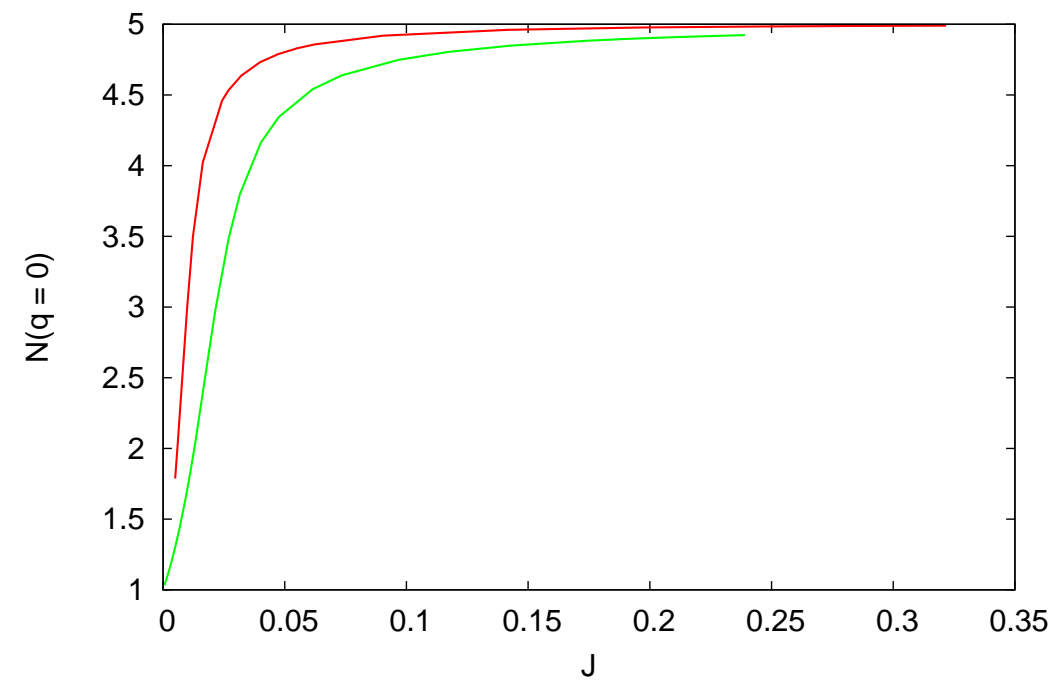

barreiras delta barreiras retangulares

(a) $\omega=0$

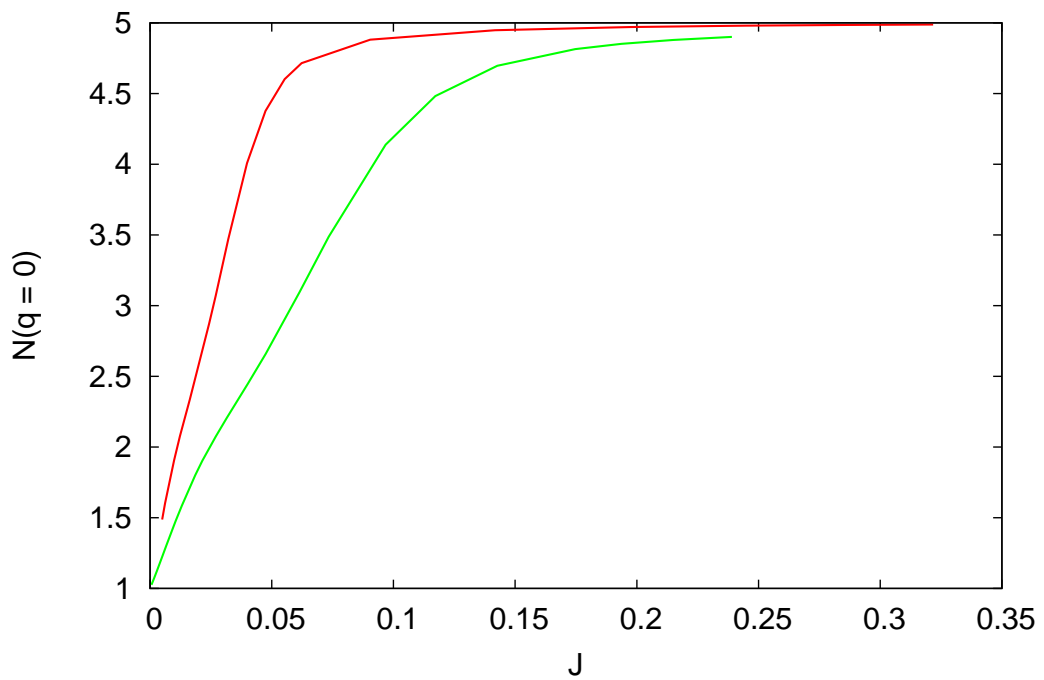

barreiras delta barreiras retangulares

(b) $\omega=0.48 \omega_{0}$

Figura 5.14: Comparação direta entre as ocupações dos estados de quasi-momento para um sistema com 5 partículas e 5 barreiras do tipo $\delta$-Dirac e retangulares com largura igual a metade do período (aqui, $\frac{\pi}{5}$ ). Estes resultados indicam que a descrição obtida a partir do modelo com potenciais $\delta$ reproduz qualitativamente bem o modelo em que os potenciais simulam as redes ópticas reais. 


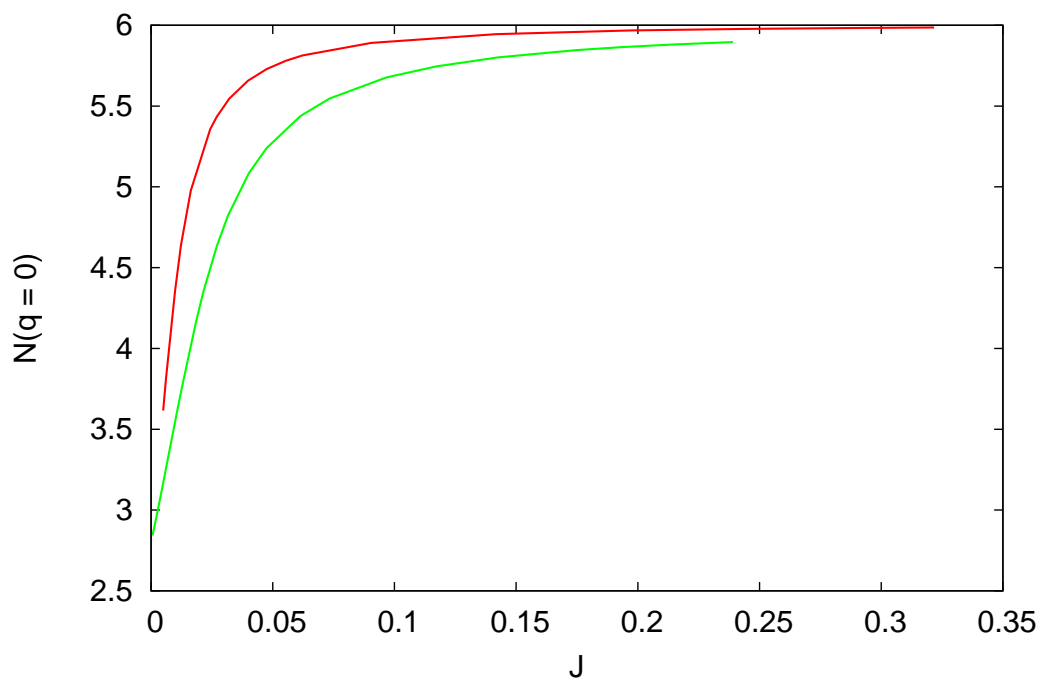

barreiras delta barreiras retangulares

(a) $\omega=0$

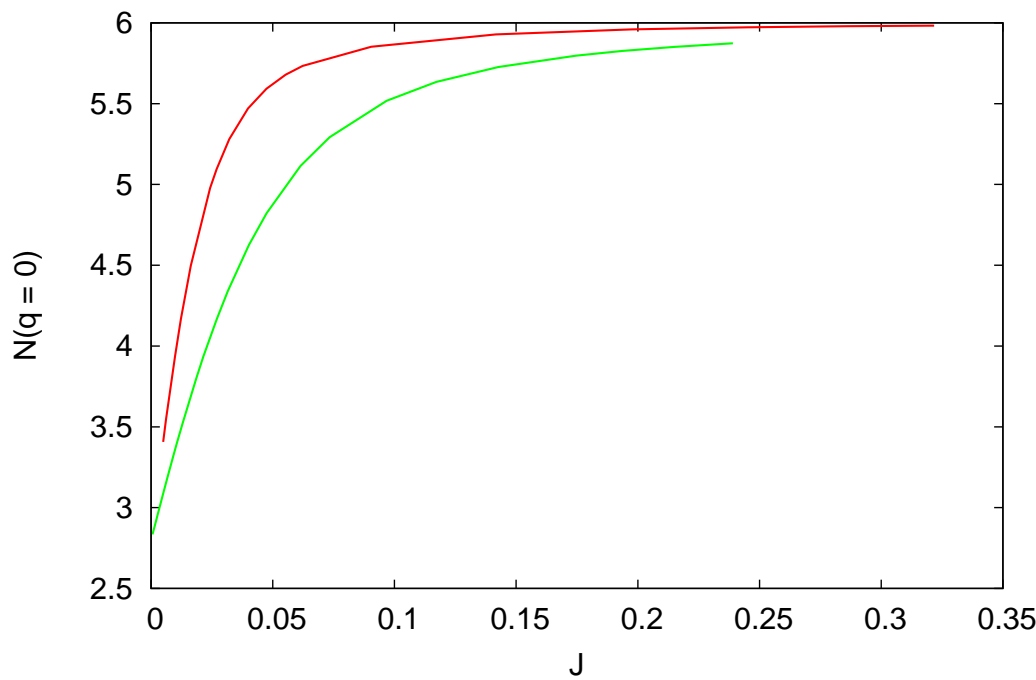

barreiras delta barreiras retangulares

(b) $\omega=0.48 \omega_{0}$

Figura 5.15: Comparação direta entre as ocupações dos estados de quasi-momento para o sistema 6 partículas e 5 barreiras do tipo $\delta$-Dirac e retangulares com largura igual a metade do período. Aqui, assim como na situação comensurável, a descrição obtida a partir do modelo com potenciais $\delta$ reproduz qualitativamente bem o modelo em que os potenciais simulam as redes ópticas reais. 


\subsection{A superfluidez}

As propriedades do sistema relacionadas ao fenômeno da superfluidez são caracterizadas aqui no contexto do critério de dois fluidos discutido no capítulo 3, em que é obtida uma expressão para a fração de superfluido em termos de um parâmetro inercial. Essencialmente, este parâmetro inercial depende da diferença de energias do estado fundamental do Hamiltoniano do sistema com e sem cranking no limite em que $\omega \rightarrow 0$, que pode ser escrito, explicitamente, como

$$
\frac{1}{N}\left(E^{(\omega)}(N)-E^{(0)}(N)\right)=f_{s} \frac{1}{2} m R^{2} \omega^{2}+O\left(\omega^{4}\right) .
$$

Nesta expressão $E^{(\omega)}(N)$ e $E(N)$ correspondem, respectivamente, às energias do estado fundamental dos Hamiltonianos $H_{\omega}$ e $H_{\omega=0}$ e que na resolução numérica são obtidos diretamente da diagonalização de cada Hamiltoniano. Os resultados obtidos para a superfluidez em diversas situações podem ser conferidos nos gráficos das figuras 5.16 e 5.17.

Estas curvas ilustram a propriedade de que, ao contrário da ocupação dos estados de quasi-momento, $f_{s}$ é uma quantidade que depende muito mais de $J$ do que da força de interação repulsiva entre as partículas $U$. A comparação direta entre as frações de condensado (fração da ocupação do estado fundamental de partícula independente) e superfluido revelam que estes dois fenômenos se desenvolvem em escalas diferentes, uma vez que a curva correspondente à condensação atinge seu máximo para valores de $J$ muito menores que os da saturação da superfluidez. De fato, o aparecimento da condensação está relacionado com o fechamento dos lobos de Mott do diagrama de fases do estado fundamental [19], enquanto que para os valores de $J$ correspondentes a esta situação $f_{s}$ se encontra longe da saturação.

Ainda, outra característica possível de extrair da solução numérica deste modelo, é que com o aumento da interação repulsiva a fração de condensado satura para alturas das barreiras cada vez menores, aumentando as diferenças com a saturação da fração de superfluido, que no limite de $J$ grande tende sempre a 1 . Este resultado se assemelha um pouco ao que se obtém da descrição e da realidade experimental para a condensação e superfluidez no Hélio líquido abaixo da temperatura crítica $\mathrm{T}=2.17 \mathrm{~K}$, que apesar de $100 \%$ superfluido contém uma fração de condensado de aproximadamente $9 \%$ [23], e abre espaço para explorações e adaptações futuras deste modelo à aplicações no estudo das características de sistemas em que as interações repulsivas entre as espécies são bastante fortes, como o próprio Hélio e também o gás de Tonks-Girardeu. 


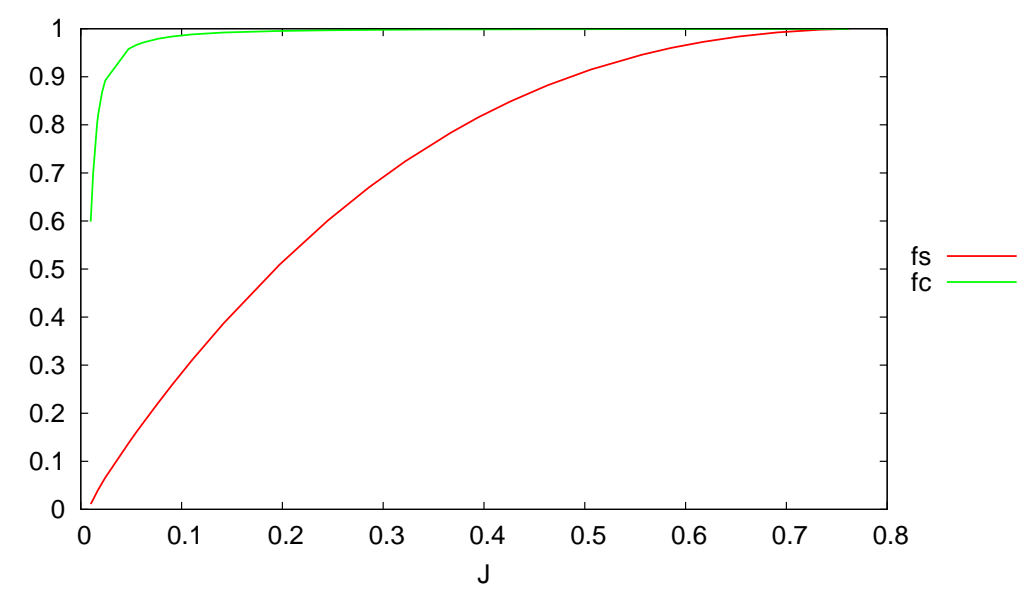

(a) $U=0.06 \epsilon_{0}$

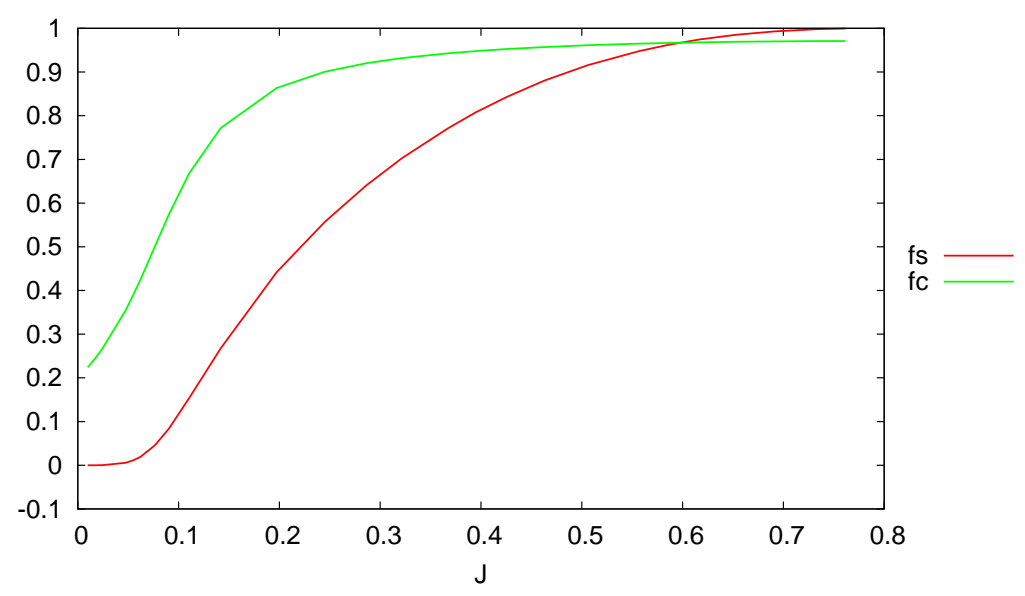

(b) $U=0.6 \epsilon_{0}$

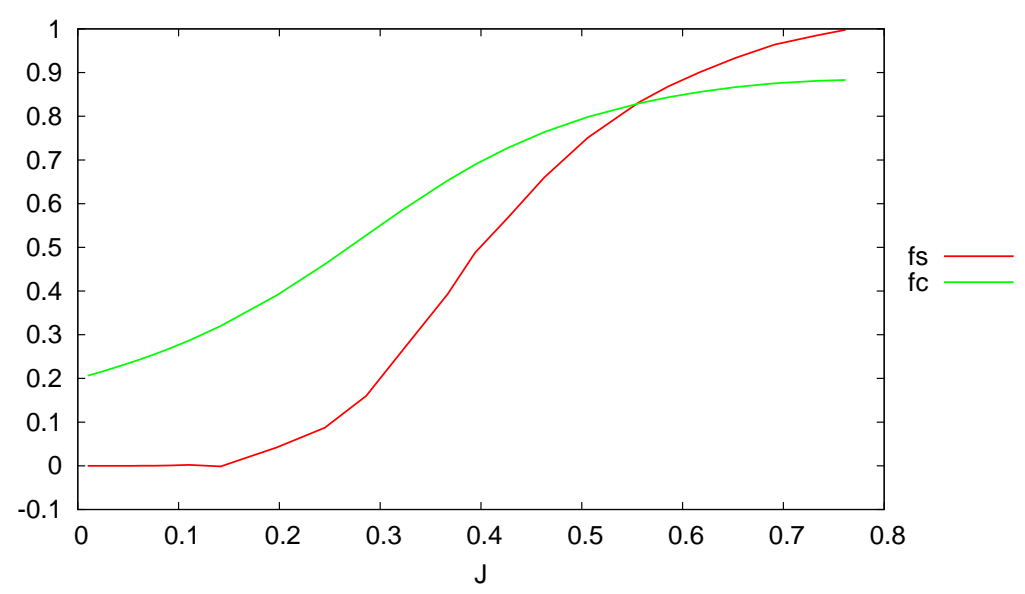

(c) $U=2.4 \epsilon_{0}$

Figura 5.16: Comparação entre as frações de condensado e de superfluido obtidas para diferentes valores da energia de interação $U$ para 5 partículas e 5 barreiras. Os gráficos acima mostram como estas quantidades se comportam com a variação da altura das barreiras, aqui do tipo $\delta$-Dirac, para o sistema com velocidade angular $\omega=0.01 \omega_{0}$. Note que o aumento de $U$ implica, no limite de hopping grande, valores cada vez menores para a saturação da condensação, enquanto que a superfluidez continua saturando em 1. 


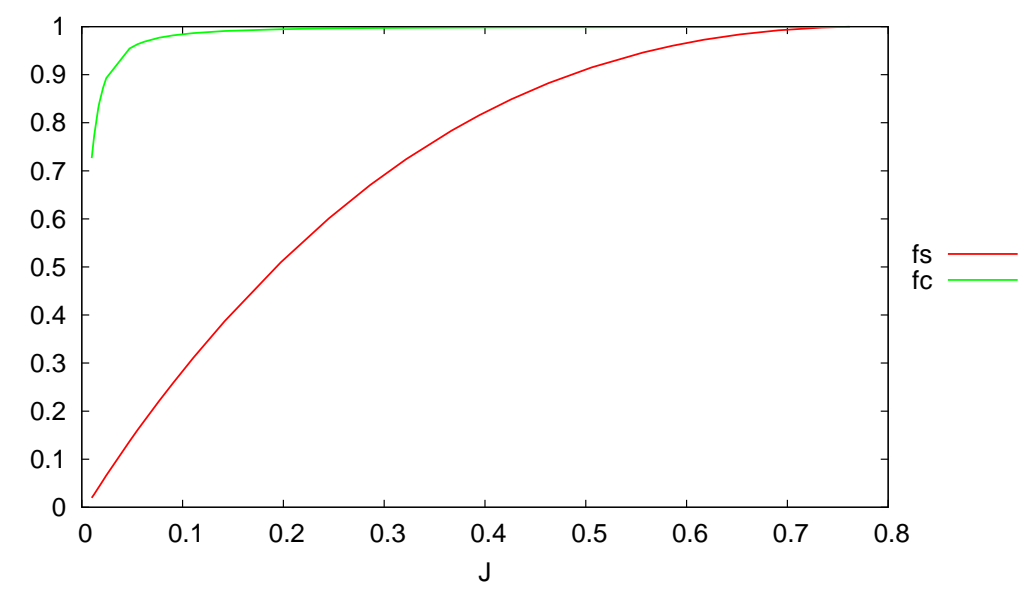

(a) $U=0.06 \epsilon_{0}$

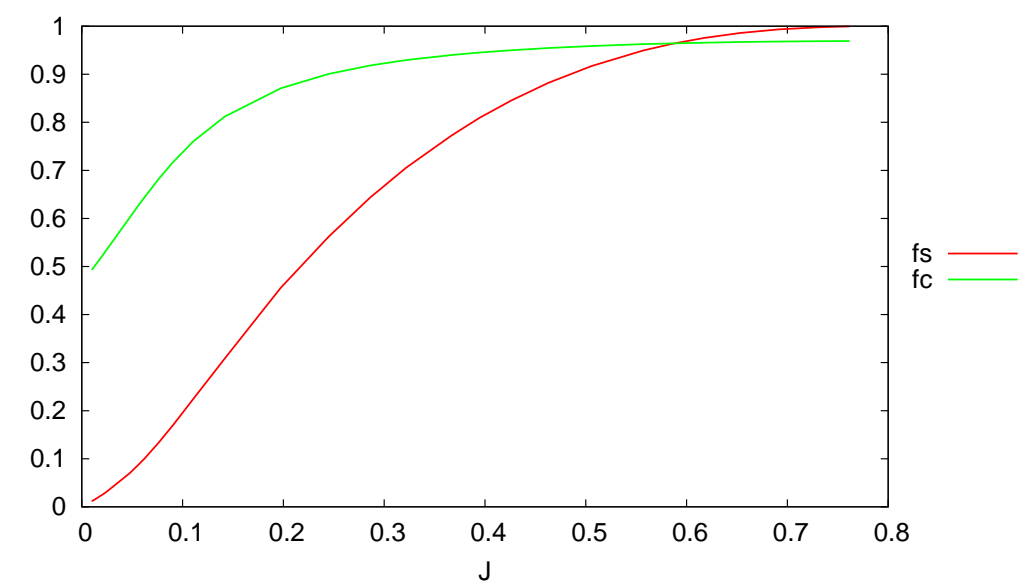

(b) $U=0.6 \epsilon_{0}$

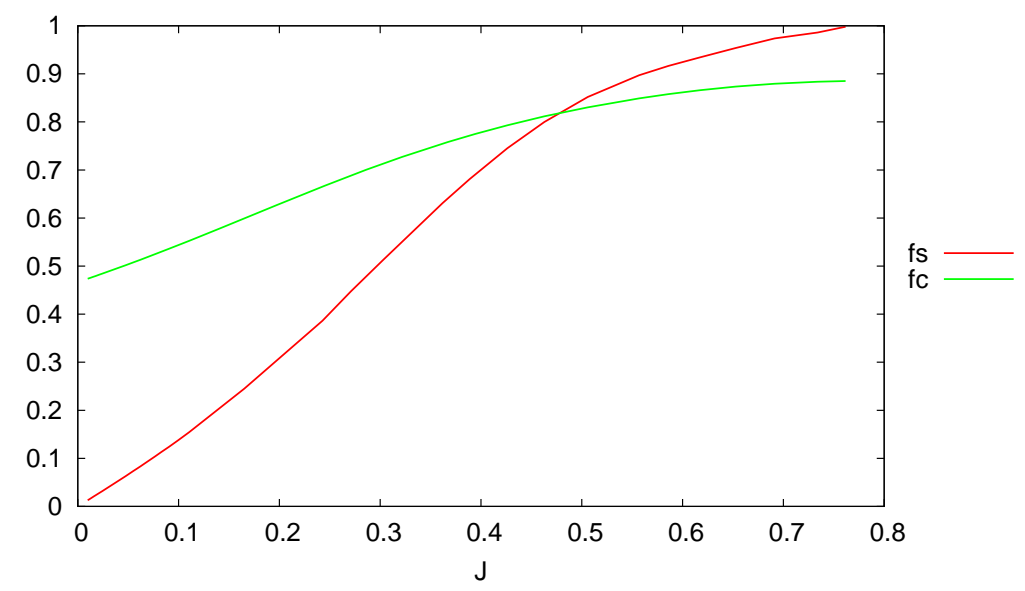

(c) $U=2.4 \epsilon_{0}$

Figura 5.17: Comparação entre as frações de condensado e de superflúido obtidas para diferentes valores da energia de interação $U$ para o caso incomensurável, com 6 partículas e 5 barreiras. Os gráficos acima mostram como estas quantidades de comportam com a variação da altura das barreiras, aqui do tipo $\delta$-Dirac, para o sistema com velocidade angular $\omega=0.01 \omega_{0}$. Note que assim com no caso comensurável ilustrado nos gráficos anteriores da figura 5.16, o aumento de $U$ implica, no limite de hopping grande, valores cada vez menores para a saturação da condensação, enquanto que a superfluidez continua saturando em 1. 


\section{Capítulo 6}

\section{Conclusões e Perspectivas}

Este trabalho apresentou o estudo das propriedades relacionadas aos fenômenos da condensação e superfluidez em um gás rarefeito disposto em um potencial periódico com geometria de anel e que efetua rotação. Ao invés da aplicação direta do Hamiltoniano do modelo de Bose-Hubbard, o Hamiltoniano efetivo usual de sistemas de muitos corpos foi tratado aqui na representação construída em termos das funções de Bloch da primeira banda. Como foi mostrado no capítulo 5, esta descrição é essencialmente equivalente ao modelo usual de Bose Hubbard na representação dos operadores de quasi-momento no domínio em que o termo de hopping é grande, mas inclui efeitos de natureza não local através das energias de Bloch de partícula independente e dos elementos de dois corpos da matriz de interação para valores pequenos do termo de hopping.

Com o objetivo de acessar especialmente as propriedades relacionadas ao fenômeno da superfluidez, o Hamiltoniano do sistema foi adaptado para incluir efeitos de rotação através de técnicas de cranking. Esta forma de incluir a ação de um campo externo de velocidades, colocado aqui como a rotação do container (e do potencial periódico) no qual o sistema está disposto, permite caracterizar a superfluidez através do critério de dois fluidos e possibilita a obtenção de uma expressão para a fração de superfluido em termos do parâmetro inercial do sistema. A grande vantagem deste método, em relação aos métodos tradicionais que definem a fração de superfluido a partir da resposta do sistema a um campo de externo de velocidades imposto através de condições de contorno torcidas na fase do parâmetro de ordem do sistema, é que aqui não existe a necessidade de utilizar a hipótese do modo condensado, o que permite estudar o fenômeno da superfluidez de maneira independente da condensação. De fato, os resultados obtidos através da diagonalização numérica do Hamiltoniano da primeira banda com cranking mostram que pelo menos para o sistema tratado aqui, as frações de condensado e de superfluido se desenvolvem em escalas diferentes, coincidindo apenas no limite em que o sistema compreende um gás ideal. Enquanto a intensidade da força de interação efetiva entre as partículas do sistema exerce um papel dominante nos resultados da fração de condensado, a fração de superfluido se mostra muito mais dependente da intensidade da força repulsiva (altura) das barreiras de potencial, que neste trabalho foi parametrizada pela quantidade $J$.

Ainda, foi realizada uma comparação entre a variação das frações de condensado e superfluido com a altura das barreiras para diferentes valores do parâmetro $U$, que controla a intensidade da força de interação efetiva entre as partículas, cujo resultado ilustra a propriedade de que quanto maior o valor de $U$, menor é o limite de saturação da fração de condensado no domínios de barreiras baixas, enquanto neste mesmo domínio, a fração de superfluido continua saturando em 1. Este resultado se assemelha um pouco da situação encontrada em sistemas de Hélio, no sentido em que este é um sistema onde as interações 
são muito fortes e a fração de condensado é muito pequena, enquanto que ao mesmo tempo, o sistema inteiro é superfluido. Entretanto é preciso ressaltar que a teoria explorada aqui não é adequada para a modelagem do Hélio líquido. Mesmo assim, é possível adaptá-la e empregá-la para o estudo situações intermediárias que podem prover algum entendimento no comportamento deste ou de outros sistemas quânticos de bósons fortemente correlacionados, como por exemplo o gás de Tonks-Girardeu. 


\section{Apêndice A}

\section{Apêndices}

\section{A.1 Resolução do problema de Kronig-Penney com potenci- ais $\delta$-Dirac}

Ao longo do trabalho foram utilizados diversos resultados do problema de Kronig-Penney com barreiras de potencial do tipo $\delta$-Dirac. A resolução deste sistema pode ser obtida tomando-se o limite no problema com barreiras de largura definida - que está resolvido de forma geral na seção 4.1.2 - ou então de uma forma mais direta, como será mostrado nesta seção.

Considere o Hamiltoniano do problema de Kronig-Penney unidimensional de um corpo de massa $m$, com $M$ barreiras de potencial do tipo $\delta$-Dirac igualmente espaçadas em um anel de raio $R$ :

$$
H=-\frac{\hbar^{2}}{2 m R^{2}} \frac{d^{2}}{d \phi^{2}}+\gamma \sum_{\nu=0}^{M-1} \delta\left(\frac{2 \pi}{M}\left(\nu+\frac{1}{2}\right)\right)
$$

e com $\gamma$ o parâmetro que caracteriza a intensidade da força barreira.

A este Hamiltoniano está associada a equação de autovalores $H \psi(\phi)=E \psi(\phi)$, tal que as autofunções compreendem funções de Bloch $\psi(\phi)=e^{i q \phi} u(\phi)$, com $q$ o quasi-momento do sistema e $u(\phi)$ uma função periódica tal que $u(\phi)=u(\phi+n p), n$ inteiro e $p$ o tamanho de um período deste arranjo.

A substituição da expressão de $\psi(\phi)$ na equação de autovalores do acima resulta

$$
\left(-\frac{\hbar^{2}}{2 m R^{2}} \frac{d^{2}}{d \phi^{2}}+\gamma \sum_{\nu=0}^{M-1} \delta\left(\frac{2 \pi}{M}\left(\nu+\frac{1}{2}\right)\right)\right) e^{i q \phi} u(\phi)=E e^{i q \phi} u(\phi),
$$

que após a aplicação das derivadas primeira $\psi^{\prime}(\phi)=i q e^{i q \phi} u(\phi)+e^{i q \phi} u^{\prime}(\phi)$ e segunda $\psi^{\prime \prime}(\phi)=$ $-q^{2} e^{i q \phi} u(\phi)+2 i q e^{i q \phi} u^{\prime}(\phi)+e^{i q \phi} u^{\prime \prime}(\phi)$, dá origem a uma equação para a função $u(\phi)$ :

$$
-\frac{\hbar^{2}}{2 m}\left(-q^{2} u(\phi)+2 i q u^{\prime}(\phi)+u^{\prime \prime}(\phi)\right)+\gamma \sum_{\nu=0}^{M-1} \delta\left(\frac{2 \pi}{M}\left(\nu-\frac{1}{2}\right)\right) u(\phi)=E u(\phi)
$$

Entre dois $\delta$ 's a equação acima se reduz à do problema livre e portanto, as funções de onda do sistema, $\psi(\phi)$, devem compreender uma superposição de ondas planas. Da mesma forma, 
$u(\phi)$ deve satisfazer

$$
-\frac{\hbar^{2}}{2 m}\left(-q^{2} u(\phi)+2 i q u^{\prime}(\phi)+u^{\prime \prime}(\phi)\right)-E u(\phi)=0,
$$

de onde vem

$$
u^{\prime \prime}(\phi)+2 i q u^{\prime}(\phi)+u(\phi)\left(-q^{2}+k^{2}\right)=0,
$$

com $k^{2}=\frac{2 m E}{\hbar^{2}}$ e cujas soluções podem ser escritas, de modo geral, como

$$
u(\phi)=A e^{i(k-q) \phi}+B e^{-i(k+q) \phi},
$$

com $A$ e $B$ constantes a serem determinadas pela imposição das condições de contorno. Para efetuar este ajuste das constantes, é preciso escolher a célula primária sistema, que consiste em um intervalo do tamanho de um período e que seja conveniente para fins da resolução do problema. Aqui este intervalo corresponde a $\left[-\frac{\pi}{M}, \frac{\pi}{M}\right]$.

Da propriedade $u(\phi)=u\left(\phi+\frac{2 \pi}{M}\right)$, segue então que $u\left(-\frac{\pi}{M}\right)=u\left(\frac{\pi}{M}\right)$, de onde vem

$$
\frac{A}{B}=\frac{\sin \left(\frac{\pi}{M}(k+q)\right)}{\sin \left(\frac{\pi}{M}(k-q)\right)}
$$

Portanto, a menos de um fator de normalização, a expressão da parte periódica das funções de Bloch no intervalo da célula primária é dada, por

$$
\left.u(\phi)=\sin \left(\frac{\pi}{M}(k+q)\right)\right) e^{i(k-q) \phi}+\sin \left(\frac{\pi}{M}(k-q)\right) e^{-i(k+q) \phi} .
$$

É importante notar aqui, que apesar de $u(\phi)$ ser definida dentro do período correspondente à célula primária, as funções de Bloch são definidas para todo o intervalo $[0,2 \pi]$ e portanto é necessário realizar uma extensão da função $u(\phi)$ além do domínio $\left[-\frac{\pi}{M}, \frac{\pi}{M}\right]$. Uma forma de fazer isto é através da inclusão de um fator modular, responsável por identificar um ângulo qualquer $\phi$ do intervalo $[0,2 \pi]$ com um ângulo equivalente no intervalo $\left[-\frac{\pi}{M}, \frac{\pi}{M}\right]$. Portanto, uma vez que a função de Bloch é obtida a partir da multiplicação de uma fase dependente do quasi-momento pela função $u(\phi)$, sua expressão é dada por

$$
\left.\psi(\phi)=e^{i q\left(\phi-\frac{\pi}{M}\right)}\left(\frac{\sin \left(\frac{\pi}{M}(k+q)\right)}{\sin \left(\frac{\pi}{M}(k-q)\right)} e^{i(k-q)\left(-\frac{\pi}{M}+\bmod \left(\phi, \frac{2 \pi}{M}\right)\right)}+e^{-i(k+q)\left(-\frac{\pi}{M}+\bmod \left(\phi, \frac{2 \pi}{M}\right)\right.}\right)\right) .
$$

Note aqui, em particular, que o ângulo $\phi$ utilizado na expressão acima pode assumir agora qualquer valor no intervalo $[0,2 \pi]$.

Obtida a expressão das funções de Bloch que correspondem aos autoestados do sistema, o próximo passo para realizar a sua caracterização completa envolve a determinação das informações do seu espectro de energia. Isto pode ser obtido a partir do estudo da equação de autovalores do sistema na célula primária, situação em que o parâmetro $\nu$ do Hamiltoniano (A.1.1) é igual a 0. Explicitamente,

$$
-\frac{\hbar^{2}}{2 m}\left(-q^{2} u(\phi)+2 i q u^{\prime}(\phi)+u^{\prime \prime}(\phi)\right)+\gamma \delta\left(\frac{2 \pi}{M}\right) u(\phi)=E u(\phi) .
$$

A maneira tradicional de se resolver equações com potenciais $\delta$ é através da integração na descontinuidade - que por conveniências de simetria, foi escolhida a de coordenada $\phi=\frac{\pi}{M}$ e portanto, o intervalo de integração deve compreender $\left[\frac{\pi}{M}-\epsilon, \frac{\pi}{M}+\epsilon\right]$. Este procedimento 
resulta:

$$
-\frac{\hbar^{2}}{2 m}\left(u_{\frac{\pi}{M}+\epsilon}^{\prime}-u_{\frac{\pi}{M}-\epsilon}^{\prime}\right)+\gamma u\left(\frac{\pi}{M}\right)=0
$$

que devido à periodicidade da função $u(\phi), u(\phi)=u\left(\phi+\frac{2 \pi}{M}\right)$ implica $u\left(\frac{\pi}{M}-\epsilon\right)=u\left(-\frac{\pi}{M}-\epsilon\right)$.

Portanto, no limite em que $\epsilon \rightarrow 0$

$$
u^{\prime}\left(\frac{\pi}{M}\right)-u^{\prime}\left(-\frac{\pi}{M}\right)+\gamma u\left(\frac{\pi}{M}\right)=0 .
$$

Agora, através da substituição dos valores adequados de $\phi$ nas derivadas e na função acima, obtêm-se então a relação de dispersão do sistema:

$$
\cos \left(\frac{2 k \pi}{M}\right)+\frac{\gamma}{2 k} \sin \left(\frac{2 k \pi}{M}\right)=\cos \left(\frac{2 q \pi}{M}\right)
$$

cujas propriedades são ilustradas e discutidas na figura 4.3 da seção 4.1.2.

\section{A.1.1 Adaptação de técnicas de cranking ao modelo}

A caracterização do sistema cujo Hamiltoniano inclui efeitos de rotação segue o mesmo 'roteiro' do sistema que foi tratado na seção acima.

De acordo com a seção 4.2.1, a equação de Schrödinger no referencial que rotaciona com o potencial deve ser escrita como

$$
\left(\frac{1}{2 m R^{2}}\left(\frac{\hbar}{i} \frac{d}{d \phi}-m R^{2} \omega\right)^{2}+\gamma \sum_{\nu=0}^{M-1} \delta\left(\frac{2 \pi}{M}\left(\nu+\frac{1}{2}\right)\right) \psi^{(\omega)}(\phi)=E^{(\omega)} \psi^{(\omega)}(\phi)\right.
$$

cujas soluções são, da mesma forma que no problema sem rotação, funções de Bloch de quasi-momento $q$ definido:

$$
\psi^{(\omega)}(\phi)=e^{i q \phi} u^{(\omega)}(\phi)
$$

Aqui, assim como no caso do sistema sem rotação $\gamma>0$ representa a intensidade da força repulsiva de cada barreira.

Entre duas barreiras de potencial as funções de Bloch satisfazem a equação do problema livre

$$
\frac{1}{2 m R^{2}}\left(-\hbar^{2} \frac{d^{2}}{d \phi^{2}}+2 i \hbar m \omega R^{2} \frac{d}{d \phi}+m^{2} \omega^{2} R^{4}\right) e^{i q \phi} u^{(\omega)}(\phi)=\frac{\hbar^{2} k^{2}}{2 m} e^{i q \phi} u^{(\omega)}(\phi)
$$

e portanto $u(\phi)$, após a substituição de suas derivadas primeira e segunda, satisfaz a equação

$$
\frac{d^{2}}{d \phi^{2}} u^{(\omega)}(\phi)+\frac{d}{d \phi} u^{(\omega)}(\phi)\left(2 i q-\frac{2 i m \omega R^{2}}{\hbar}\right)+u^{(\omega)}(\phi)\left(-q^{2}+\frac{2 m \omega R^{2} q}{\hbar}-\frac{m^{2} \omega^{2} R^{4}}{\hbar^{2}}+\beta^{2}\right)=0
$$

$\operatorname{com} \beta^{2}=R^{2} k^{2}$ e cujas soluções compreendem

$$
u^{(\omega)}(\phi)=A e^{i\left(-q+\frac{\omega}{\omega_{0}}+\beta\right) \phi}+B e^{-i\left(q-\frac{\omega}{\omega_{0}}+\beta\right) \phi}
$$

em que $\omega_{0}=\frac{m R^{2}}{\hbar}$.

Definindo a célula primária no intervalo $\left[-\frac{\pi}{M}, \frac{\pi}{M}\right]$ é possível determinar a razão $\frac{A}{B}$

$$
\frac{A}{B}=\frac{\sin \left(\beta-q+\frac{\omega}{\omega_{0}}\right) \frac{\pi}{M}}{\sin \left(\beta+q-\frac{\omega}{\omega_{0}}\right) \frac{\pi}{M}}
$$


e portanto, já considerando a extensão da função periódica além da célula primária, as funções de Bloch podem ser escritas por

$\psi^{(\omega)}(\phi)=e^{i\left(q-\frac{\pi}{2 M}\right) \phi}\left(\frac{\sin \left(\frac{\pi}{M}\left(\beta+q-\frac{\omega}{\omega_{0}}\right)\right)}{\sin \left(\frac{\pi}{M}\left(\beta-q+\frac{\omega}{\omega_{0}}\right)\right)} e^{i\left(\beta-q+\frac{\omega}{\omega_{0}}\right)\left(-\frac{\pi}{M}+\bmod \left(\phi, \frac{2 \pi}{M}\right)\right)}+e^{-i\left(\beta+q-\frac{\omega}{\omega_{0}}\right)\left(-\frac{\pi}{M}+\bmod \left(\phi, \frac{2 \pi}{M}\right)\right)}\right)$.

Finalmente, relação de dispersão é dada pela expressão:

$$
\cos \left(\frac{2 \beta \pi}{M}\right)+\frac{\gamma}{2 \beta} \sin \left(\frac{2 \pi \beta}{M}\right)=\cos \left(\frac{2(q-\omega) \pi}{M}\right)
$$

que da mesma forma como para o sistema sem rotação, foi obtida a partir da equação de autovalores e que neste caso corresponde à (A.1.2). 


\section{A.2 A teoria de Landau}

Em 1941, Landau formulou uma teoria para explicar o fenômeno da superfluidez do Hélio líquido abaixo de $\mathrm{T}=2.17 \mathrm{~K}$ baseada nas propriedades do espectro das excitações elementares do sistema [27]. Com o objetivo de complementar o capítulo 3 , em que o fenômeno da superfluidez foi apresentado a partir do critério de dois fluidos, este apêndice traz um apanhado geral sobre a teoria de Landau, cuja formulação segue abaixo ${ }^{1}$.

Através de analogias com a hidrodinâmica clássica, Landau postulou que os estados de um líquido quântico em movimento podem ser classificados de duas formas diferentes: estados de movimento potencial - para os quais rot $v=0$ - e os estados de movimento de vórtex em que rot $v \neq 0$. $v$ é a velocidade do líquido, definida como

$$
v=\frac{1}{2}\left(\frac{1}{\rho} j-j \frac{1}{\rho}\right)
$$

com $\rho=\sum_{\alpha} m_{\alpha} \delta\left(r_{\alpha}-R\right)$ a sua densidade, determinada a partir da soma sob todas as partículas de massa $m_{\alpha}$ e $j$ a corrente dada por $j=\sum_{\alpha} m_{\alpha} v_{\alpha} \delta\left(r_{\alpha}-R\right)$. Aqui $v_{\alpha}$ e $r_{\alpha}$ são, respectivamente, a velocidade e posição da partícula $\alpha^{2}$.

Landau argumenta que o espectro de um líquido quântico deve consistir de uma combinação de dois espectros contínuos - o do movimento potencial seguido do de movimento de vórtex - separados por uma diferença finita de energia, $\Delta$, e que entre os estados dos diferentes tipos de movimento não pode existir uma transição contínua. A partir daí, com o resultado de que qualquer estado excitado pode ser considerado como um agregado de excitações elementares [47], e em um líquido o movimento potencial compreende ondas longitudinais, considera-se que as excitações elementares dos estados excitados localizados não muito acima do começo do espectro devem compreender quantas de som, logo fônons ${ }^{3}$. Isso implica que a relação de dispersão entre energia e momento destas excitações elementares deve ser linear, dada por $\epsilon=c p, \operatorname{com} c$ a velocidade do som. Já para a parte do líquido que compreende o movimento de vórtex, as excitações elementares são chamas de rótons. Como coloca Landau, no que diz respeito à relação de dispersão dos rótons não existe nenhuma condição que imponha linearidade e então é possível considerar que $\epsilon=\Delta+\frac{p^{2}}{2 \mu}$, com $\mu$ a massa efetiva do róton. A partir daí, Landau mostra que se um sistema tem o espectro de excitações elementares com as características enunciadas acima, com é o caso do Hélio líquido - sistema que inspirou a construção da teoria - a expressão do calor específico do sistema deve ser proporcional ao cubo da temperatura; portanto, como afirma a teoria de Debye.

Para as considerações da teoria relacionadas diretamente ao fenômeno da superfluidez, é adequado manter que neste contexto um superfluido consiste num líquido dotado da capacidade de fluir sem fricção por capilares muito estreitos. Portanto todos os desenvolvimentos a seguir têm por intenção dar um entendimento teórico a esta propriedade. Abaixo segue a explicação da idéia por trás da conexão entre a natureza do espectro das excitações elementares do sistema com as suas propriedades de fluxo.

\footnotetext{
${ }^{1}$ Os desenvolvimentos daqui são baseados no artigo original de L. Landau, correspondente à referência $[27]$.

${ }^{2} \mathrm{Na}$ formulação da sua teoria, Landau considerou as partículas constituintes do líquido quântico como objetos com posição e momento bem definido.

${ }^{3}$ A teoria de Landau é baseada no fato experimental de que o calor específico do He-II é proporcional a $\mathrm{T}^{3}$ quando $\mathrm{T} \rightarrow 0$. Tal comportamento é típico de um gás de fônons. Por causa disso Landau postulou que os estados do $\mathrm{He}^{4}$ líquido próximos do estado fundamental podem ser descritos como um gás de excitações elementares não interagentes [24].
} 
Considere um sistema de Hélio líquido à temperatura $0 \mathrm{~K}$, fluindo por um capilar com velocidade $V$. As duas escolhas mais naturais de referenciais para seguir com a descrição do sistema consistem em (a) no referencial em repouso com as paredes do capilar e (b) naquele em repouso em relação ao fluxo do Hélio, e com velocidade $V$ em relação ao primeiro. Desta forma, para um observador no segundo referencial, o movimento que de fato ocorre é o das paredes do capilar, com velocidade $-V$.

Suponha então que o Hélio líquido compreenda um sistema viscoso. Uma vez que as paredes do recipiente em que este se encontra têm movimento, a tendência é de que o próprio líquido comece a se movimentar junto com elas. É razoável considerar, no entanto, que qualquer que seja o movimento do líquido devido à força externa, este não acontece de imediato e por inteiro, mas sim através do movimento relativo das camadas entre si e das camadas de líquido com as paredes do recipiente. Suponha também que o movimento das camadas de líquido mais perto das paredes do capilar aconteça devido a excitação de fônons e rótons, e passe agora para o referencial em que o Hélio estava inicialmente em repouso. Uma vez que é possível excitar um fônon no sistema, a energia e o momento do líquido, dados respectivamente por $E_{f}$ e $P_{f}$ devem corresponder à energia e momento do fônon, de forma que tem-se

$$
E_{f}=c p \quad P_{f}=p .
$$

Aqui $p$ é o momento do fônon e $c$ é a velocidade do som.

Agora, no referencial em que o capilar está em repouso, a energia e o momento do sistema são obtidos através de transformações de Galileu como

$$
E=E_{f}+P_{f} V+\frac{M V^{2}}{2}, \quad P=P_{f}+M V
$$

com $M$ a massa total do líquido. Substituindo finalmente (A.2.4) nas equações acima, tem-se que a energia do Hélio no referencial em que o capilar está em repouso é dada por

$$
E=c p+p V+\frac{M V^{2}}{2} \text {. }
$$

Aqui o termo $\frac{M V^{2}}{2}$ corresponde à energia cinética inicial do Hélio líquido, enquanto que a expressão $c p+p V$ representa a mudança na energia devido à excitação do fônon. Uma vez que a viscosidade origina fricção e que por fricção o fluxo de Hélio deve ser interrompido, esta mudança na expressão da energia deve ser negativa, ou seja,

$$
c p+p V<0
$$

que dá origem à desigualdade $V>c$. Isto significa que nas situações em que $V<c$ não existe a possibilidade de excitar fônons no sistema e consequentemente, o movimento do fluido não é dissipativo. Repetindo estes procedimentos para a parte do espectro de excitações correspondentes aos rótons, o valor de velocidade a ser atingido para que o fluxo seja dissipativo é dado pela expressão

$$
V>\sqrt{\frac{2 \Delta}{\mu}},
$$

e portanto, a excitação de fônons ou rótons só é possível para valores muito altos da velocidade do movimento relativo entre o capilar e o Hélio, o que resulta, de forma geral, que o fluxo do Hélio líquido ocorre sem fricção.

Este é o resultado central da teoria de Landau para a superfluidez e em geral é enunciado da seguinte forma: uma vez que a relação de dispersão entre energia e momento das excitações 
elementares do sistema é linear, a ocorrência de fluxo sem dissipação é possível porque não é permitido ao sistema absorver quantidades arbitrariamente pequenas de momento e energia transferidos [24].

Agora que o comportamento do Hélio líquido para $\mathrm{T}=0 \mathrm{~K}$ já foi caracterizado, é interessante analisar o que acontece neste sistema quando $\mathrm{T}>0$ mas no limite em que $\mathrm{T} \rightarrow 0$. Nesta situação o sistema contém excitações e não pode mais ser caracterizado, de maneira geral, apenas pelo estado fundamental como no primeiro caso. Entretanto, como as temperaturas relevantes estão no limite em que $\mathrm{T} \rightarrow 0$, é possível considerar este sistema como um gás de excitações elementares não interagentes, e que compreendem justamente fônons e rótons. Uma vez que os resultados do sistema à $0 \mathrm{~K}$ não utilizam nenhuma condição sobre o estado fundamental na sua obtenção, estes continuam válidos para a situação tratada agora [47]. Isto implica, portanto, a validade do resultado de que não é possível excitar nenhuma quasi-partícula no sistema a menos que a velocidade do movimento relativo entre as paredes do container e do Hélio seja muito grande. Entretanto, diferente do sistema anterior este aqui já é constituído por excitações elementares, de forma que é interessante estudar o seu comportamento.

Para prosseguir com este estudo suponha que o Hélio esteja disposto em um container com simetria cilíndrica de raio $R$, que rotaciona com velocidade angular $\omega$. Aqui os dois referenciais mais naturais para se tomar a descrição do sistema são (a) aquele que rotaciona com as paredes do container e (b) aquele em repouso em relação ao gás das excitações elementares. Uma vez que do ponto de vista de um observador no referencial que efetua rotação as paredes do container estão paradas, a resposta externa imposta ao líquido é estacionária [47] e portanto é possível utilizar a distribuição de Gibbs para realizar o estudo estatístico deste sistema. Daqui segue que a probabilidade não normalizada de se obter um estado excitado no Hélio é proporcional à energia deste estado, $\epsilon^{\prime}$, e dada por $P\left(-\beta \epsilon^{\prime}\right)$.

Agora, a descrição estatística do ponto de vista de um observador no referencial em repouso em relação ao gás de excitações elementares pode ser obtida a partir da transformação de energias entre estes referenciais, dadas por

$$
\epsilon^{\prime}=\epsilon-M \omega
$$

com $M$ o momento angular do sistema em um dado estado excitado. A partir destas considerações é possível obter a expressão da probabilidade (não normalizada) de se encontrar um estado excitado no sistema, mas agora do ponto de vista do referencial em repouso em relação ao gás de quasi-partículas:

$$
P(\epsilon-M \omega)=e^{-\beta(\epsilon-M \omega)} .
$$

Ainda, é possível utilizar o fato de que este gás de quasi-partículas é constituído de fônons e rótons, para escrever as expressões

$$
E=\sum \epsilon, \quad M=\sum m,
$$

com $\epsilon$ e $m$, a energia e o momento angular, respectivamente, destes fônons e rótons.

A partir da substituição das expressões acima na fórmula da probabilidade, a distribuição das excitações elementares do sistema pode ser escrita como

$$
n(\epsilon-M \omega)=\frac{1}{e^{\beta(\epsilon-M \omega)}-1},
$$

que é exatamente a função de distribuição que seria obtida caso o sistema considerado con- 
sistisse em um gás girando como um todo, com velocidade angular de rotação dada por $\omega$. Daqui segue o resultado de que durante a rotação de um container em que o sistema de Hélio-II está contido, o equilíbrio estatístico estabelecido é diferente daquele que se estabeleceria na situação do recipiente em repouso, e isto se deve ao fato de que agora gás de fônons e rótons rotaciona junto com o container.

O cálculo do momento angular do Hélio no container sob rotação à temperatura definida pode ser obtido a partir da distribuição acima e resulta:

$$
\bar{M}=\frac{1}{2 \pi \hbar} \iint d \tau_{p} d V \frac{m}{e^{\beta(\epsilon-m \omega)}-1} .
$$

Note que esta quantidade é igual a zero no zero absoluto, situação em que não há presença nem de fônons nem de rótons. Para temperaturas que não o zero absoluto, o momento angular deixa de ser nulo mas o momento de inércia (ou seja, o fator de proporcionalidade entre $M$ e $\omega$ ) será, em temperaturas suficientemente baixas, muito menor que o resultado usual, que corresponde à rotação de toda a massa do líquido junto com a rotação do container.

Portanto segue daqui o resultado de que quando as paredes do container estão em movimento apenas uma parte da massa do Hélio líquido é carregada junto com elas, enquanto a outra parte permanece estacionária.

Estas consideração reforçam o fato de que a descrição Hélio líquido pode ser tratada como se de fato o sistema fosse constituído de uma mistura de dois líquidos: o superfluido - sem viscosidade e que permanece estacionário mesmo com o o movimento das paredes do container - e o normal, que responde ao movimento imposto ao sistema como qualquer fluido ordinário. Entretanto é importante notar que é essencial que não haja fricção entre estas componentes, ou então que às componentes deste líquido não é permitido a transferência de momento. 


\section{Referências Bibliográficas}

[1] Richard Feynman, The Character of Physical Law, Modern Library Edition, (1994).

[2] Erwin Schrödinger, Mathematical Proceedings of the Cambridge Philosophical Society, 32, 446-452 (1936).

[3] A. J. Leggett, Quantum Liquids, Oxford University Press (2006).

[4] S. N. Bose, Z. Phys. 26, 178 (1924).

[5] Albert Einstein Sitzungsberichte der Preussischen Akademie der Wissenschaften, Physikalich-mathematische Klasse, 261-267 (1924).

[6] A. F. R. de Toledo Piza, Brazilian Joural of Physics, 34, $n^{o}$ 3B, Setembro (2004).

[7] Allan Griffin arXiv:cond-mat/9901123v1, Janeiro (1999).

[8] Allen, J. F. e Missener, A. D., Nature, 141, 75 (1938).

[9] Kapitza, P. L., Nature, 141, 913 (1938).

[10] Anderson, M. H., Ensher, J. R., Matthews, M. R., Wieman, C. E. e Cornell, E. A., Science, 269, 198 (1995).

[11] Davis, K. B., Mewes, M-O., Andrews, M. R., van Druten, N. J., Durfee, D. S., Kurn, D. M. e Ketterle, W., Phys. Rev. Lett., 75, 3969 (1995).

[12] Ph. W. Courteille, V. S. Bagnato e V. I. Yukalov, Laser Physics, 11, 659-800 (2001).

[13] A. F. R. de Toledo Piza, Projeto de Mestrado submetido à FAPESP referente a este trabalho. (2007).

[14] B. P. Anderson and M. A. Kasevic, Science, 282, 1686-1689 (1998).

[15] Markus Greiner, Olaf Mandel, Tilman Esslinger, Theodor W. Hänsch e Immanuel Bloch Nature, 415, 39-44 (2001).

[16] D. Jaksch, C. Bruder, J.I. Cirac, C. W. Gardiner e P. Zoller, Phys. Rev. Lett., 81, No 15, Outibro (1998).

[17] A. N. Salgueiro et. al., Eur. Phys. J., D44, 537 (2007).

[18] Makrus Greiner, Tese de Doutoramento, http://greiner.physics.harvard.edu/PDF $\%$ 20Files/PhD_greiner.pdf.

[19] A. F. R. de Toledo Piza, www.mpipks-dresden.mpg.de/ccm08/Abstract/piza.pdf (2008). 
[20] E. A. Cornell, J. R. Ensher e C. E Wieman, Proceedings of the International School of Physics - Enrico Fermi, Course CXL, Società Italiana di Fisica (1999).

[21] C. J. Pethick, H. Smith Bose-Einstein Condensation in Dilute Gases, Cambridge University Press (2002).

[22] A. J. Leggett, Bose-Einstein Condensation: from Atomic Physics to Quantum Fluids, Proceedings of the 13th Physics Summer School, editado por C. M. Savage e M. Das (World Scientific, Singapore) (2000).

[23] Oliver Penrose e Lars Onsanger Phys. Rev. 104, 576-584 (1956).

[24] Kerson Huang em Bose Einstein Condensation, editado por A. Griffin, D. W. Snoke e S. Stringari, Cambridge University Press (1996).

[25] A. J. Leggett, Rev. Modern Physics 71, No 2 (1999).

[26] L. Landau, Phys. Rev. 75, 884-885 (1949).

[27] L. Landau Journal of Physics USSR, 185-191 (1941).

[28] A. Griffin, Excitations in a Bose-Condensed Liquid, Cambridge University Press (December 15, 2005).

[29] P. C. Hohenberg e P. C. Martin, Annals of Physics 281, 636-705 (2000).

[30] Robert Roth e Keith Burnett, Phys. Rev. A 68, 023604 (2003).

[31] Antony Leggett em Bose Einstein Condensation, editado por A. Griffin, D. W. Snoke e S. Stringari, Cambridge University Press (1996).

[32] E. L. Pollock e D. M. Ceperley, Phys. Rev. B 36, 8343-8352 (1987).

[33] R. Roth e K. Burnett, Phys. Rev. A 67, 031602(R) (2003).

[34] Michael E. Fisher, Michael N. Barber e David Jasnow, Phys. Rev. A 81111 (1973).

[35] Luigi Amico, Andreas Osterloh e Francesco Cataliotti, Phys. Rev. Lett. 95, 063201 (2005).

[36] Lev Pitaevskii and Sandro Stringari, Bose-Einstein Condensation, Oxford Press University (2003).

[37] Vanderlei Bagnato e Daniel Kleppner, Phys. Rev. A, 44, No 11 (1991).

[38] A. F. R. de Toledo Piza Mecânica Quântica, Editora da Universidade de São Paulo, São Paulo (2003).

[39] Richard Liboff Introductory Quantum Mechanics, Addison Wesley, $4^{a}$ edição, Agosto (2002).

[40] Felix Bloch Z. Physik, 52, 555-600 (1928).

[41] Elliott H. Lieb, Robert Seiringer, Jakob Yngvason, arXiv:math-ph/0305025.

[42] A. Griffin, http://www.physics.utoronto.ca/griffin/Griffin\%20LT25\%20Lecture\%20.pdf.

[43] A. Griffin, comunicação particular. 
[44] Elliott H. Lieb, Robert Seiringer e Jakob Yngvason Phys. Rev. B 66134529 (2002).

[45] A. F. R. de Toledo Piza Brazilian Journal of Physics, 35, $\mathrm{n}^{o}$ 1, Março (2005).

[46] Matthew P. A. Fisher, Peter B. Weichman, G. Grinstein e Daniel S. Fisher Phys. Rev. $B$ 40, 546-570 (1989).

[47] L. P. Pitaevskii e E.M. Lifshitz, Statistical Physics, Part 2, Butterworth-Heinemann, January (1980). 